Releasing Anxiety

a design exploration into the four levels of anxiety 


\section{Releasing Anxiety}

a design exploration into the four levels of anxiety

A 120 point thesis submitted to the School of Architecture and Design. Victoria University of Wellington, in partial fulfilment of
the requirements for the degree, Masters of Interior Architecture

Victoria University of Wellington, school of Architecture

2018 


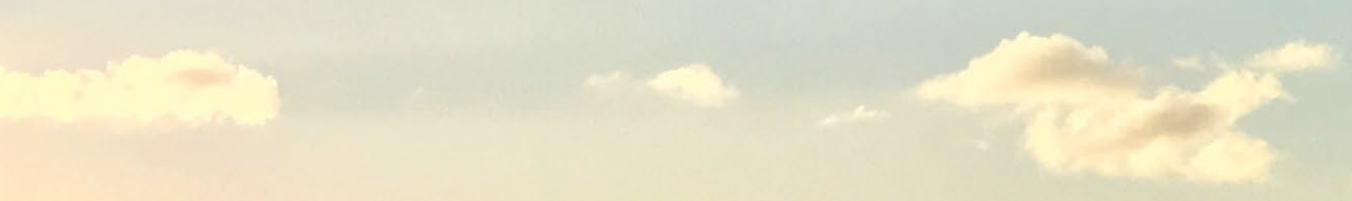

6.

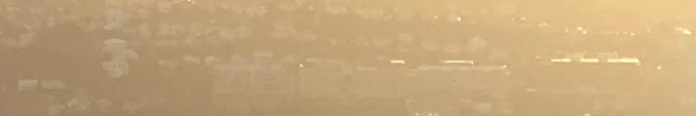

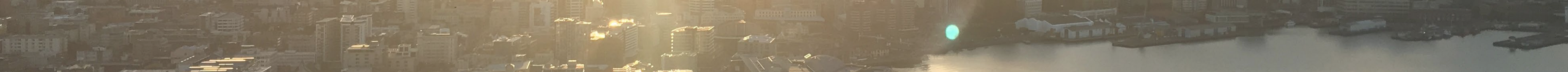

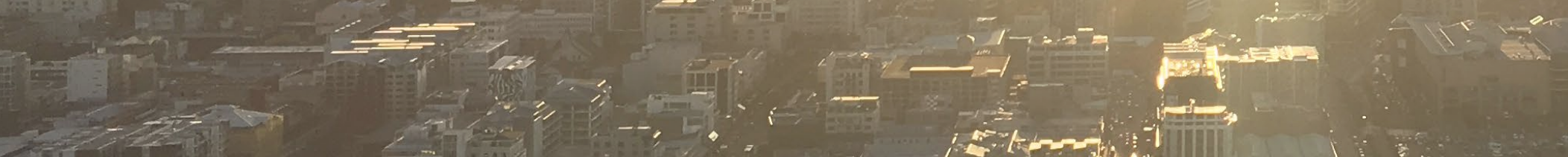

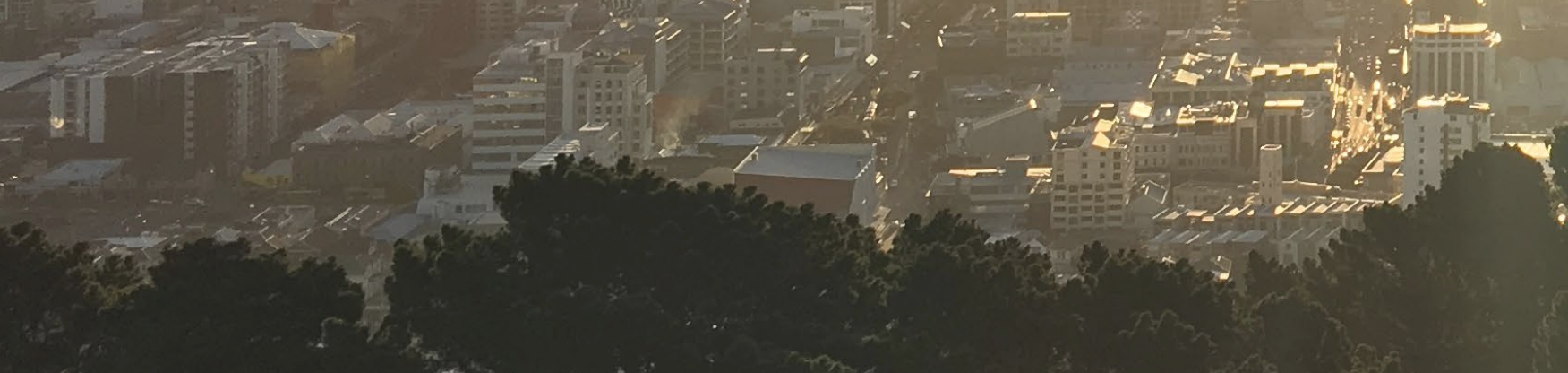

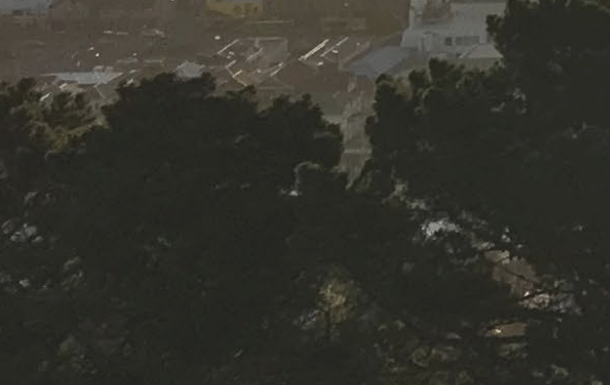
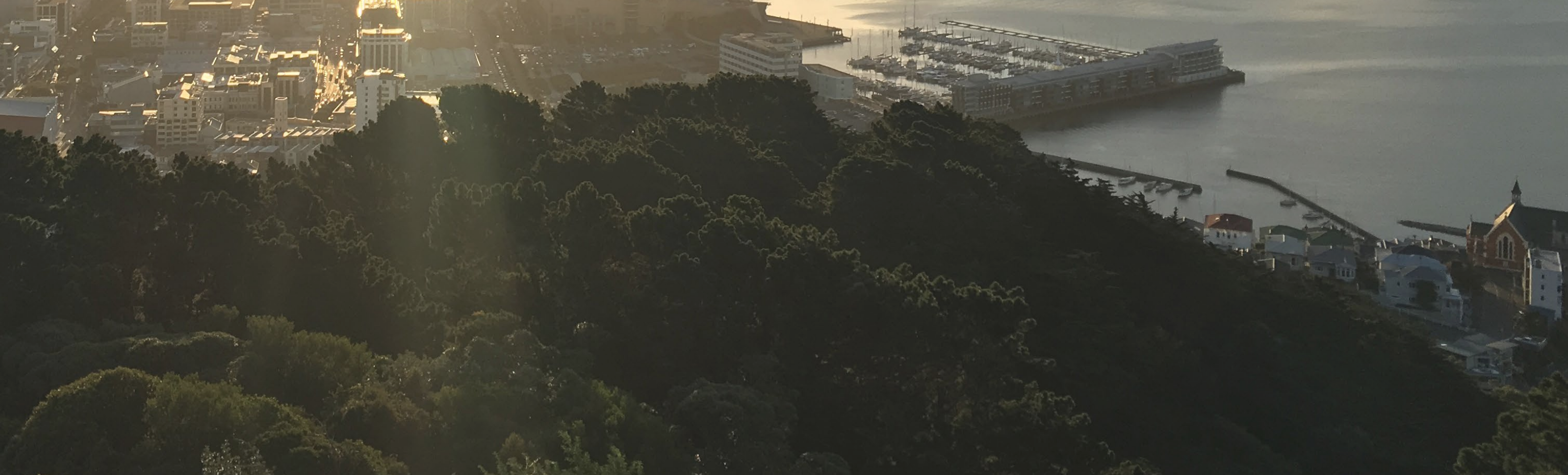


\section{ACKNOWLEDGEMENTS}

To my supervisor, Joanna MerwoodSalisbury, thank you for your guidance and support throughout the year.

To Mum, I would not have been able to do this without your love and support.

To my friends and fellow classmates throughout my university education, thank you for making it an enjoyable experience. 
RESEARCH QUESTION

This research project aims to investigate how spatial principles can be used to construct intimate connections between architecture and occupant, creating relief from anxiety. The body reacts to anxiety in many different ways, progressing through a series of and physical states from mild to panic level. This then raises the question, how can architecture create relief from anxiety in the context of a dense urban environment? How can sensory design create a narrative journey that transitions from anxious to calming? 
ABSTRACT

Releasing Anxiety

Being the most common mental disorder, anxiety is especially co-related with busy urban environments. The rise of urbanisation and modern technology has created a world that has a anxiety. In this context, our social responsibility and accountability as architects is increasing. How can we design with peoples' health an wellbeing in mind? Through iterative design processes, I will create an emotional experience that connects the body with architecture, heightens the occupant's self-awareness, and engages with site, creating a place of calm and belonging. Sensory design will be used to model the four levels of anxiety (mild, moderate, the four levels of anxiety (mild, moderate, severe, panic level). The final design will create from aniourness to calsing.
The research proposition will be tested on a site located in a highly developed area on the corner of Elliott, Albert and Victoria Streets in central location but because it is the site of a new metro station (predicted to be he busiest station in the Auckland rail network) s well as a linear park connecting Victoria and Albert Parks. Together these infrastructural dditions will increase pressure on an already ver-stimulated environment. The station (Aotea station) will be incorporated into the design, creating an urban park that provides access from the concourse level to street level, rawing people up into a protected landscape an inted to relieve anxiety and provide place of respite. 


\section{TABLE OF CONTENTS}

2.

\begin{tabular}{|c|c|c|}
\hline ACKNOWLEDGEMENTS & VII & $\begin{array}{l}\text { SENSORY DESIGN / } \\
\text { NARRATIVE ARCHITECTURE }\end{array}$ \\
\hline RESEARCH QUESTION & IX & $\begin{array}{ll}8 & \text { Problem Epigraph } \\
10 & \text { Introduction }\end{array}$ \\
\hline ABSTRACT & $X I$ & $\begin{array}{ll}12 & \text { Sensory Design } \\
17 & \text { - Monastery of Nový Dvưr } \\
20 & \text { Narrative Architecture } \\
23 & \text { - The Dantum }\end{array}$ \\
\hline 1. & & 3. \\
\hline INTRODUCTION & & CASE STUDIES \\
\hline $\begin{array}{ll}2 & \text { Introduction } \\
3 & \text { Thesis Structure } \\
4 & \text { Methodology }\end{array}$ & & $\begin{array}{ll}27 & \text { Introduction } \\
29 & \text { Jewish Museum, Berlin / Studio Libeskind } \\
33 & \text { Endlless House, Frederick Kiesler } \\
37 & \text { Tierra del Fuego, Martin Masse } \\
41 & \text { The Broad Muesum, Diller Scofidio + Renfro } \\
45 & \text { Brion Cemetry, Carlo Scarpa }\end{array}$ \\
\hline
\end{tabular}

4.

\section{TEST DESIGN phase one}

52 Introduction

53 Levels of Anxiety

55 Test One

61 Test Two

65 Test Three

5.

PRELIMINARY DESIGN phase two

82 Introduction

84 Site Analysis

95 Test four

106 Test Five

119 Form
6.

FINAL DESIGN phase three

$\begin{array}{ll}\mathbf{1 2 4} & \text { Introduction } \\ \mathbf{1 2 6} & \text { Reflection } \\ \mathbf{1 2 7} & \text { Program } \\ \mathbf{1 3 0} & \text { Light Study } \\ \mathbf{1 3 8} & \text { Anxiety on Site } \\ \mathbf{1 4 0} & \text { Form Iterations } \\ 144 & \text { Design Iterations } \\ \mathbf{1 5 6} & \text { Final Design }\end{array}$

7.

CONCLUSION

186

BIBLIOGRAPHY

APPENDIX 


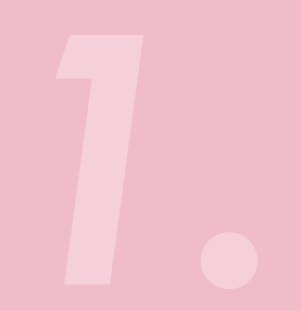

INTRODUCTION 


\section{INTRODUCTION}

Releasing Anxiety

The intention of this research project is to explore how, in a commercially motivated modern society, the use of intimate connections between architecture and the human body can create a place where anxiety is released. The body reacts in many different ways to the surrounding environment. The same can be said surrounding environment. The same can be said about anxiety; each level progresses to a more severe mental and physical state, as anxiety
affects the entire body (through all senses), Sensory Design is an appropriate method to solve this pressing issue. The exploration into the four levels of anxiety can be used as a tool to challenge and evolve the user's spatial perception. This then raises the question how can modelling the levels of anxiety be used as a method to ma an occupant, in be as a muled of their mal and physical state; and how of their mental and physical state; and how might this transition through an emotional multisensory experience evoke our awareness of self?
Creating a narrative journey that transitions from anxious to calming, can the relationship between Sensory Design and narrative be used to release an individual's anxiety?

The project will employ the idea of Narrative Architecture and a method of Sensory Design. Narrative Architecture and Sensory Design, though two different things, are similar in many ways. Spatial narrative is more about the physical environment guiding us through space whereas Sensory Design uses our senses to direct us through these physical environments. The idea that the built environment is designed for all the sensory needs of the human body, more so than the typical practice of structure unding f the mind and physical body. The gather of the mind and physical body. The gathering of sensory data is critical to design decision in this process: the senses are treated equally, ather than prioritizing vision. 


\section{THESIS STRUCTURE}

\section{PART ONE research}

The first part of the research portfolio is to establish a theoretical background, focusing on Narrative Architecture and Sensory Design. This rection provides a greateris for the design the research outlined in part two.

2. Sensory Design \& Narrative Architecture

This section identifies the relationship between Narrative Architecture and Sensory Design and the relationship with the human body, both physical and mental.

\section{Case Studies}

This section investigates five case studies that each illustrate, in different ways, how narrative archifecture and sensory design is used by arspace. In particular, anxiety to oalm the use of dark and light, material changes, and noise to

\section{PART TWO design}

The second part is the core of the design lead research which uses a variety of methods to produce a final design to altempt reduce anxiety wign phase citicelly tests material and spatial qualities against the research question.

\section{Test Design phase one}

This section tests three series of abstracted models that use the four levels of anxiety to create a physical and visual sensory narrative from one level to the next. Each series showcases the first being more interactive, decond ways, the about the physical and the third being a bstract ed drawings produced from the second series.

\section{Preliminary Design phase two}

This section is a continuation of the first, and in troduces the first architectural test to a specific site, taking the experimental series from phase one and lesting these on a real site. The reverse progression of the levels of anxiefy is introduced anxious environment that then develops into

\section{Final Design phase three}

The final design is a development of the reverse progression of anxiety, from an anxious underground thoroughfare to an elevated and calming urban park, where the narrative sensory journey is the fransition from the underground to the evated park.

\section{Conclusion}

The concluding section reflects on the design es findings that were design phase and discussfor adjustment to the design research, and highlighting future possibilities.
METHODOLOGY

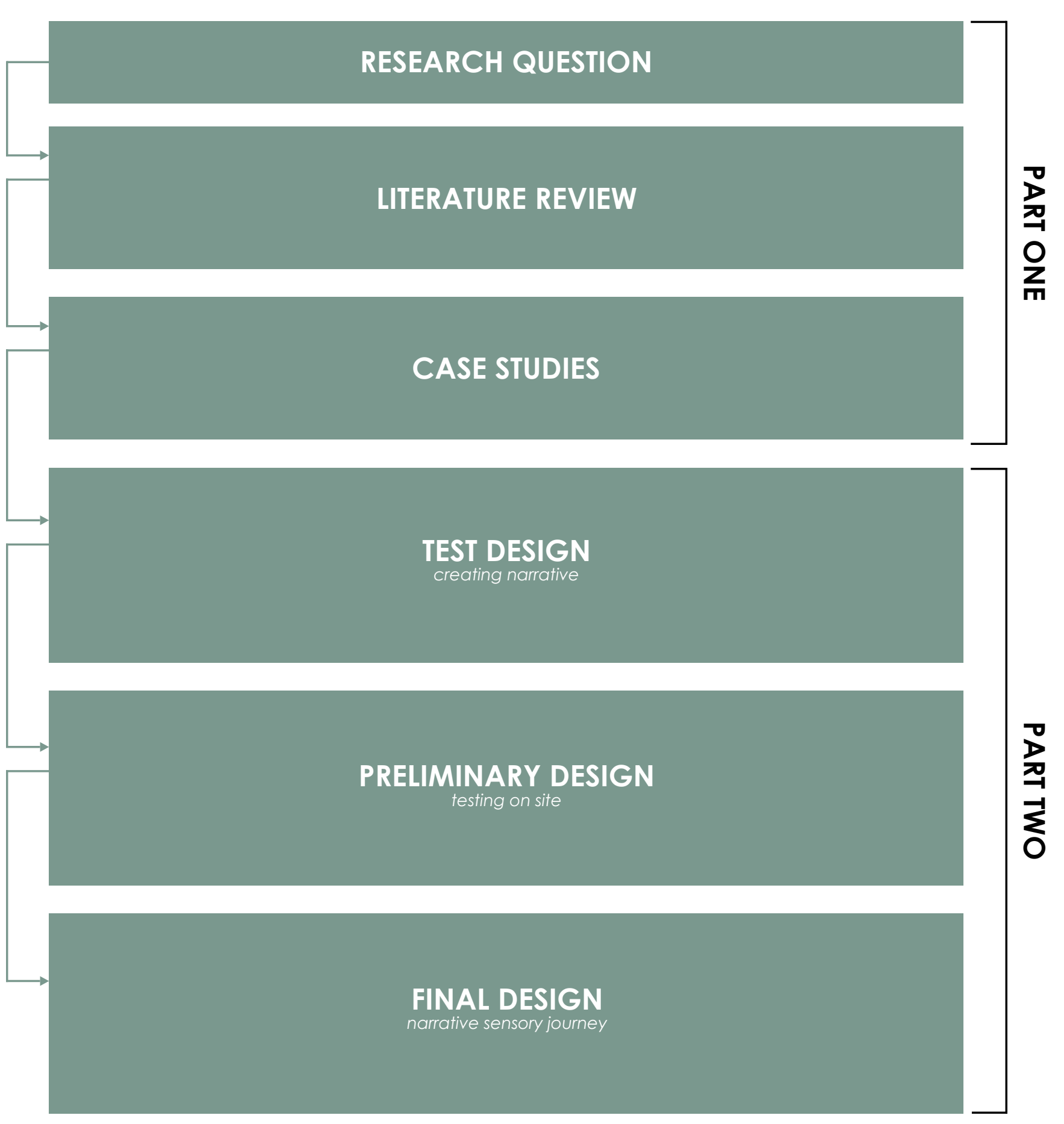




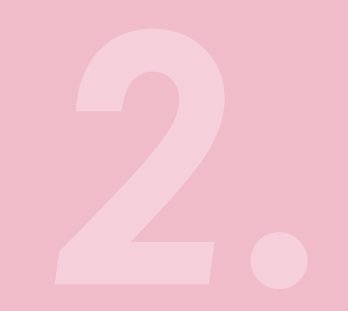

LITERATURE REVIEW 


\section{PROBLEM EPIGRAPH}

"The architecture of our time is turning into the retinal art of the eye. Architecture at large has become an art of the printed image fixed $b$ the hurried of the camera. The gaze itself tends to flatten into a picture and lose it plasticity. instead of experiencing our being in the world,

ertar we behold it from the outside as spectators of 


\section{INTRODUCTION}

Narrative Architecture \& Sensory Desig

This section summarizes important texts on the topics of narrative architecture and sensory design, and draws out ideas to be used in the design iterations. It focuses on with design iteration. It focuses on writings from Cathy J Ganoe, Christel Nisbeth and Moa Liew, Frank Vodarka and Joy Monice Malnar, Jame Gibson, Juhani Pallasmaa, and Peter Zumtho

Narrative architecture and sensory design are essential to the research design, guiding occupants through a series of forms and changes, while sensory design connects the body and mind, (the senses), to the narrative path, creating a deeper relationship between architecture and the human body. 


\section{SENSORY DESIGN}

Joy Monice Malnar and Frank Vodarka discus Sensory Design in their book, Sensory Design (2004). Sensory data is critical to desig decisions but they are rarely applied to in the built environment. All humans experience three types of sensory response, "the firs immediate physical response; second, a response conditioned by prior knowedge of its source; and hird, a respro know to ices a it has become identified in ones memory with a particular time and place."' The immediate response is an involuntary reaction to what a person experiences, whereas the second is dependent on the person and their understanding (knowledge) of space, where unfamiliar sounds and smells might make a person anxious. Others may be curious a person anxious. Ohis may be anious a person The third is based more on experience of The third is based more on experience of the user, stimulating memories and tend to have an awareness of place. An example of this smelling a particular material such as wood. creates a sense of place, which may be different or different people. An example of this is the feeling of home, an experience. Light doesn't create the same sensation as a fire place, which ople. A place is location of experience. It evokes the senses, and the work of imagin eelings of a place are indeed the mental projections of individuals, but they come from collective experience and they do not happen anywhere else. They belong to that place."

The experience of a place is enhanced by an nexplicable but enjoyable odour. Our sense of mell excels in its ability to invoke awareness. Thing the ability to evoke ones' memories, it ches f fortionas a s cer for therefore serve as memory aids or as mean conducting our reactions and performance. articular odours can endow otherwise neutra spaces with specific character. 
Without sound, visual perspective is different less contrasting, less attention-demanding, and less informative. Quiet spaces foster sense of independence, informative places and constantly varying soft personal sounds which have an important emotional and social impact on individuals.

The experience of the city can be closely related to the surrounding sounds. Sound would be a significant factor for the design of urba environments. "....sound plays a crucial role in the anticipation, experience and rememberin places."

Sound creates sensations rather than reflections, but an environment without sound is lifeles and unreal, be frightening. Sounds can produce a sensory overload, but these are normal in an
environment which can be reassuring.

"Every touching experience of architecture is a multi-sensory; qualities of matter, space and scale are measured equally by the eye, ear, nose skin, tongue, skeleton and muscle. Architecture involves seven realms of sensory experience which interact an infuse each other."

James J Gibson places the five senses into systematic categories rather than detached senses: visual system (sight), auditory system (sound), the taste-smell system (taste an smell), the basic-orienting system and the haptic system. The basic-orienting system uses all the other systems which guide our orientation and the haptic system refers to the sense of touch, but this extends to include physical feeling of pain, hot and cold, muscle movement and body sensations. This is incredibly important as it looks at how each system works with one another rather than being detached senses.

"The basic-orienting system is based on the relationship between the horizontal ground plane and our vertical posture" Gibson stound plane and our vectical posture." Gibson state the basic orieng system as being the core system, while the haptic, the olfactory system, the auditory system, and the visual system al contribute information to direct us through our environment. The function of the auditory system is the arousal of the auditory sensations, permitting identification of it. Its function is to register the sounds made by the individual. If a sound is heard, you either move towards it or away from it, which is similar to the othe systems in terms of its connection to the basic systens in terion to basic orientating systen, where the information received from each other system determines ou movement from how we walk through a city to the posture of our bodies. This can also be said about the olfactory system. Our orientation to an odour, whether it is positive or negative, attracts us towards or away from it. The haptic system is different to the other systems, it gives detailed information of the environment relative to the body, the body exploring the physical aspects of the environment we are surrounded by. The of the envire haptic system includes the whole body, most of
its parts and all of its surface. The sense of smell, 'sniffing' brings a foreign scent from an individual's surrounding into contact with the olfactory membrane. Good odours often make a person act to maximise their intensity, using their orientation to increase the intensity of smell. Whereas with bad smells an individual will do the opposite, using the basic orienting system to move away from the odour.
The visual system is deemed necessary for basic movement within the environment we live in.

Juhani Pallasmaa describes the importance of the connection between architecture and the body through the senses in his text An Architecture of the Seven Senses, 1994. Smell is assocture Smell is associate with being the one of remenbrance, a particula smell can make us imagine a space, creating space that isn't through the vison of the eye For example freshly cut wood has a differen odour to treated wood. Natural woods scen sends memories of walking through a forest, relating back to nature. Memory is dynamic, it often forms and reforms experience with a spontaneous emotional response. Experience is the most important way for us to connect space through the senses.

Pallasmaa argues that there is an increasing disconnection between human senses an architecture. Architecture becoming more of a visual pleasure loses its connection with the body, rather than being shaped and moulded for human interaction, all that is seen is a $2 \mathrm{D} \mathrm{image}$ through camera lenses. Something as little as using natural materials gives an interior feeling, expressing its age and history and human aspects. Synthetic materials do not have the aspects. Synthe have the owledge of being created in a factory and never having the connection with nature and human connection. Touch being the weakest sense is still able to enhance texture, the skin

"The surface of an old object, polished to perfection by the tool of the craftsmen and the assiduous hands of its users, seduces the stroking of our hand. It is pleasurable to press a door handle shining from the thousand hands that have entered before us.. the door handle is the handshake of the building."

What is meant by quality architecture? The Swiss architect Peter Zumthor, a master of Sensory Design, describes it in term of ar Sensory Design, describesinintern a mosphere. The only way to create an atmosphere is through the emotional sensibility of the human body. In his book "Atmospheres," 2006 Zumthor extend this idea through nine illustrated chapters, which discuss the significance to create an atmosphere. Buildings that offer people havens not just for one person but for anyone who occupies space, from the macro to micro scales. Architecture can be the same as when making first impressions of a person, that the judgement or feeling in the first few seconds, ultimately or feeling in the ultimately a spontan the feling of the archisection an atmosphere, is to create environments that offer people havens not just for one person but for anyone who occupies space, from the macro to micro scales. Quality makes one react differently, the amount of work gone into crafting any architectural piece gives the sense that it's taken a great deal of time to generate and thus can be appreciated. Spaces can react in their own unique in the way materials and its composition.

"Material is endless. Take a stone: you can saw it, grind it, drill into it split it, or polish it - it will become different thing each time. Then take tiny amounts of the same stone, or huge amounts, and it will turn into something different else again. Then hold it up to the light-different again."

This will be valuable in creating further detail 
on how to create spaces that engage with every occupant with the use of materials and composition through experience.

The following case study is an example of Sensory Design. 


\section{Monastery of Nový Dvưr}

Bohemia, Czech Republic

1999-2004, John Pawson

Exemplar Work: Sensory Design/Religious Space

The sensory environment is important in the monastery for

both practical and religious reasons. Due to monks spending a

lot of their time here, it needed to be a quiet space: doors were designed not to slam, floors that did not creek and because they spent a long time on their knees, monks required a softer material than stone. The monastery church interior is an architectural expression of the sacred. The light pours down from the sides, creating an ambiguous spatial arena where the eye is drawn to the front. Light is filtered through sculptural openings rather tha the front. Ligs. ite walls floated like blades above the heads of the congregation.

"Pawson's design is anchored in long standing Cistercian aesthetic principles, but develops new and distinctive vocabulary for their expression... A steel frame removes the need for columns, creating volumes of great purity from which all distracting detail has been stripped away." 11

The design draws on St Bernard of Clairvaux's twelfth-century blueprint for Cistercian architecture, with the emphasis on light simplicity of proportion and clarity of space. The simple des allows the occupant to not be distracted by the outside, wing allows the occupant to not be distracted by the outside, windows are hidden which allows light to filter down from above, giving clarity and a space of thought and expresses its intentions through light guiding the eye to a particular point. 


\section{NARRATIVE ARCHITECTURE}

The threshold is a central component of external, and influenced by the position Narrative Architecture, moving the occupant of the body, psychological and influenced from one spatial experience to the next by the mind"13 Viewing an object con alter from Whether that is a physical or sensory change, a ones perception of space thus changing their transitional experiencertor in creating or totally internal experience of changes. narrative designs. It creates an experience, of
People tend move between their physical which most designs fall into a type, a house, People tend move between their physical which most designs fall into a type, a house,
environments using their sensory experiences. environments using their sensory experiences. hotel, etc, giving it a more personalized quality.
"The basis for considering threshold spaces is Depth of attachments is based on symbolic "The basis for considering threshold spaces is Depth of attachments is based on symbolic
the phenomenological view of space... Humans meanings on four different levels. The singular move between space defining elements."’2 (nonsalability); the scared level (expressions of self-identity); the fetish ("providing Individuals tend to structure their own concrete meaning through realization of understanding of space in a narrative way. the abstract meanings through forms that
Using narrative as a guide to designing can become inseparable from ideology;"'14 and the ultimately create a strong relationship between magical (transforming an individual). Design individuals and space. Cathy Ganoe expands is capable of containing existing meaning on the human response to interiors through a and also creating new meaning, expressing on the human response to interiors through a and also creating new meaning, expressing
narrative approach. The nature of the narrative old and new ideas. Human understanding narrative approach. The nature of the narrative old and new ideas. Human understanding
design process is based on the experience of of the world is not experienced just through an individual's movement through space. "The objective data provided by cultural symbols, movement through space is viewed as physical/_ but an individual's unique interaction through 
personal experience, feelings, and memory. The angle of viewing may alter ones perception and response to space, and their movement is physical and influenced by the bodies position, and influenced by the internal (state of mind). The journey describes how the design for human narratives within the environment and how narrative design cotes an entiont, mental and physical (multisensory experience) through personal experience. This in itself is hard to do, so by designing and understanding human personality traits.

Moa Liew and Christel Nisbeth's text Monument of Anxiety investigates how architecture can send signals and messages to the visitor through communication theories, and the design process of the narrative. The use an filmic processes, tools and whe The use of the mind and body thes. Exploring a new and spatial seques. Exploing a new tool to create a strong relationship between the individual and their perception of experience of space. Equally to a film that engages the emotions of the viewer, the process of the narrative is the same, inviting the user in an emotional journey creating a narrative process that make architecture more of a surprise tha a structural element. The physical space sends signals to our pure memory while our reaction

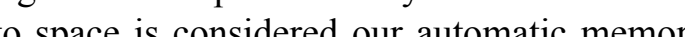
"It can be seen as the stere auscope for mevealing the secrets of human behavior, the threshold the secrets of human behavior, the threshold between the imaginary and the physical space,
and the framework of life."15 The monument is built to give some form of symbolic value, that symbolic message comes from our pure memory. Atmosphere within architecture sends emotive messages and puts the visito of space into an emotionally charged state. Once the person no longer feels emotions within space, they become uninterested. A method to structure spatial relations and create an atmospheric effect that connects with the emotions of the individual through a sequence of spatial of events. This text is important to the project as its main objective was the narrative jour a joject on phinomentere a pis is important to the same process of Narrative Architecture where the visitor connects on similar emotional state through story the space is trying to communicate.

Narrative can be much more than a writing, reading, drama and cinema, narrative can shape and simplify events into a sequence that can cim sta everyone, combining both instinct and knowlede, comstinct . manten thandscapes and architecture. Cities are both, like architecture, spatial and atmospheric, giving structure and shaping experiences.

"The various physical parts of a space signify as a result of the actions and experiences - of the participant who assembles them into a personal construct. The narrative coefficient resides in a system of triggers that signify poetically, above the addition to functionalitr. Name in aduition to finctionality. Narrative means that the object contains some 'other' existence in parallel with its function." $" 16$

The church through the centuries has accumulated narrative through the desire of reflecting the story of god, configuration of the body in plan and their decoration. "The process of familiarisation with any one urban environment requires endlessly complex and risky experiment, with every main route encountered deepened by experiments in wandering, or what the Situationists called dérive."17

The following case study exemplifies Narrative Architecture. 


\section{The Danteum}

Rome, Italy

Unbuilt 1938, Giuseppe Terragn

Exemplar Work: Narrative Architecture

The Danteum by Giuseppe Terrangi is an unbuilt project from 1938 based on the square and the golden ratio. The significant aspect of this project is the repetition of forms, making the user iliar with the space but changing its atmosphere, it is a great familiar forms, and spaces of the Danteum arragni's . The levels, forms, and spaces of the Danteum are Terragni's interpretatio of Dante's Divine Comedy. The sequence of spaces experience by the visitor leads through hell, purgatory, and paradise. As the Divine Comedy includes references to numerology and geometry, the poem could be seen as a written allegory of the physical structure of the afterlife. Terragni, in his turn, took the text and designed a physical model of that written allegory, also

using numerology and geometry. The project uses very simple gestures that are repetitive but have different elements, which creates an entire different experience for the user. The Don wich has a strong narrative journey where spaces are juxtaposed cos a a presting the expressed though the atmosphere, mainly through the amount of light entering a space, paradise being a place of light while hell being one of darkness. ${ }^{18}$ 


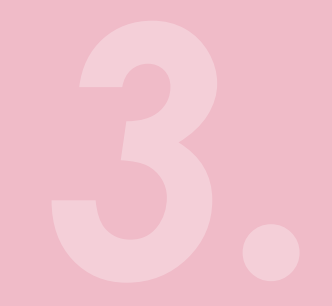

CASE STUDIES 


\section{ENDLESS HOUSE
FREDERICK KISLER}

\section{INTRODUCTION}

case studies

TIERRA DEL FUEGO

MARTIN MASSE

This section analyses five case studies that each illustrate different ways in which the architects have used aspects of Sensory Design to create narrative within architecture. The first case study looks at how the Jewish people' ordeal in the Holocaust during WWII is translated through the users experience into narrative sensory journey rather than a museum displaying works. The Jewish Museum in Berlin gives a glimpse into the suffering of the Jewish people. The creation of an emotion experience connects with the body. The Endless experience con House was an on constantly, the same as the hunan body; this case study was selected for the closeconnection between the architecture and human body. Th is an example where the architect wanted the movement through architecture to be like moving through your body and thoughts. The third case study by architect Martin Masse, is more of a monumental architectural form that expresses memory, representing a town which onced lived, but has now dissappeared. Tomba Brion by architect Carlo Scarpa created a memorial to enhance the experience of the user through his forms and attention to detail through rawing. Believing that that a cemetery should be a place of happiness not sadness. (a) case study, the Broad

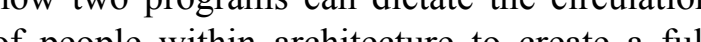
experience for the occupants.
BROAD MUESUM DILLER SCOFIDIO + RENFRO 
Jewish Museum

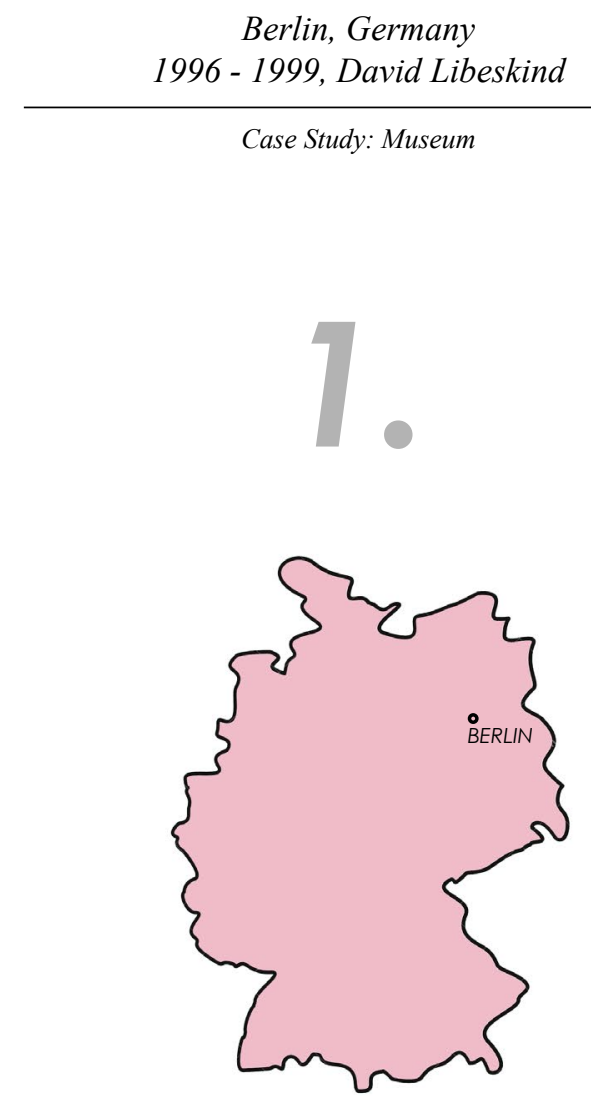

GERMANY

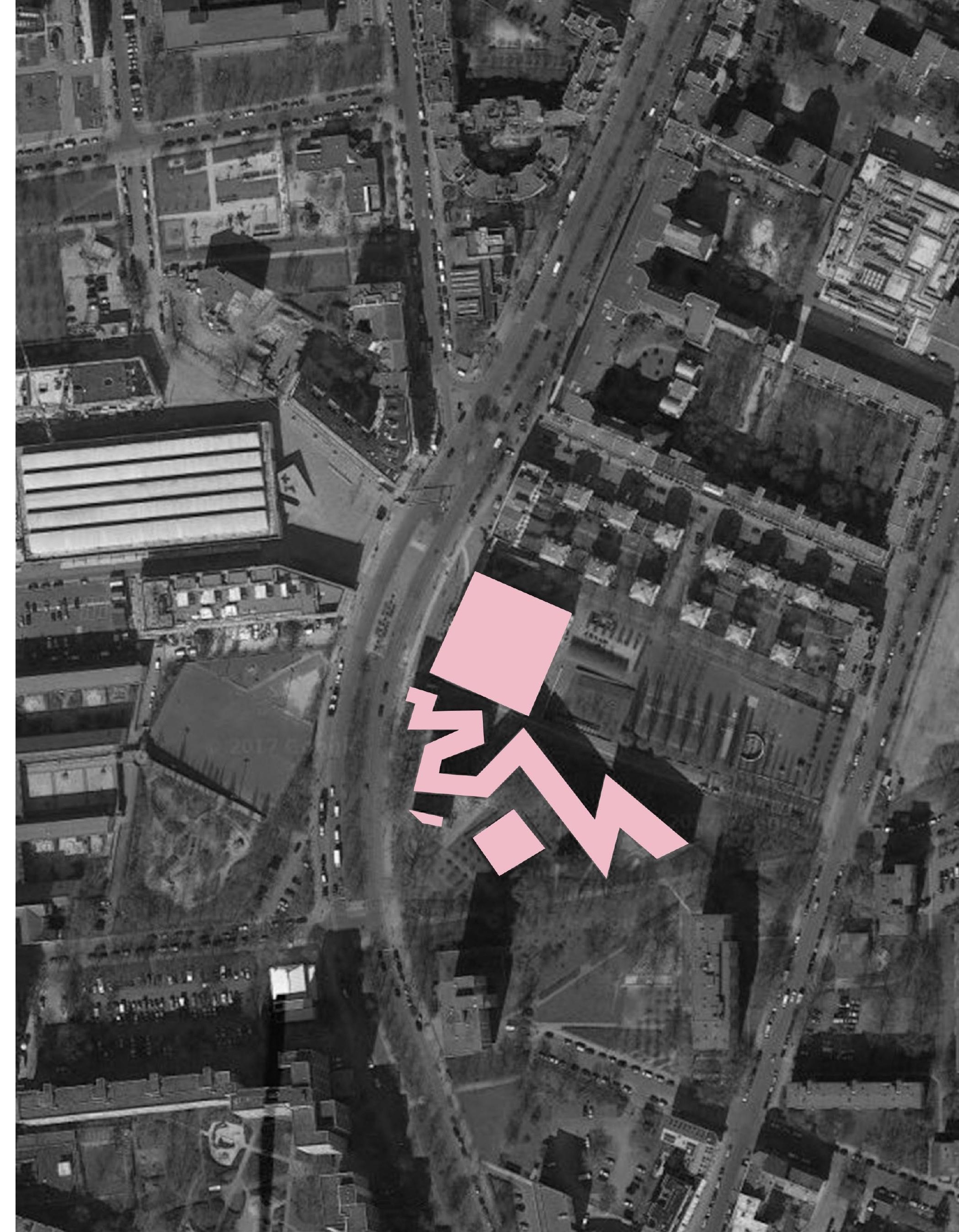


In describing his design intention Libeskind says; "A visitor must endure the anxiety of hiding and losing the sense of direction before coming to a cross roads of three routes." ${ }^{18}$ This creates a narrative for the occupant, who has to endure the experience of three different routes, which represent German history, emigration from Germany, and the Holocaust. An extensive amount of the building is void and glass, making the viewer look up towards the light, making the viewer look up towards the light, giving the experience of the Jewish people in WWII, in their darkest moment, where you fee you will never escape, yet "the small amount of light sends a little hope." 19 The concrete helps create an overwhelming atmosphere, being cold created a chill and where a small slit in the wall allowed small amount of light. The interior is mainly reinforced concrete, and takes the user through multiple spaces, galleries, empty spaces, and dead ends. Even though it is a museum, the extension is intended to create an experience that depicts what most create understand. 
Endless House

1950, Frederick Kiesler

Case Study: Unbuilt

2. 


\section{ENDLESS HOUSE}

The Endless House is Frederick Kiesler's answer to the intricate relations between man, nature, and technology. His main concern wa the psycho-social aspect beginning with the aesthetic element then then functional after.

Kiesler wanted to create architecture that when inhabited, felt as though it were your own body, moving from each room as you do when you move through thoughts. Kiesler believed in elastic spatial concepts, arguing the shape of the concept design is based on a lighting system, allowing ample light throughout each corner of every room. His project the endless house was called endless because all ends meet constantly, like the human body. ${ }^{20}$ 
Tierra Del Fuego

Tierra Del Fuego, Argentina 2014, Martin Masse

Case Study: Monument, unbuilt
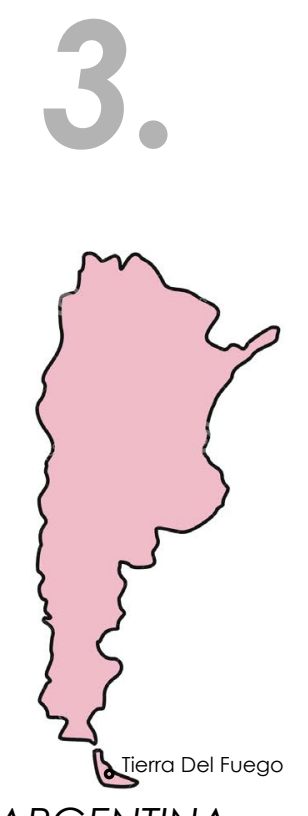

ARGENTINA 
TIERRA DEL FUEGO

The Tierra del Fuego project is a huge and dramatic inverted pyramid, tribute to a former tribe, the Selk'nam people. The memorial design has the purpose of avoiding the repetition of the mistakes of the past. Its structure sinks into the ground "bowels of the earth" to take the visitor

to an underground space, where an interactive experience is lived with sculptures and a huge mural. The project is trying express our duty to the past, avoiding the repetition of the genocide the past, avoing the of the American Indins. The design tries to search for a new architectural form and mean of expressing memory. It makes the emotion very visual, and transmits the sensitive memory through spatial experience. It represents a town that once lived, and has now disappeared without a trace. From the ground level base, the pyramid extends down towards death and oblivion. The descent down symbolises different stages of the genocide: colonization, evange extermination, disease, confinement of people, miscegenation and the confinitive of people, heir customs and 
The Broad Museum

Los Angeles, California, USA

2015, Diller Scofidio + Renfro

$$
4 .
$$

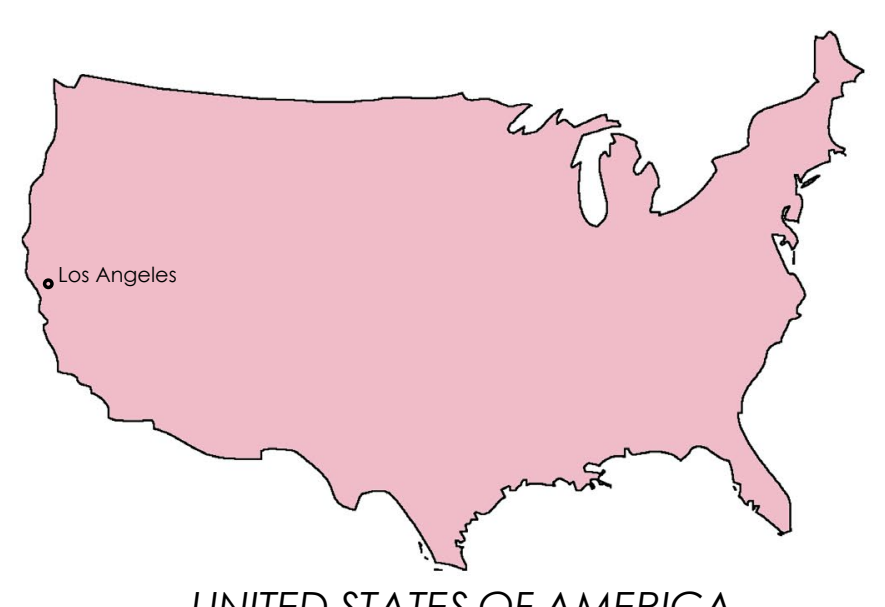

UNITED STATES OF AMERICA

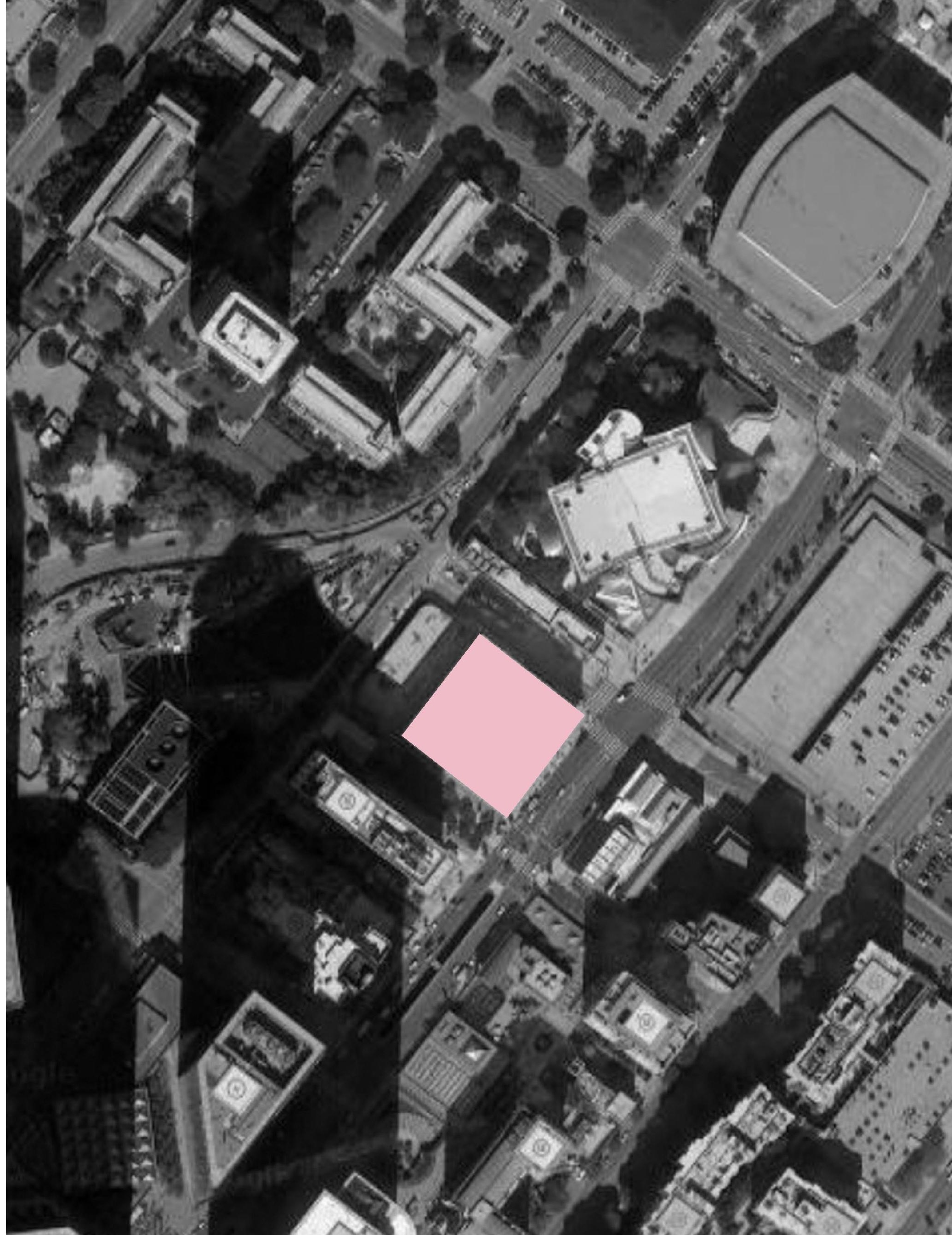


The Broad Museum is a contemporary art museum built in downtown Los Angeles. Designed by Diller Scofidio + Renfro, it will have the capacity to hold 2000 art works with an 11148 sqm of floor space.

The museum was designed to support two different programs, public exhibition and a storage area. The form of the buildings are also in two parts, named the veil and the vault, he organic form of the on being the vell. The architects believed rather than making the storage a secondary program to the public gallery, the "vault" played a key role in the way people experienced the Broad from entry to exit, where the curved underside creates a lobby space for public circulation which draws people up through to the third floor gallery. Leaving the gallery floor requires the user to move through the vault, where there are glimpses into the storage area of the att into the storage area of the art collections. ${ }^{22}$ 
The Brion Cemetery

San Vito, Italy

1977, Carlo Scarpa
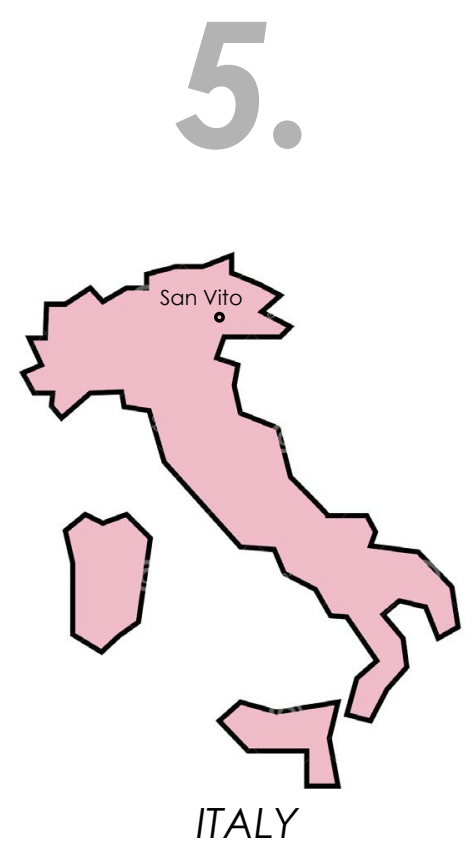


\section{THE BRION CEMETERY}

The Brion Cemetery was designed for Giuseppe Brion who died in 1968. Scarpa was commissioned to devise a memorial, that contain multiple features in a modern style which was respectful rather that overwhelming. He created a memorial that was not only fitting its purpose, but enhancing the experience of the living with form, light and space which, engages them into contemplation. This was one of his only works with plosu ".. with pleasure, ....everyone is happy to go there the children play, the dogs run around - all cemeteries should be like this."

Scarpa's incredible work and execution of handrails, floor patterns, benches and door pulls set him apart from others in his generation. He did not use spatial themes, but rather using and manipulating materials in relation to the human body. The way in which he worked was by constantly drawing with pencil work which by his way of rwing wint pencil work which was his in of resenching the intervento the user through touch and feel of the materials used, rough stone and fragmented concrete. This is critical to the design development of the four levels of anxiety, through design iteration will both the forms of each level evolve but also the atmosphere and the connection to body through the senses. 


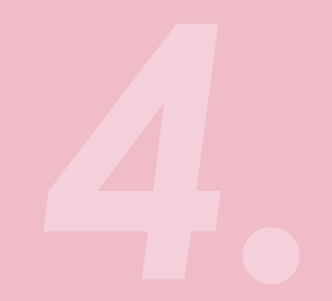

TEST DESIGN 

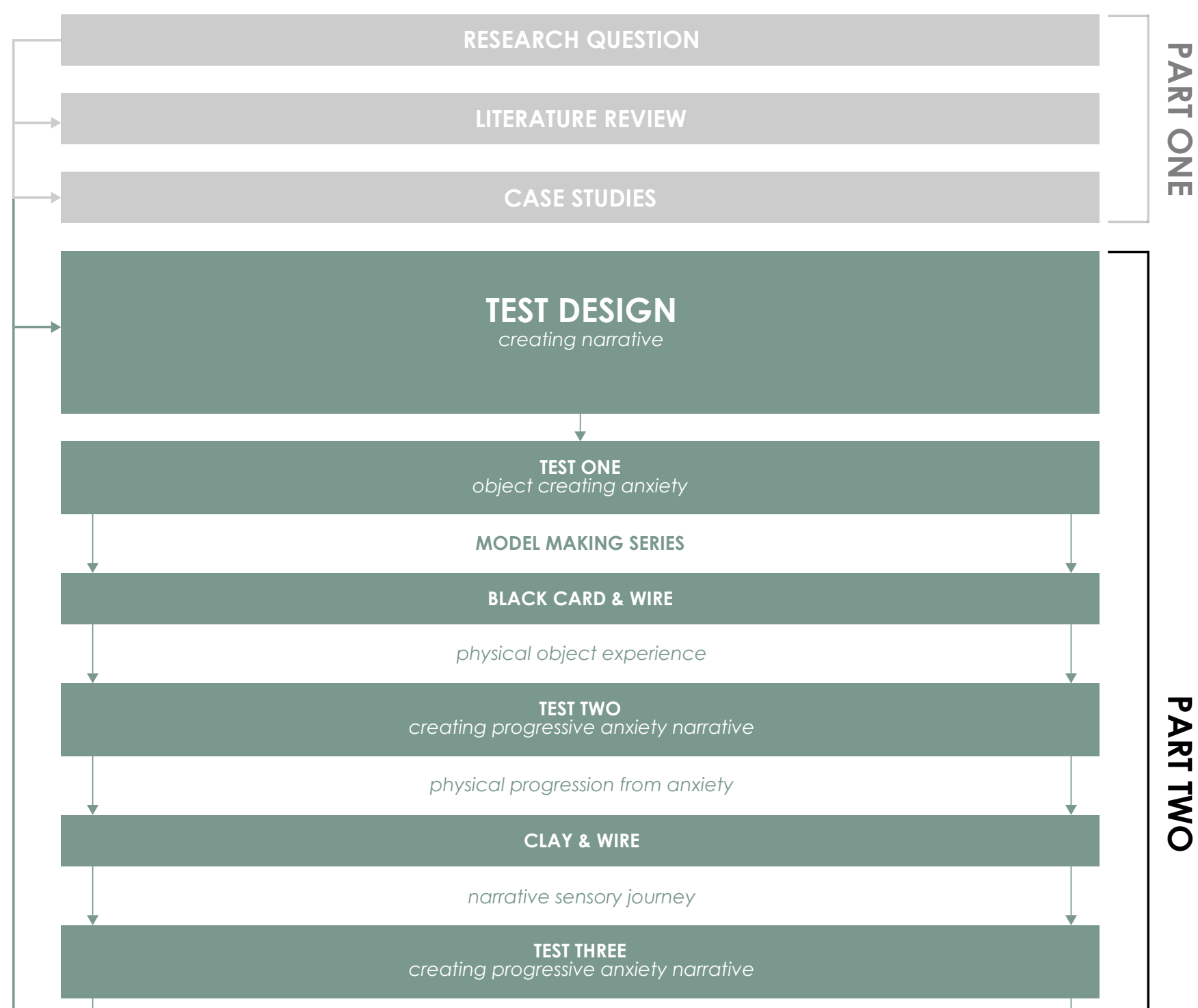

DRAWING SERIES

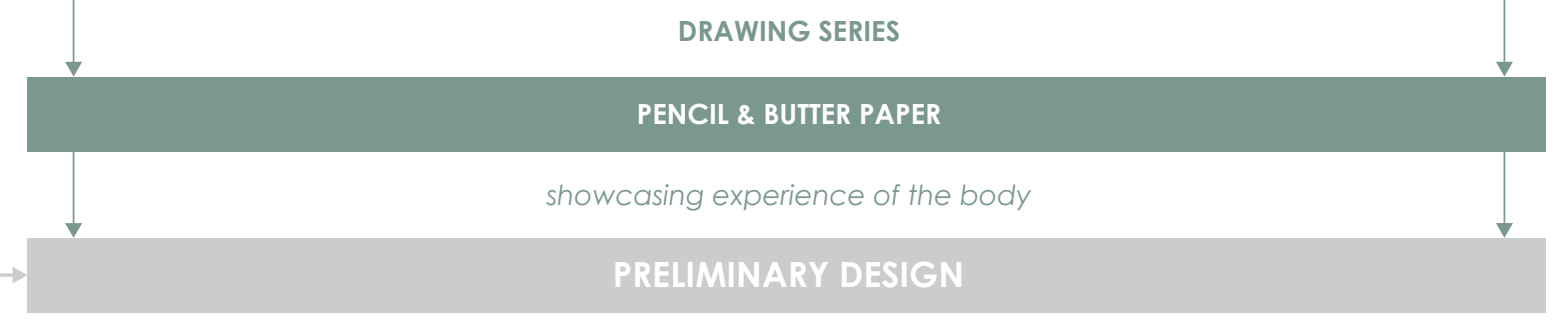

FINAL DESIGN

\section{INTRODUCTION}

The first design phase presents a series of sculptural tests that investigate the progressive levels of anxiety from mild to panic level as spatial and irs sences an which looked id and picked up gradually becane more fragile, creating some form of immediate anxiety. The second series is a more abstracted version of the first. These are presented as a progressive, material and spatial journey analytical drawings of these sculptural models led into the next design phase. 


\section{Levels of Anxiety}

Your body responds to anxiety in a
variety of different ways, causing more

variety of different ways, causing more

numerous and intense symptoms as the

level of anxiety increases.

MILD

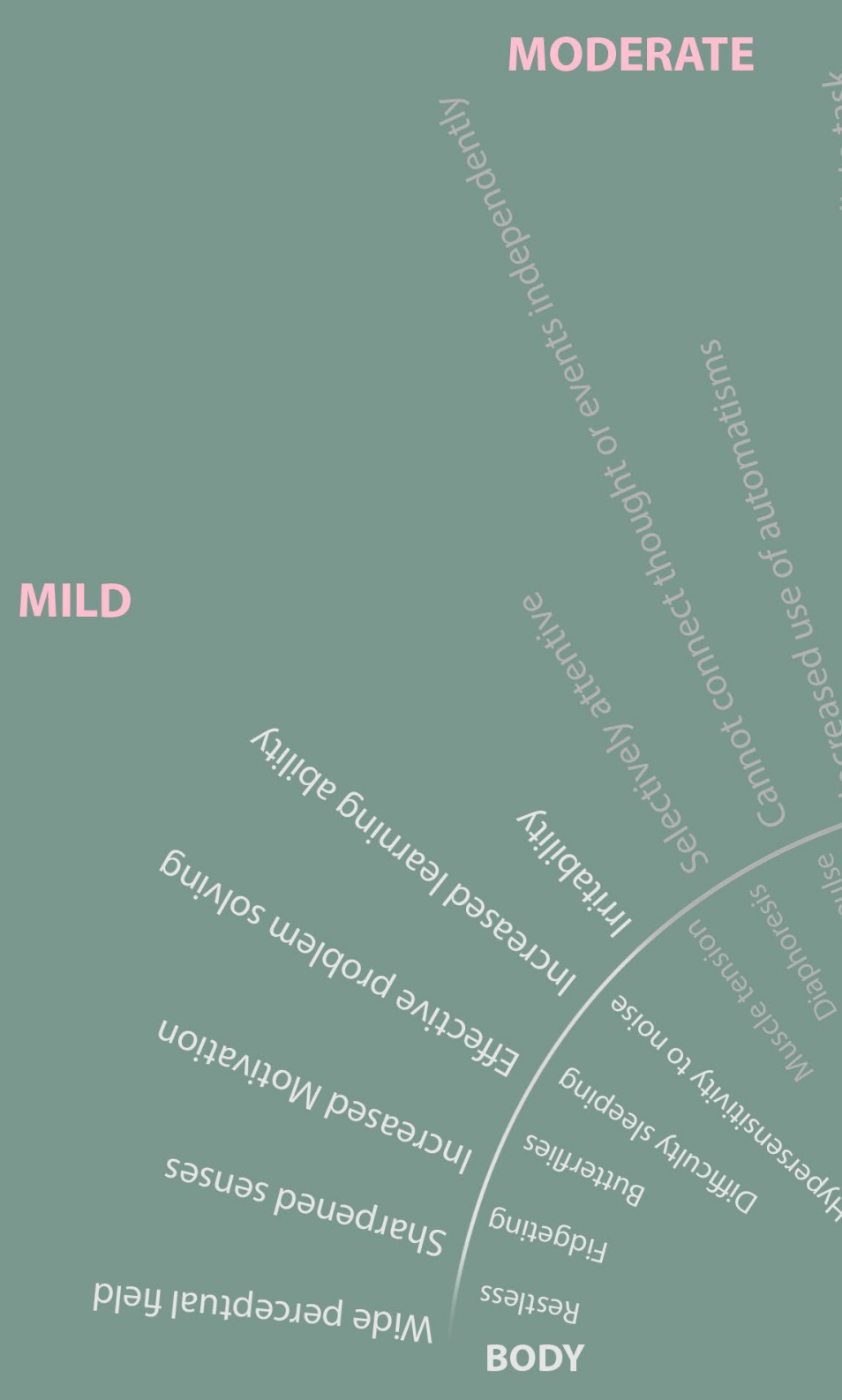

SEVERE

PANIC 


\section{TEST ONE}

The beginning of the design phase started with idea of representing the levels of anxiety with idea of representing the levels of aniety as physical models. This led the creation cardboard cubes $120 \times 120 \mathrm{~mm}$ with interactive installations inside each cube. However, it was limited in that it only represented levels of anxiety from one the perspective of one sense, vision. The next phase was using the same idea but each cube was slowly deteriorating. The intention behind this was if someone interacted with each cube, they would react differently.

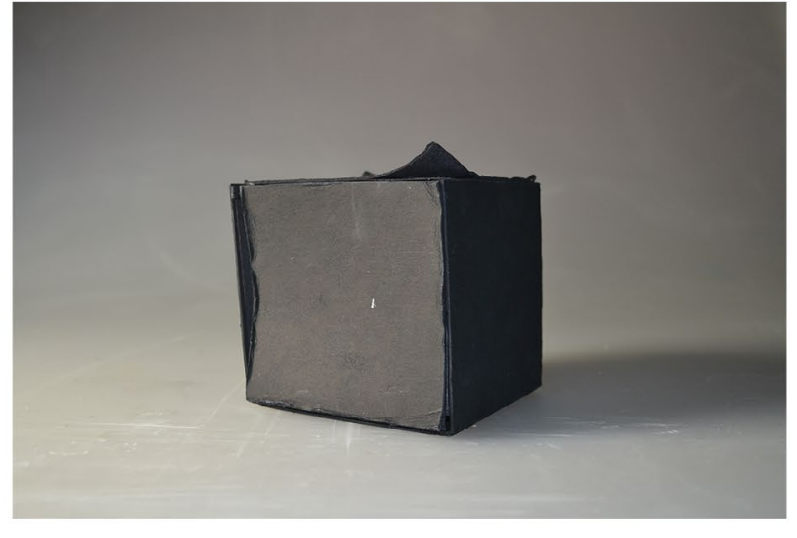

Mild

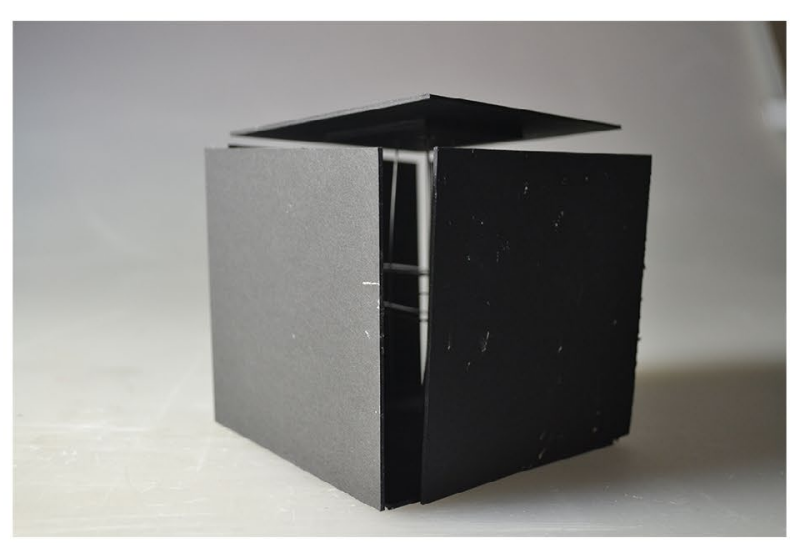

Severe

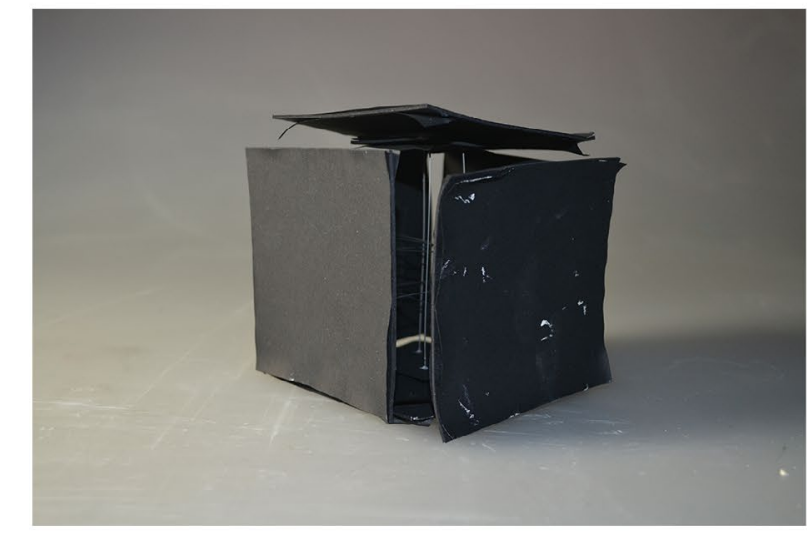

Moderate

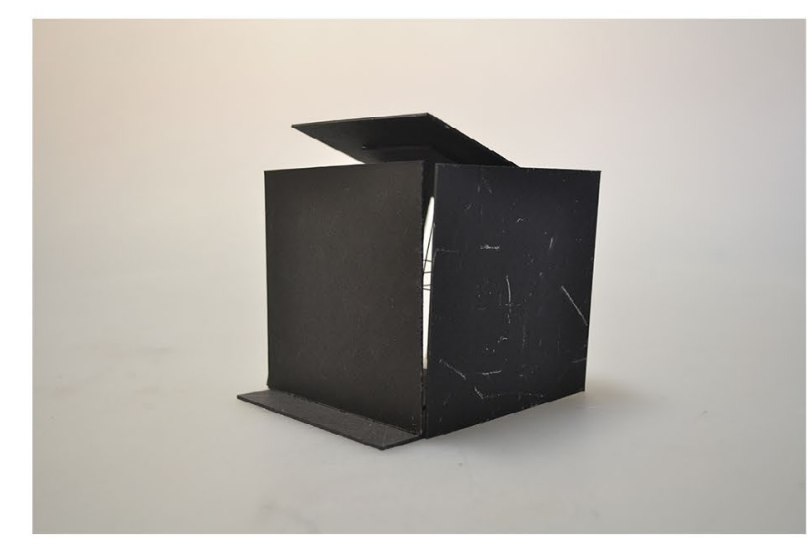

Panic Level the person who experiences the objects feels the same about it as another does, the last cube being as though it is about to fall apart.

The first iteration was a deteriorated solid cube, which slowly progressed to each surface becoming detached with metal rods holding hem in place, continuing onto becoming less table as you interact with them. The idea stable as you interact with them. The idea
behind this experiment was to see how the form 

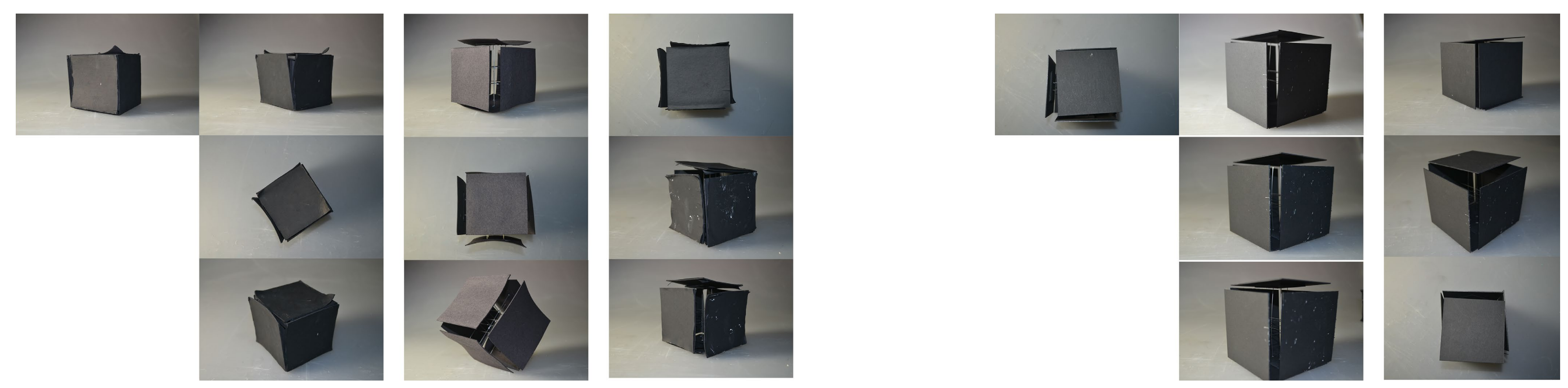


\section{TEST TWO}

Clay \& Wire

The second experiment of the levels of anxiety in a physical form represents a narrative progression from the mild anxiety to panic level. The use of clay and wire mesh created a series of small models that when organise into a liner configuration represented abstract ideas of what each level could look like, an how it transitions from pure form to one that's deteriorating revealing the emotional an physical distress felt when experiencing anxiety. The visual aspect of each level is clear; the

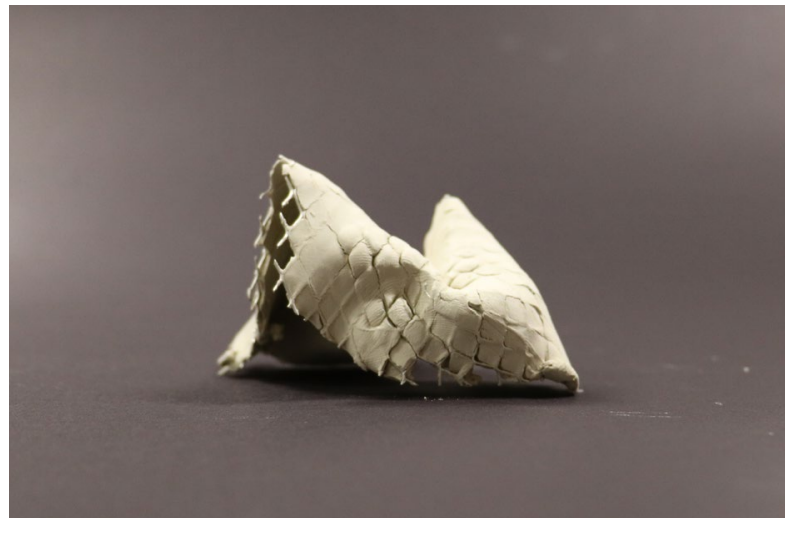

Mild

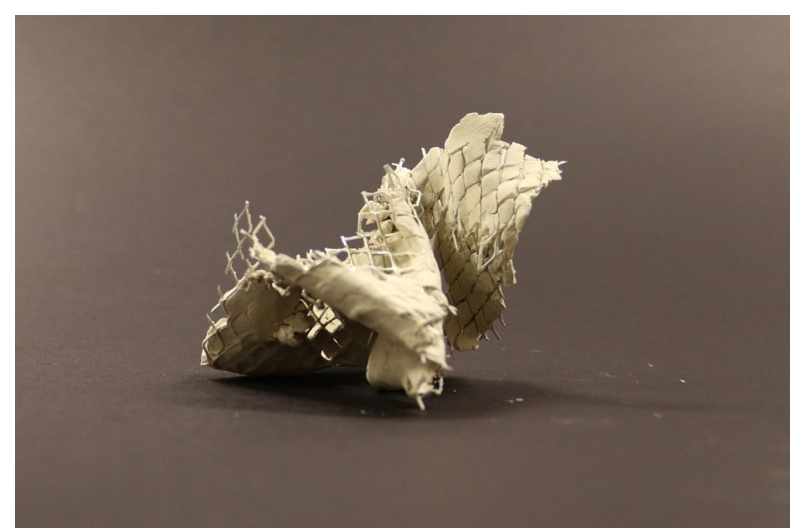

Severe

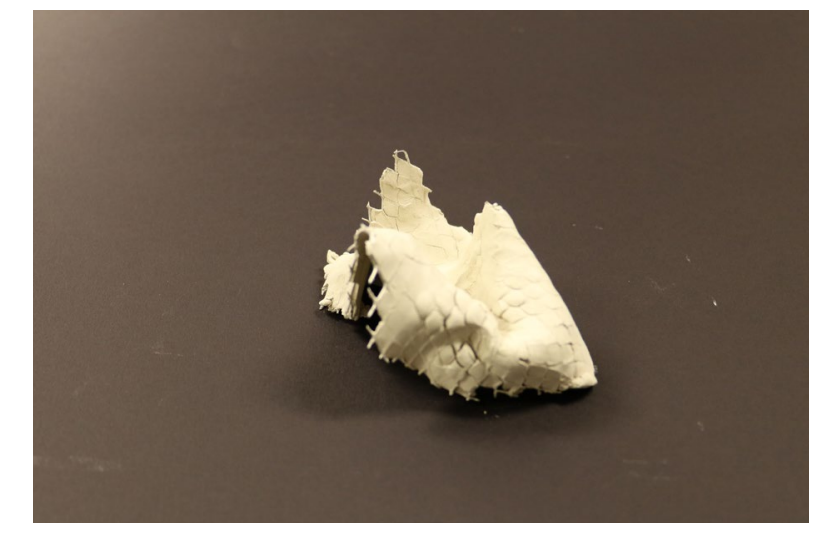

Moderate

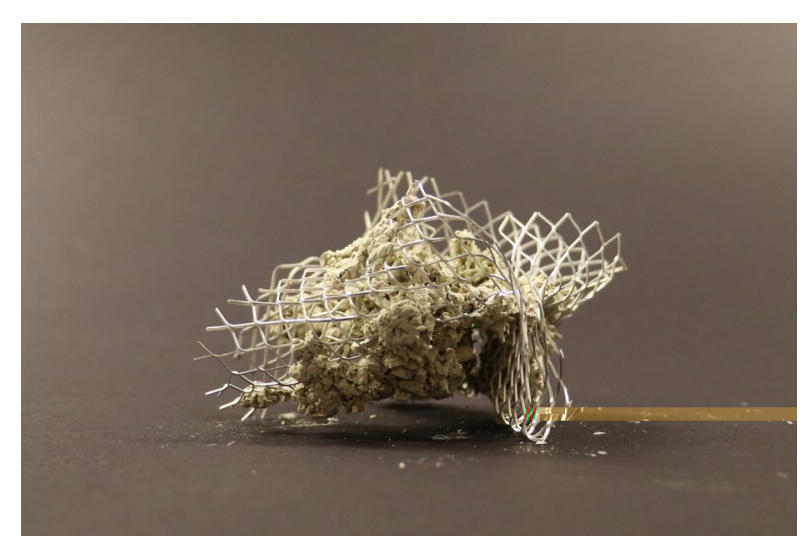

Panic Level mild series are smooth where the mesh wire is covered in clay but also reveals the mesh shape. Moderate level starts to deteriorate where the clay begins to crack and more of the wire mesh is exposed. Severe is where the model clay to the eye, whilst the panic level models have completely deteriorated, the wire mesh is highly exposed and the clay has become very rough and fragile, almost cave-like. 


\section{TEST TWO}

Narrative sensory progression

After photographing the models in linear series I began to test how this series could become more of an architectural narrative and sensory progression. When placed into human scale, the physical development of the linear series highlights how an occupant could navigate through each series and these models could become spaces and connections to other programs. Placing these images into a long series to create one journey showcases the progression and the narrative journey experience from level to level.
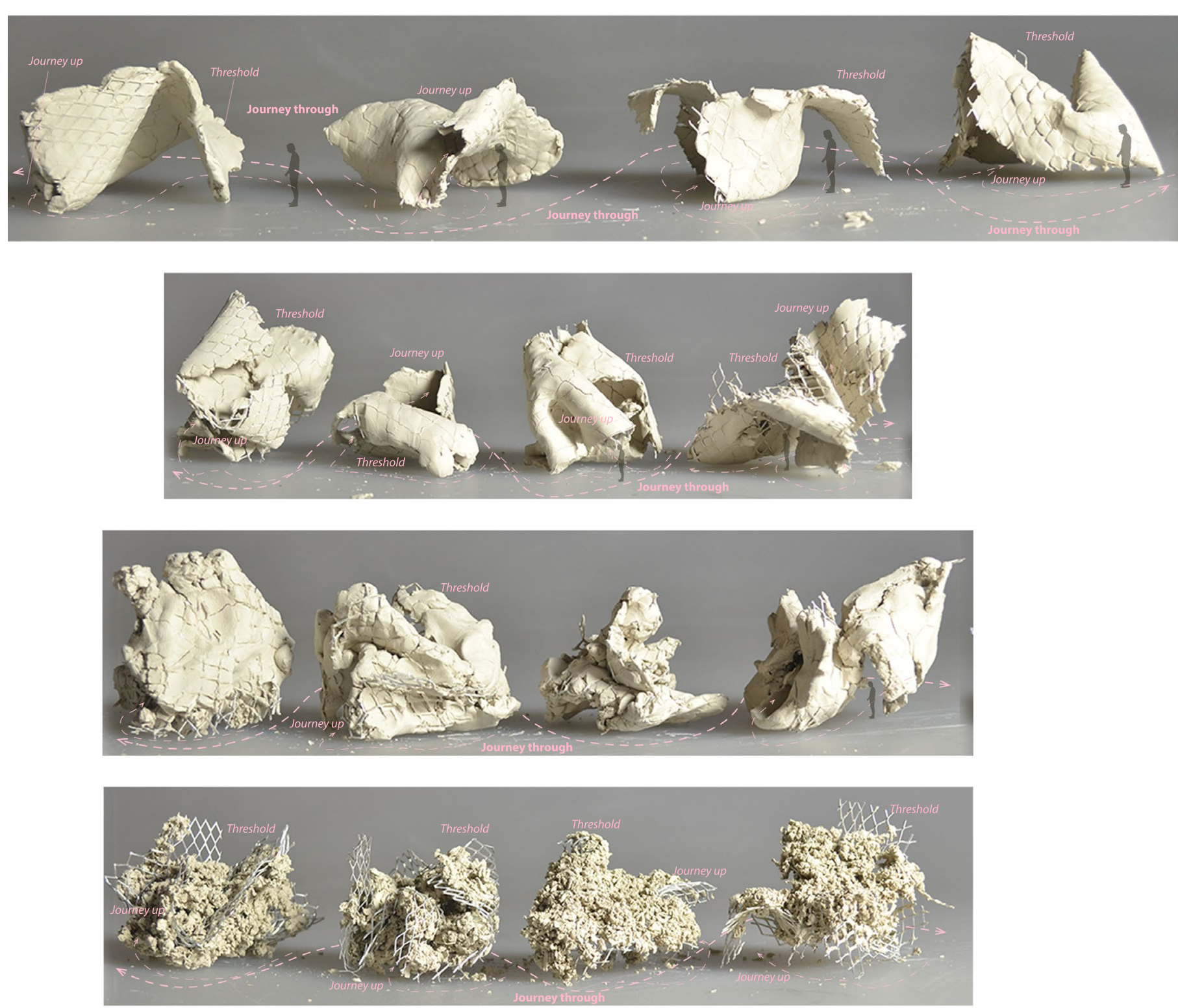


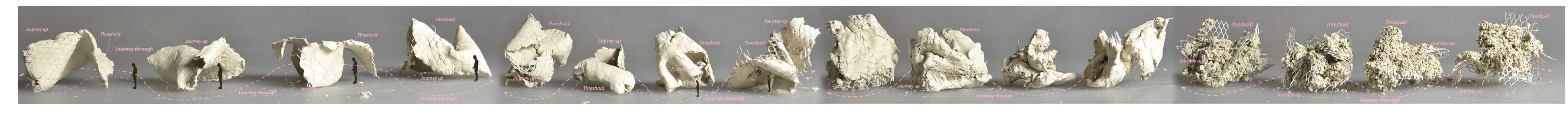




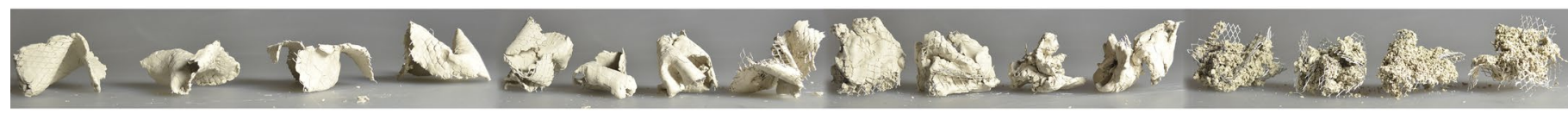

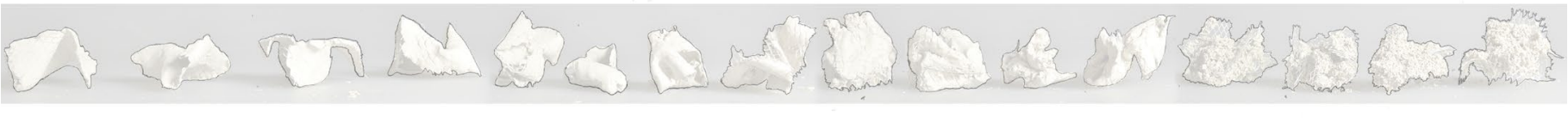

\section{TEST THREE}

Drawings series

Photographing these models as a linear configuration collectively, I explored different configurations, where the models were separated

and connected. I then produced overlaid and connected. I then produced overlaid
drawings highlighting the spaces the models created, the space created between them and the shadow they produced. The drawings can be interpreted as the experience of the body slowly degrading from level to level, under the stresses from the over-stimulated urban environment, or potential plans for designed spaces.

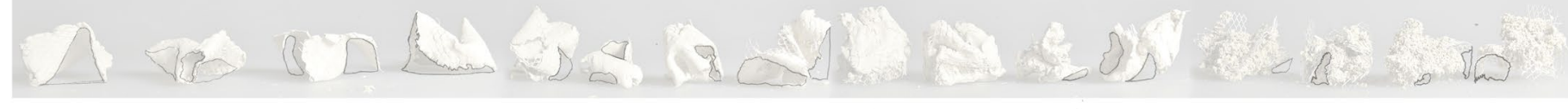

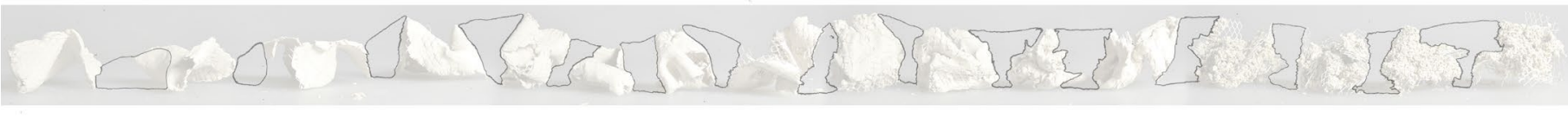

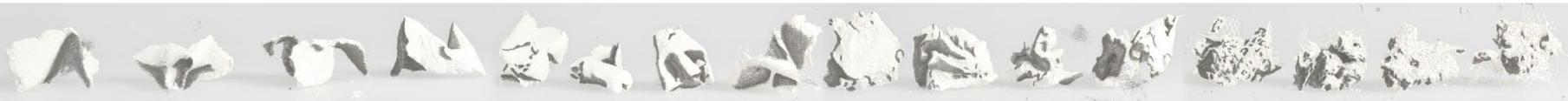




\section{(2007)}

\section{0}

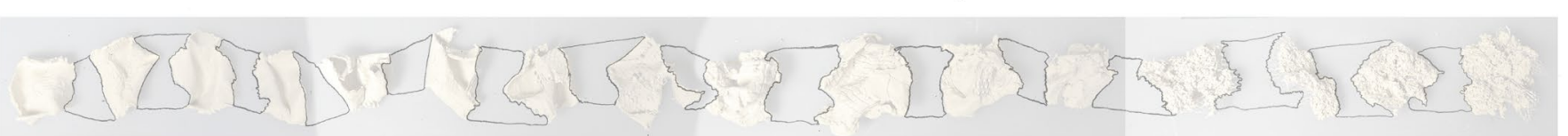

G0.

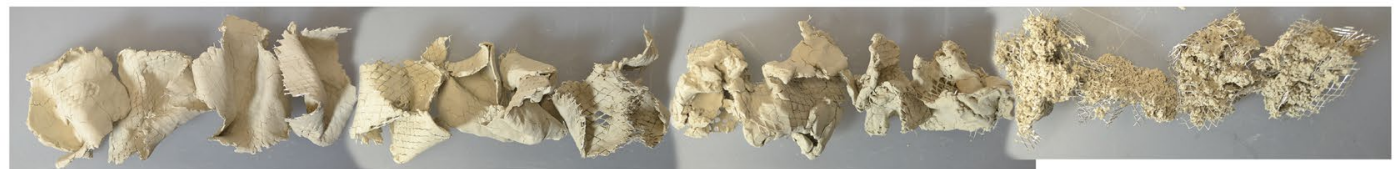

ardy

(4)

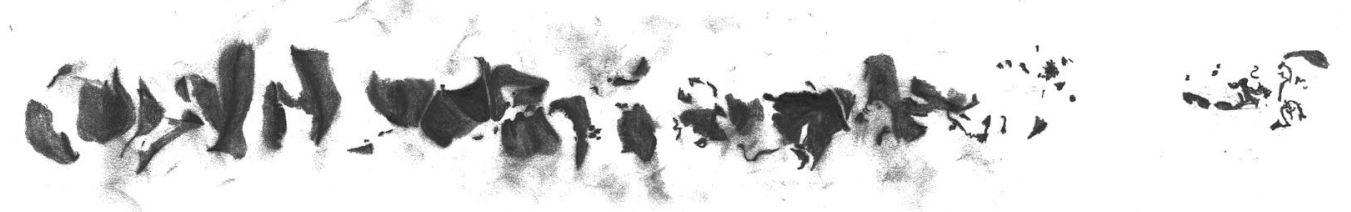




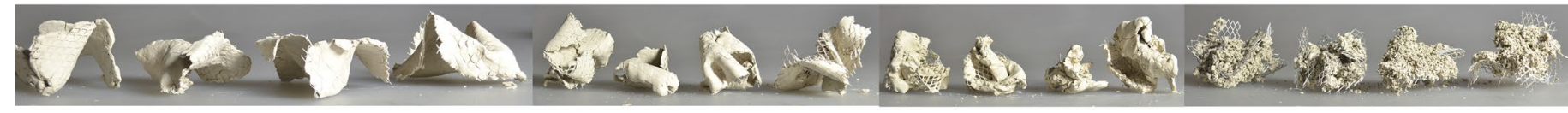

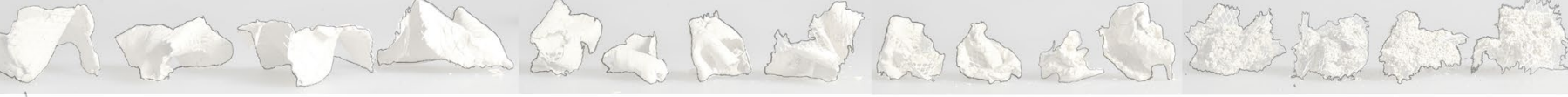

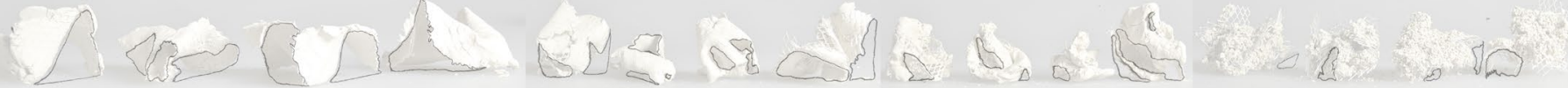

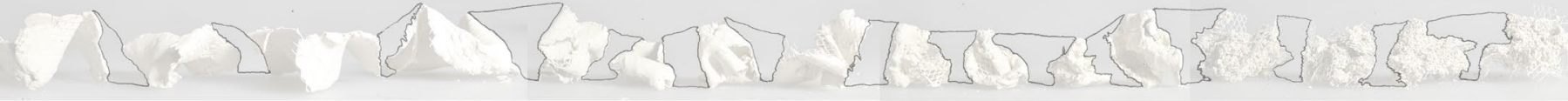

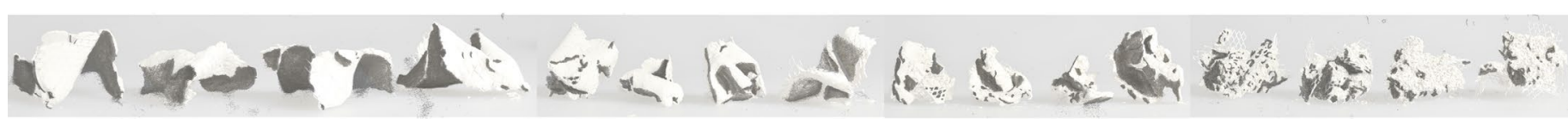

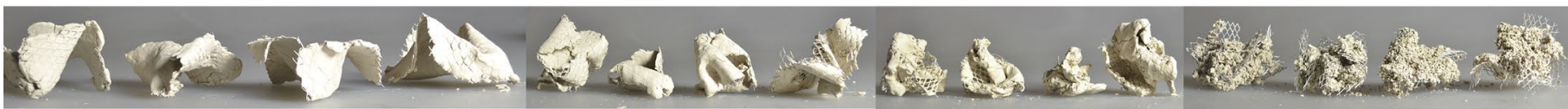

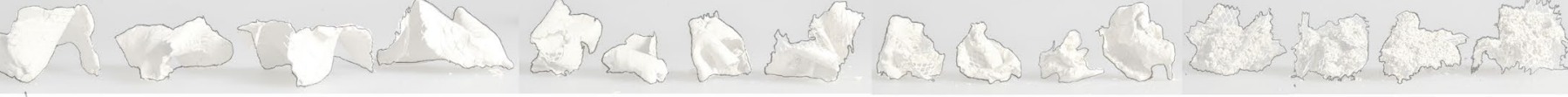

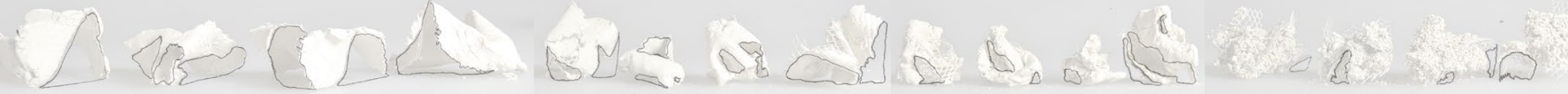

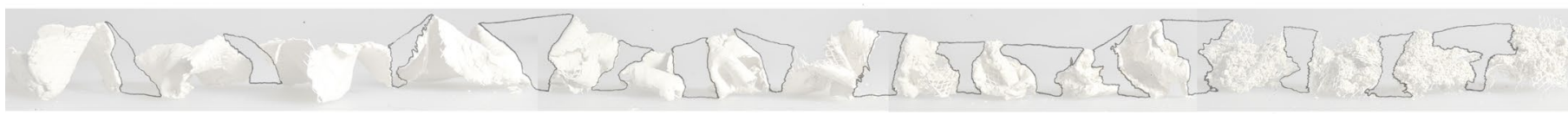

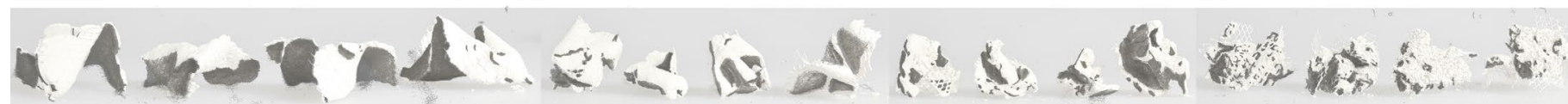




\section{कास}

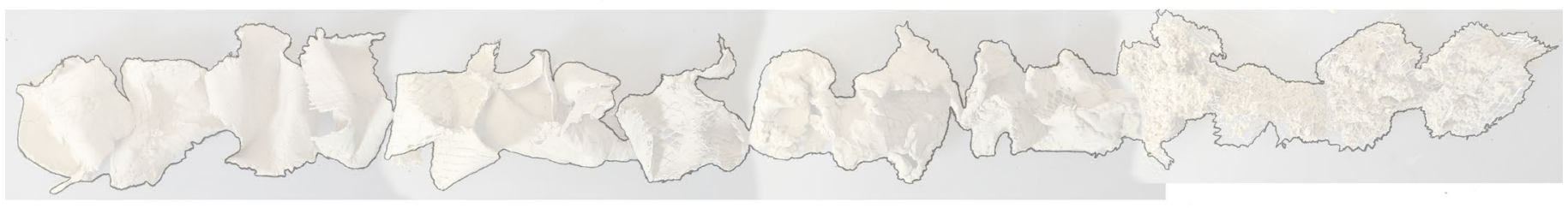

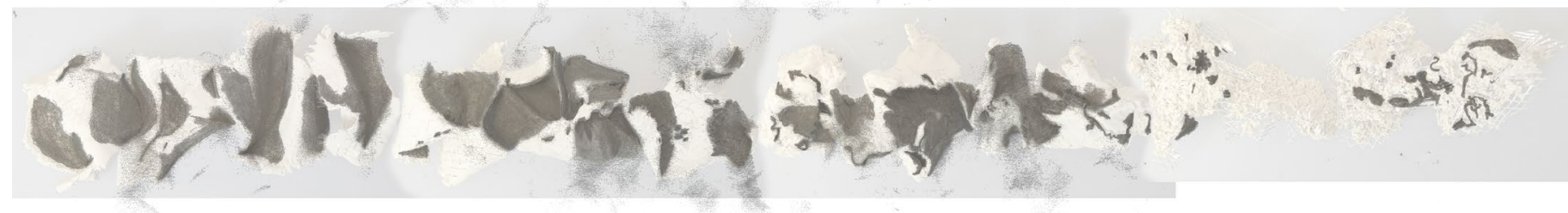


TEST THREE cont

Drawings series

This series takes the drawings and breaks up the linear progression into categories where each different drawing could be analysed, showcasing the different levels of anxiety that showcasing the different levels of anxiety that
have been extracted from test two models.

have been extracted from test two models.
There is a definitive difference between each

There is a definitive difference between each drawing type, the shaded series have more
depth in gradient whereas the others give more detail in the outlines. shaded

$$
\text { A d }
$$

moderate

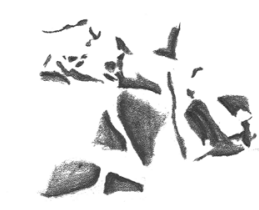

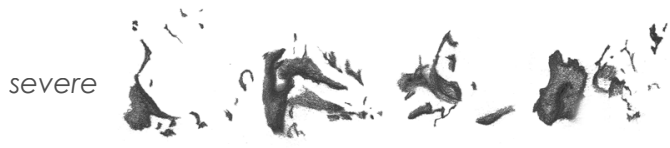

panc $\frac{1}{4}+40$ space between

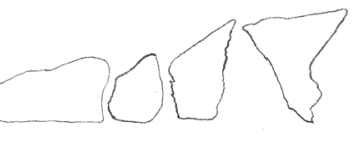

तS 93

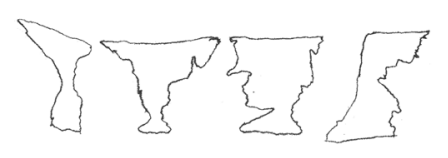

$\infty\{\Delta$

o) $\{$ \& 


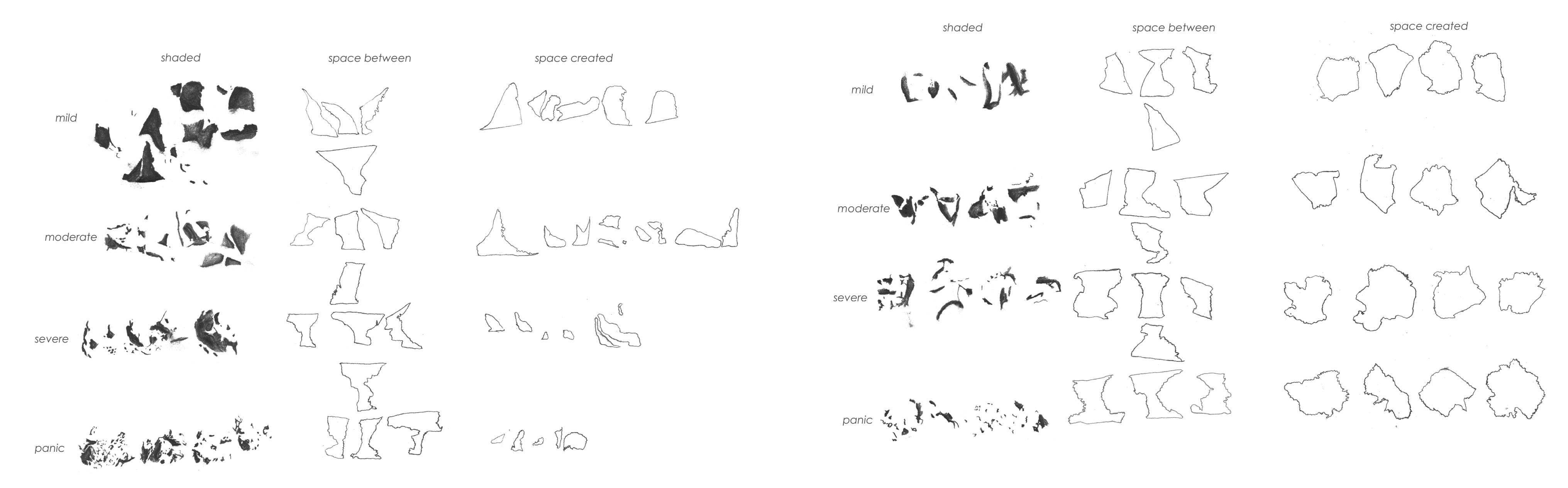


shaded

(invents

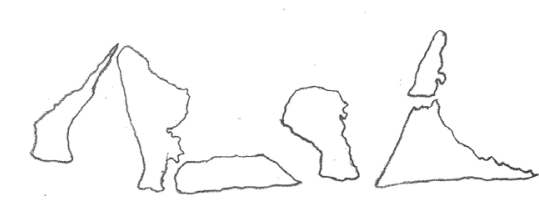

moderate 44

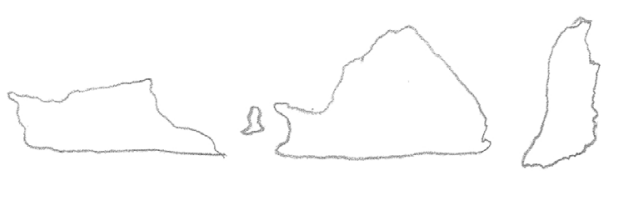

moderate $\{2+1$

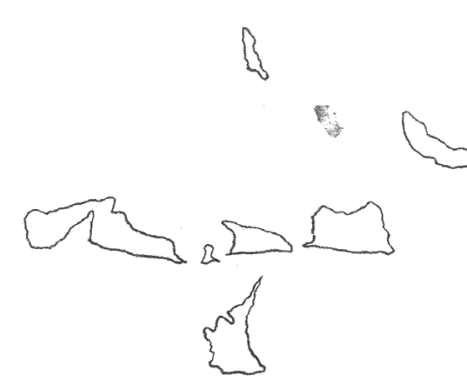

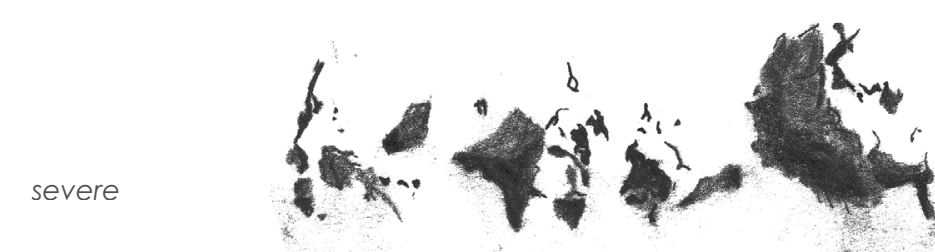

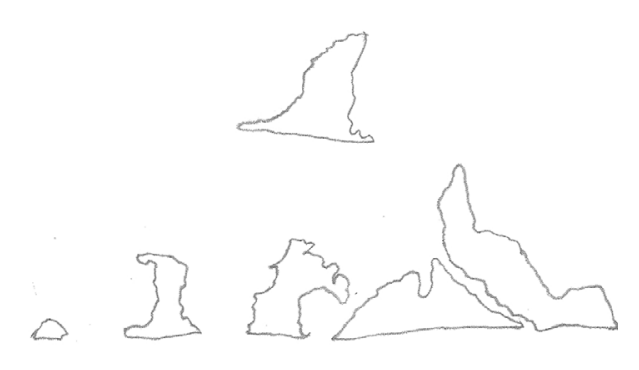

sever

$\rightarrow \frac{5}{3}$

pom 1 ind

3 sm

$\triangle$ FIGURE 4.17 drawing series

$\triangle$ FIGURE 4.18 drawing series

78 


\section{PRELIMINARY DESIGN}




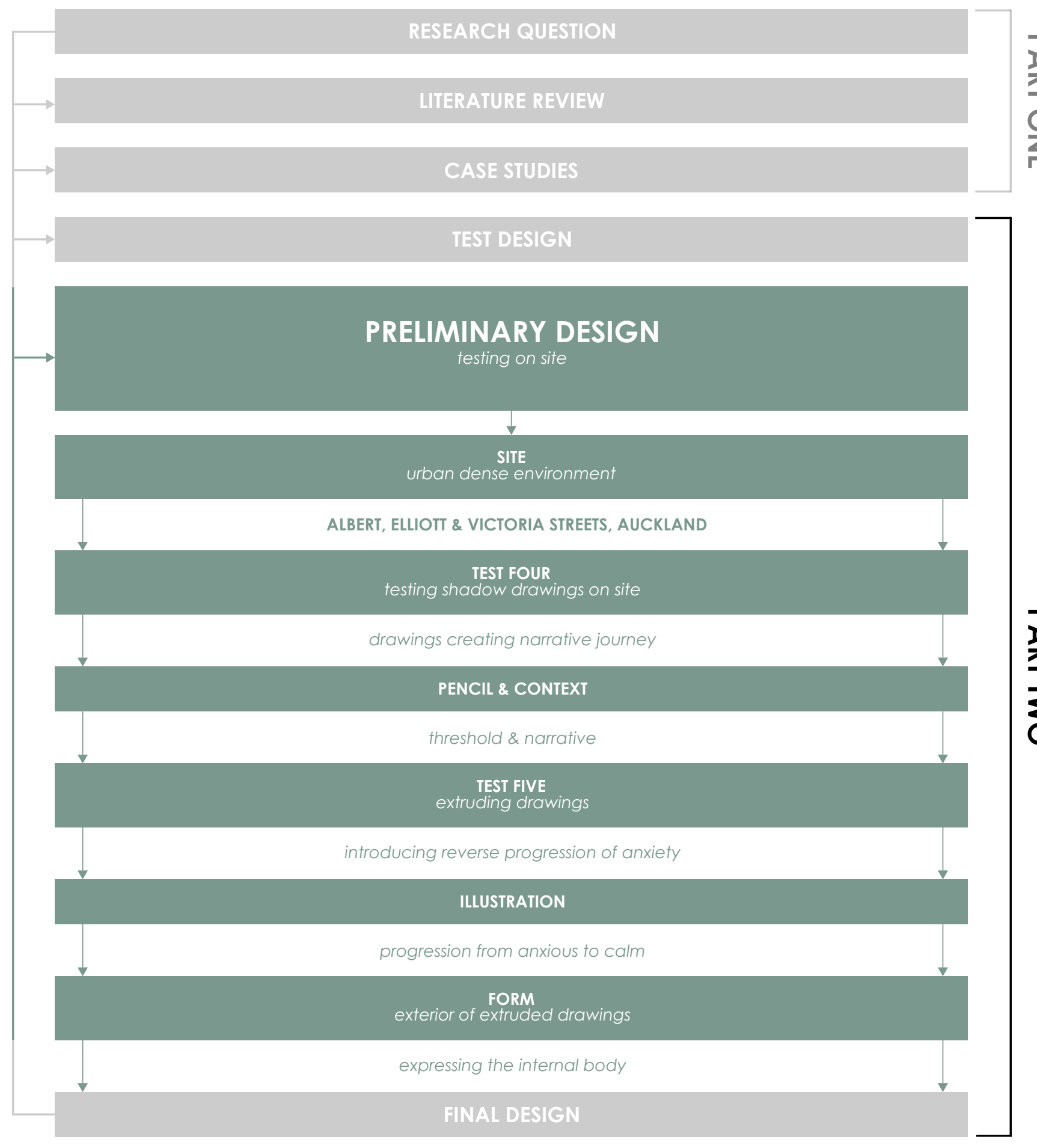

\section{INTRODUCTION}

phase two

produced can create thresholds and a narrative journey through a chosen site Auckland central was an idel location to test: an empty sentr. Wo was urban dense envi to test: an enpty sile in had the potential to integate the redevelopment around the site. This included the curren construction of the underground Aotea Station adjacent to the site. This design phase will investigate how the design will respond to the construction of the station which, will increase the over-stimulation of the surrounding environment. 


\section{Site Analysis}

Albert, Elliott, Victoria Streets

Auckland, New Zealand

Urban Dense Environmen

The proposed site for this research is located in the heart of Auckland's central business

hub. The site, exposed on three faces, can be

aid to be exposed like the human body is to

the urban environment, creating a

between our experiences with the

environment in architecture. For Auck

his locetion is essentiat as it is locaced in the

cost dense part of the cily, aligning with

me city, aligning with the architecture that releases anxiety for people in an urban dense environment. As Auckland becomes more developed, the city is only going to increase its density, especially near the site, we the well as a linear park connd rail network) as All as a linear park connecting Victoria and Albert Parks, will ultimately increase the overstimulated environment. 
Site Analysis

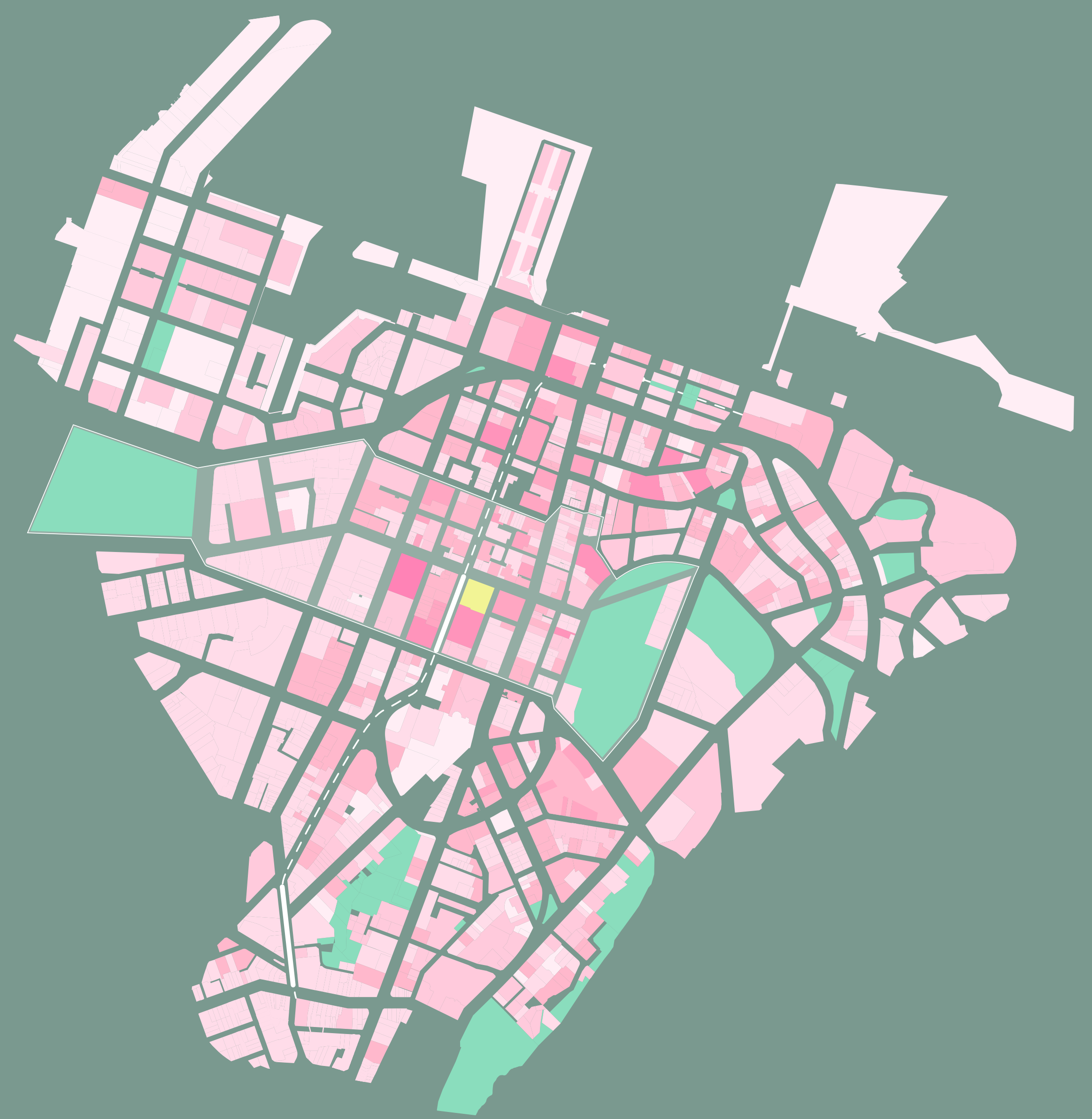


Site Analysis

auckland

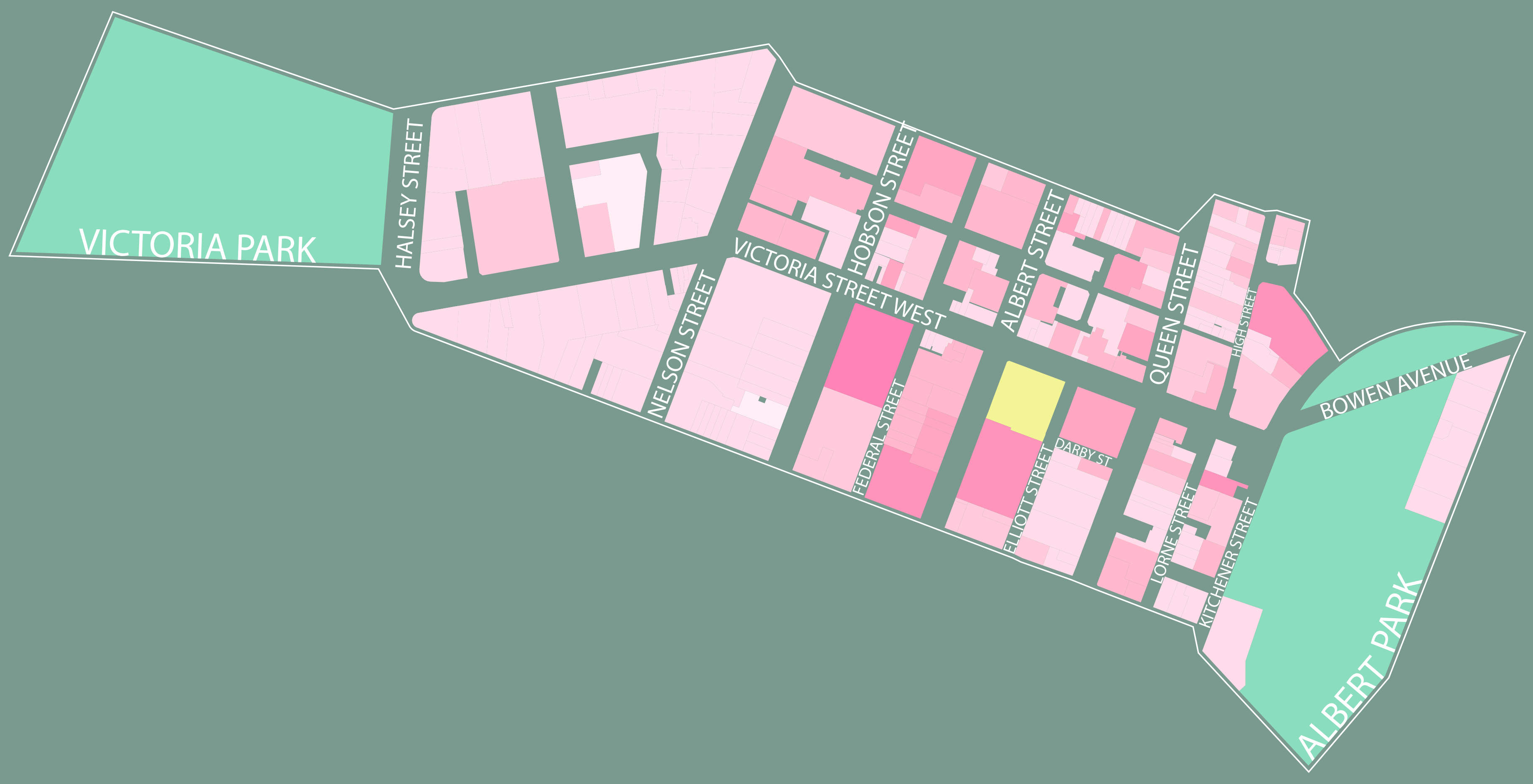


Site Analysis

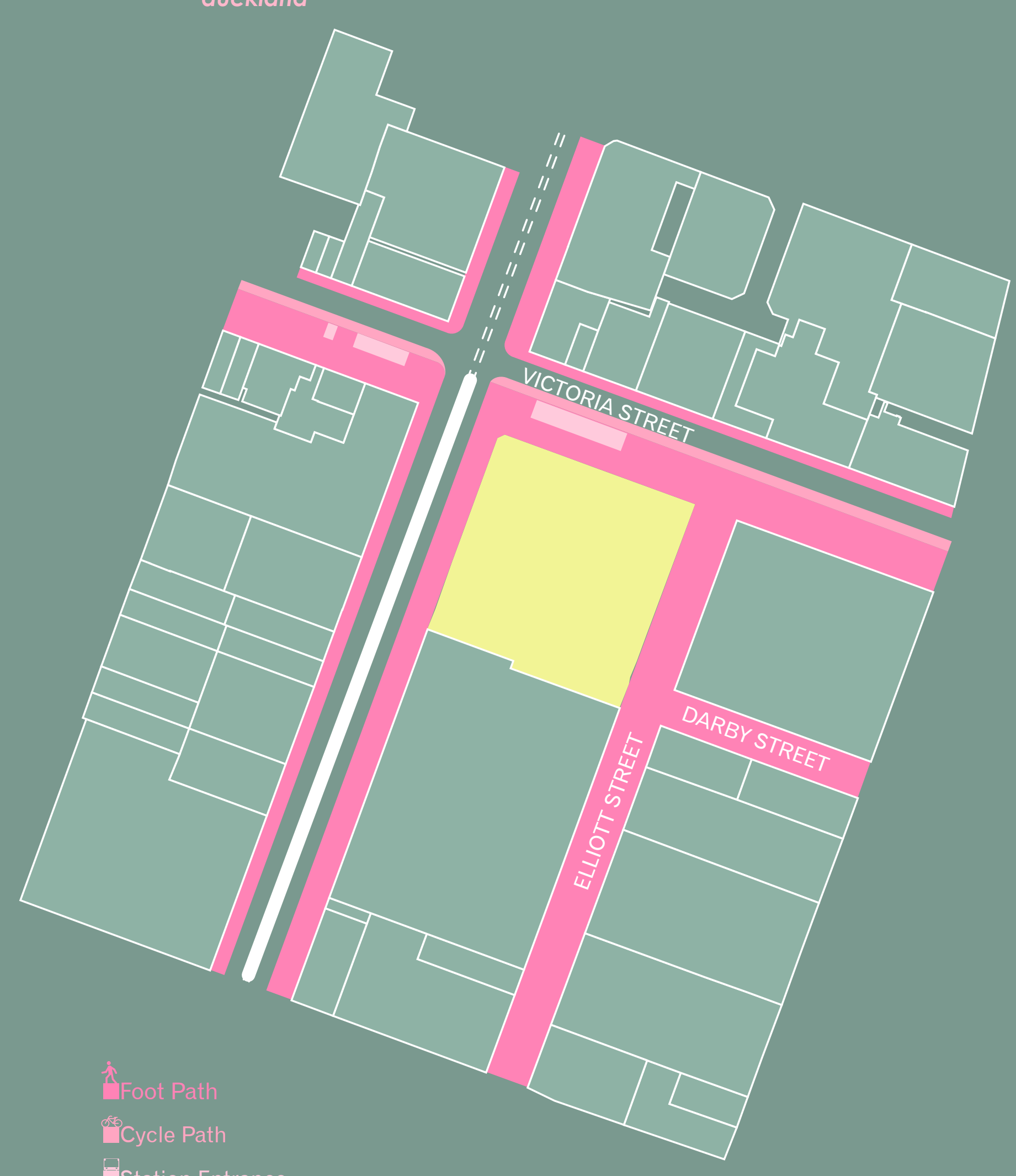

ËStation Entrance

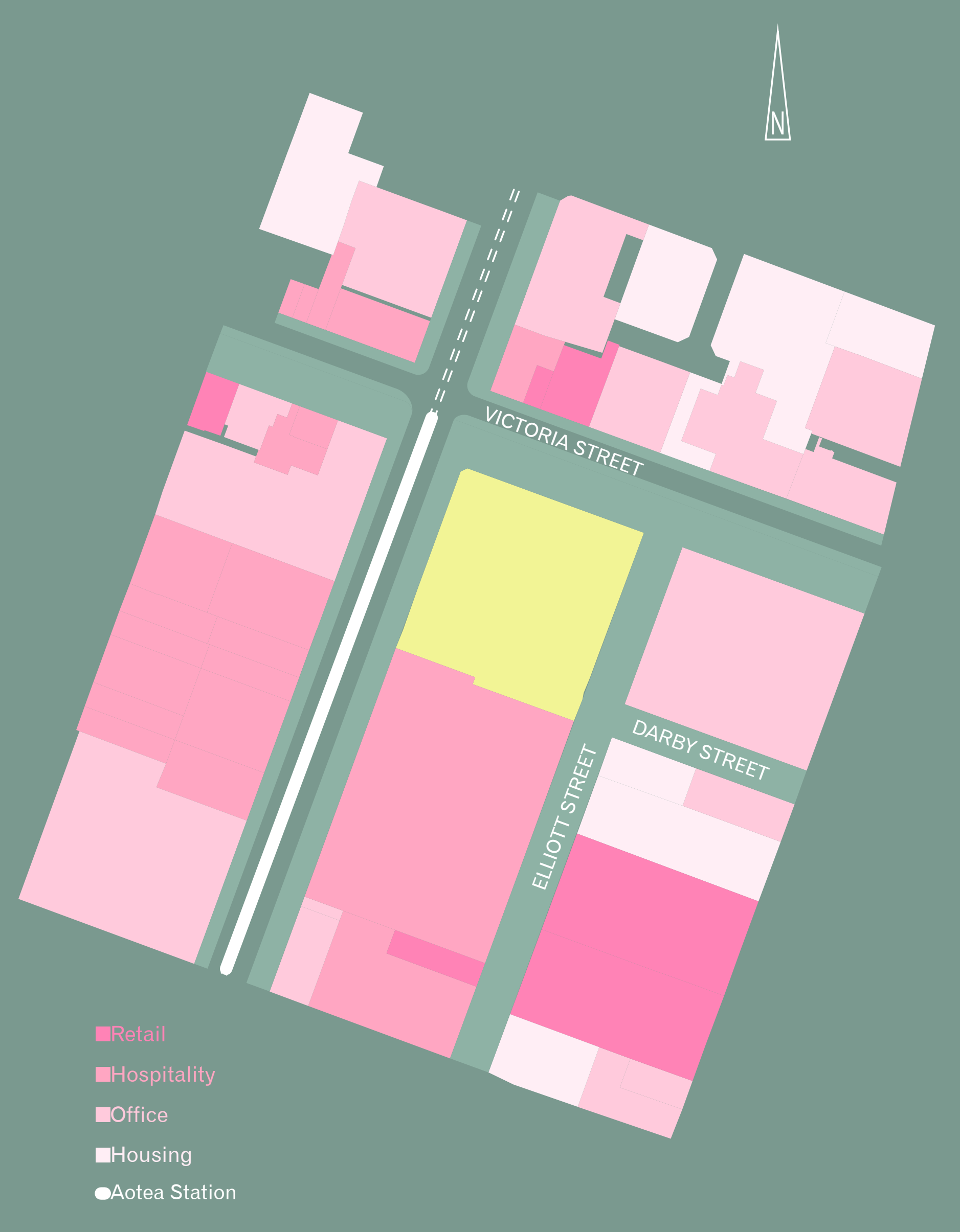




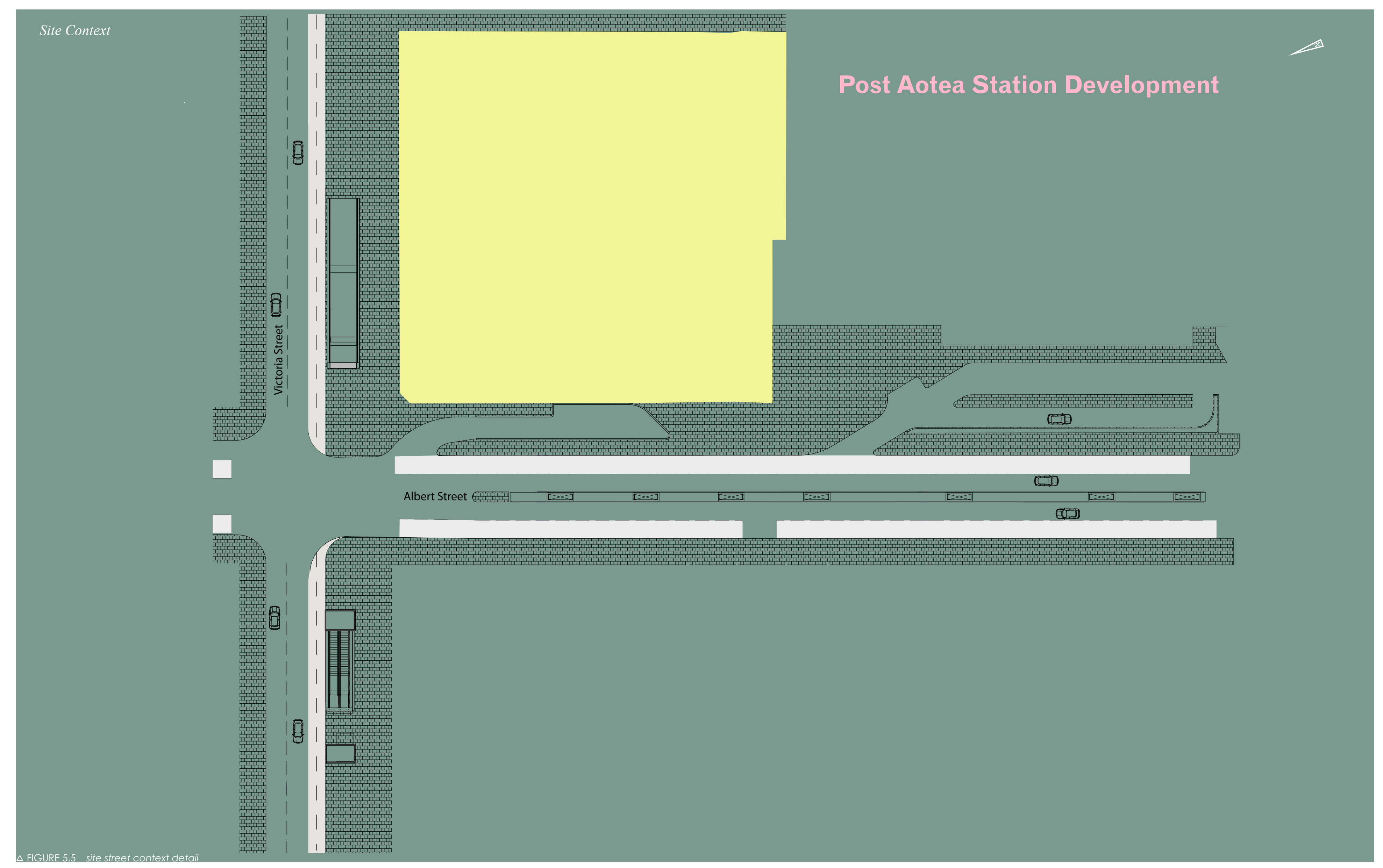


Aotea Station Concourse Level

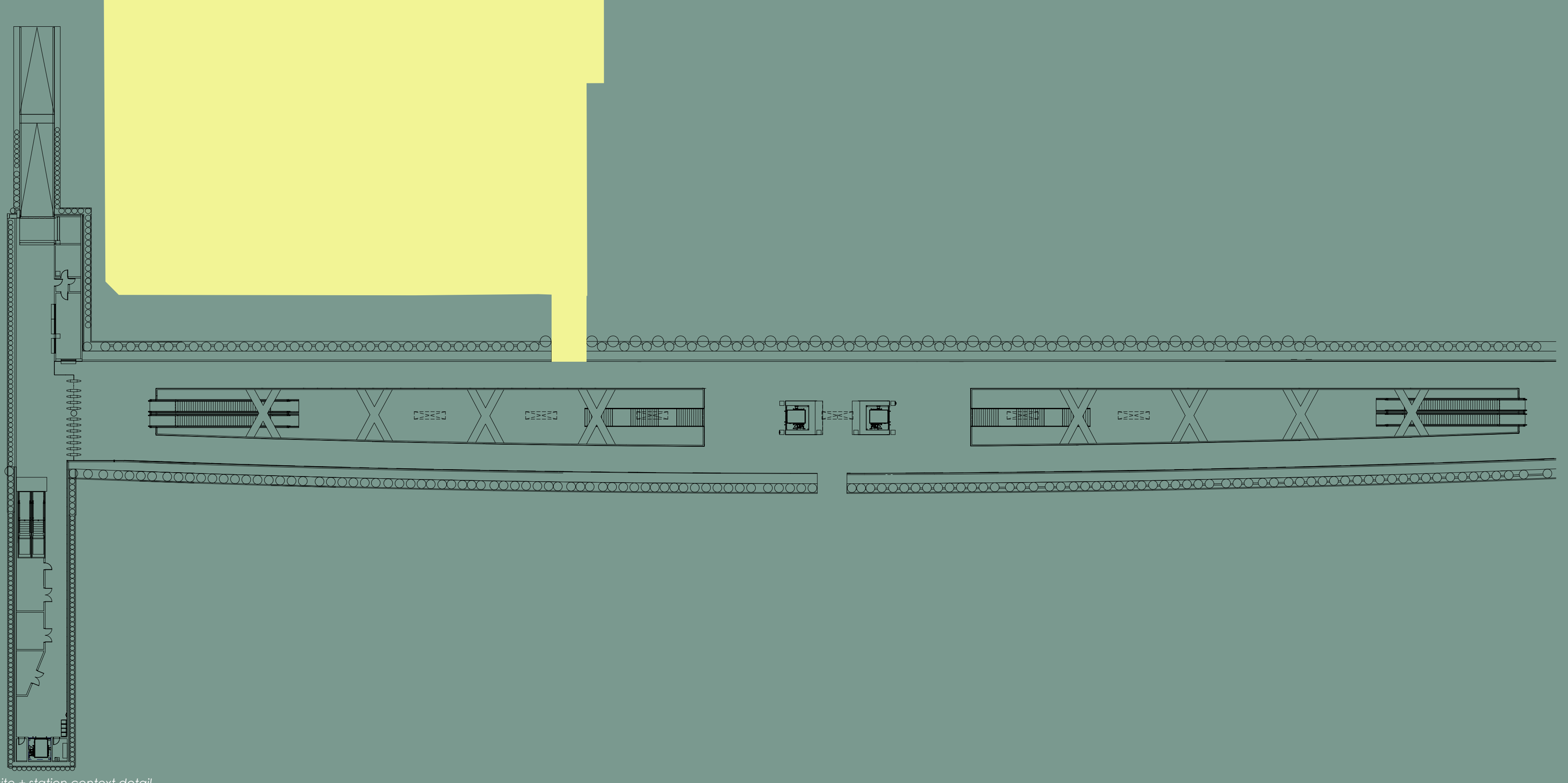




\section{TEST FOUR}

Drawings to create narrative journey

The beginning of this series continues what had been done in phase one but now starts testing on the selected site: taking the selected drawings (shadow drawings) from test three and placing them on site to create thresholds and a narrative journey through the site. The chosen narrative journey was then tested on the site's surrounding context. The four corners where the site interacts with its immediate context is where the pressure points are located, with the larger threshold placed on the corner
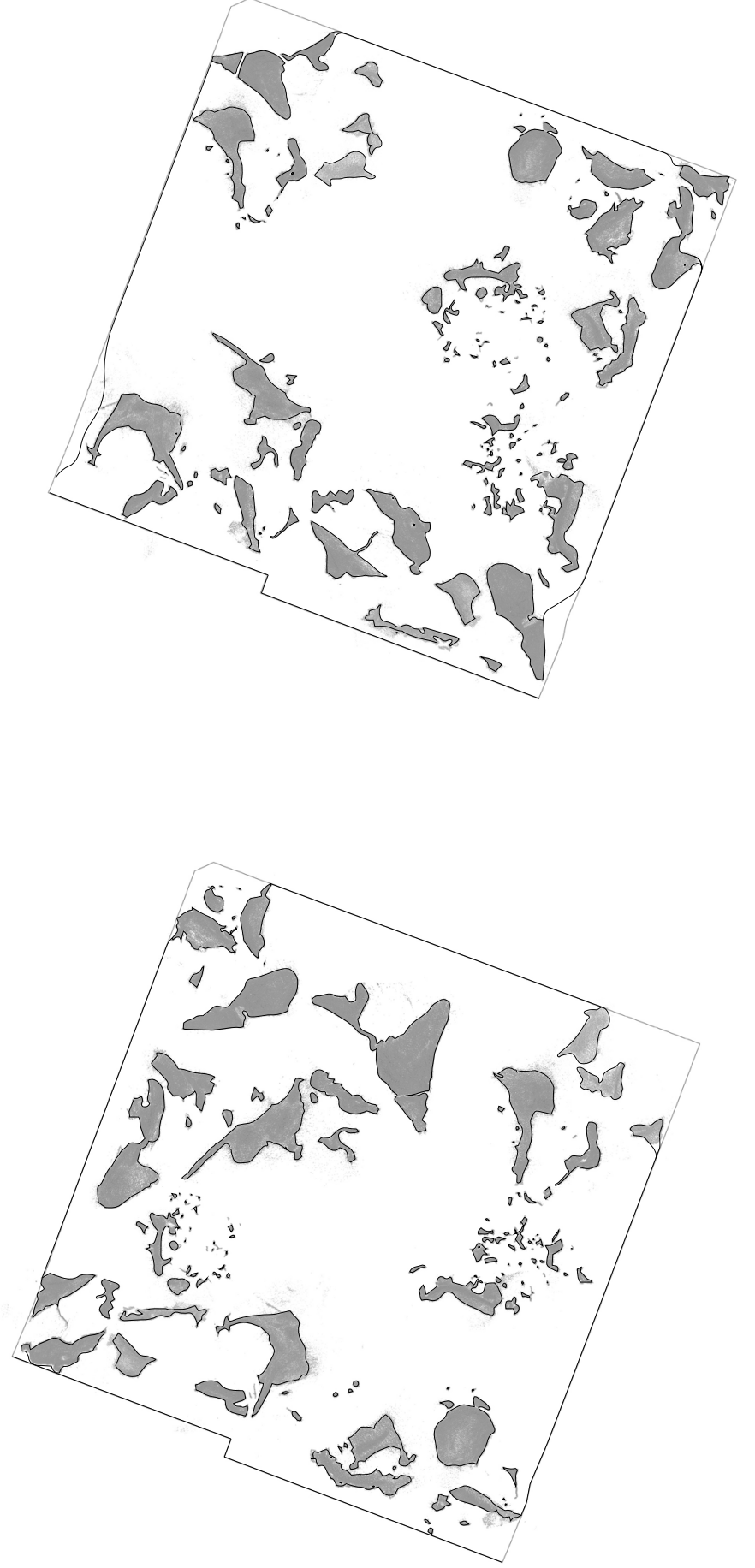

of Albert and Victoria streets as this is where most of the stimulation will come from. Crowds of people and passing traffic contribute to the increasing over-stimulated environment as Auckland density grows. The connection to Aotea station and the journey from the train station to the street forces people to potentially have a new experience every time. Occupants will encounter, while moving through the thoroughfare, large open and tight small spaces. 

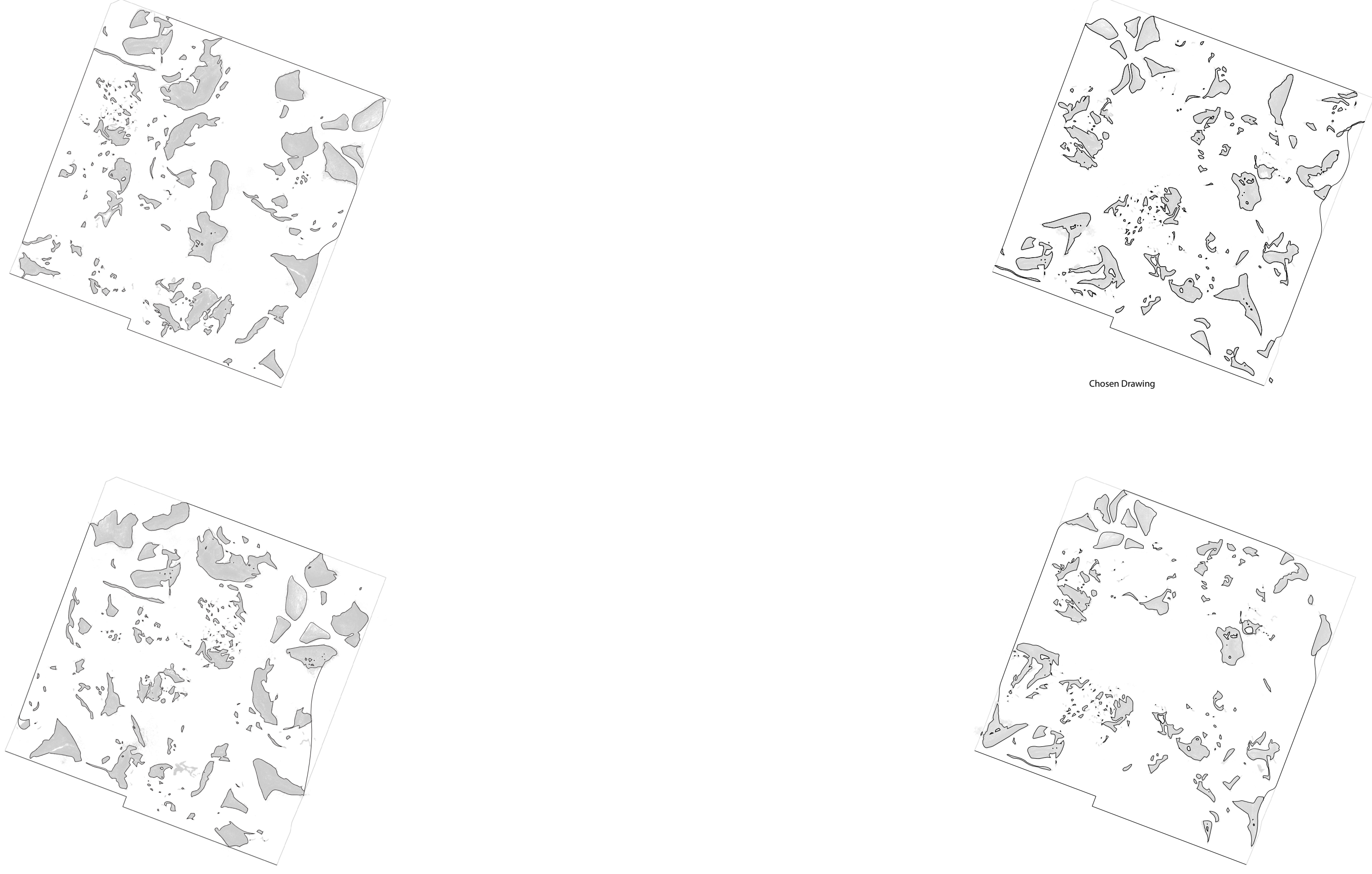

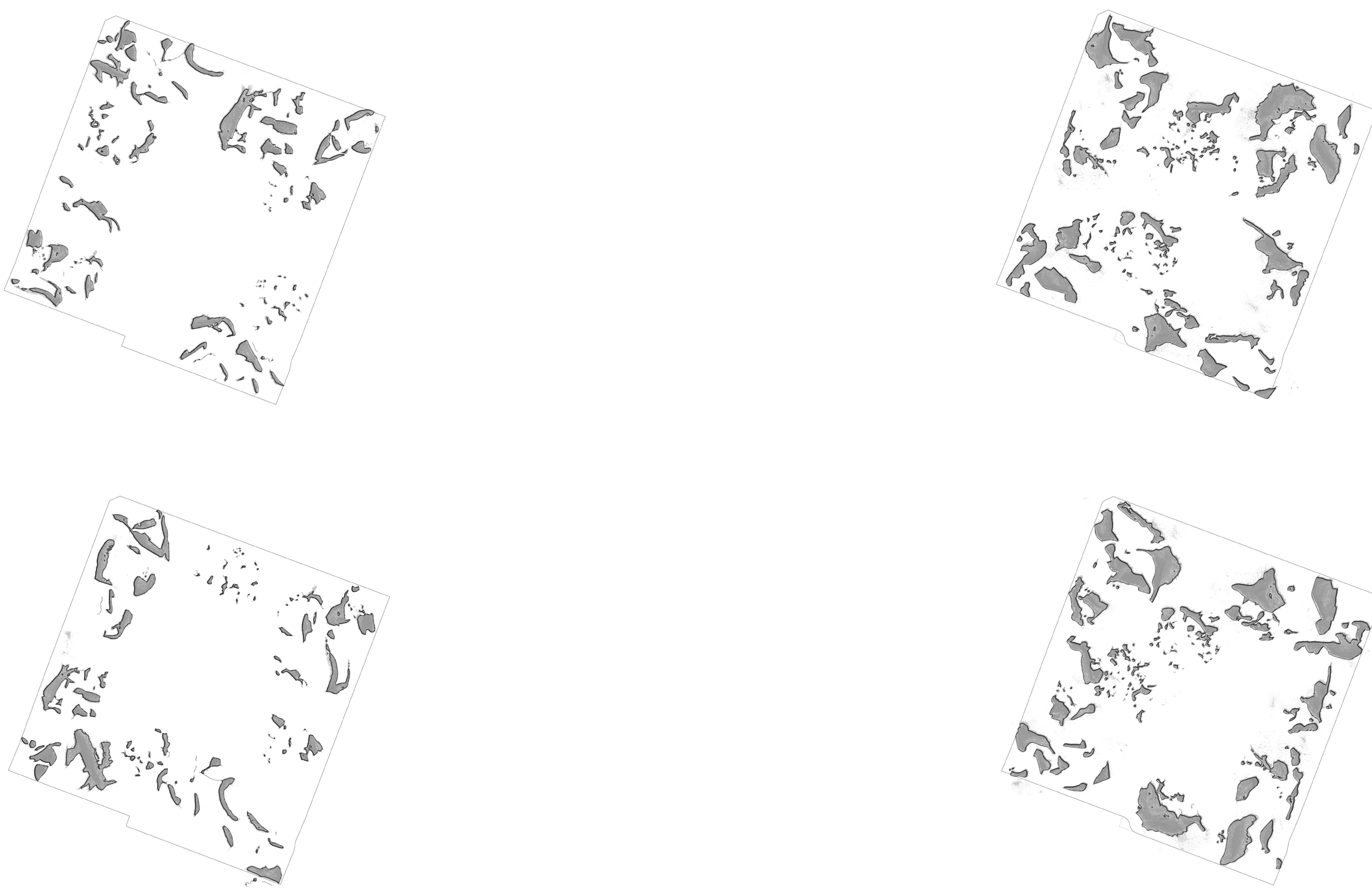

$\triangle$ FIGURE 510 shadow drawn g sells $>$ On ste

$\triangle$ FIGURE 5.10 shadow drawing series $>$ on site 


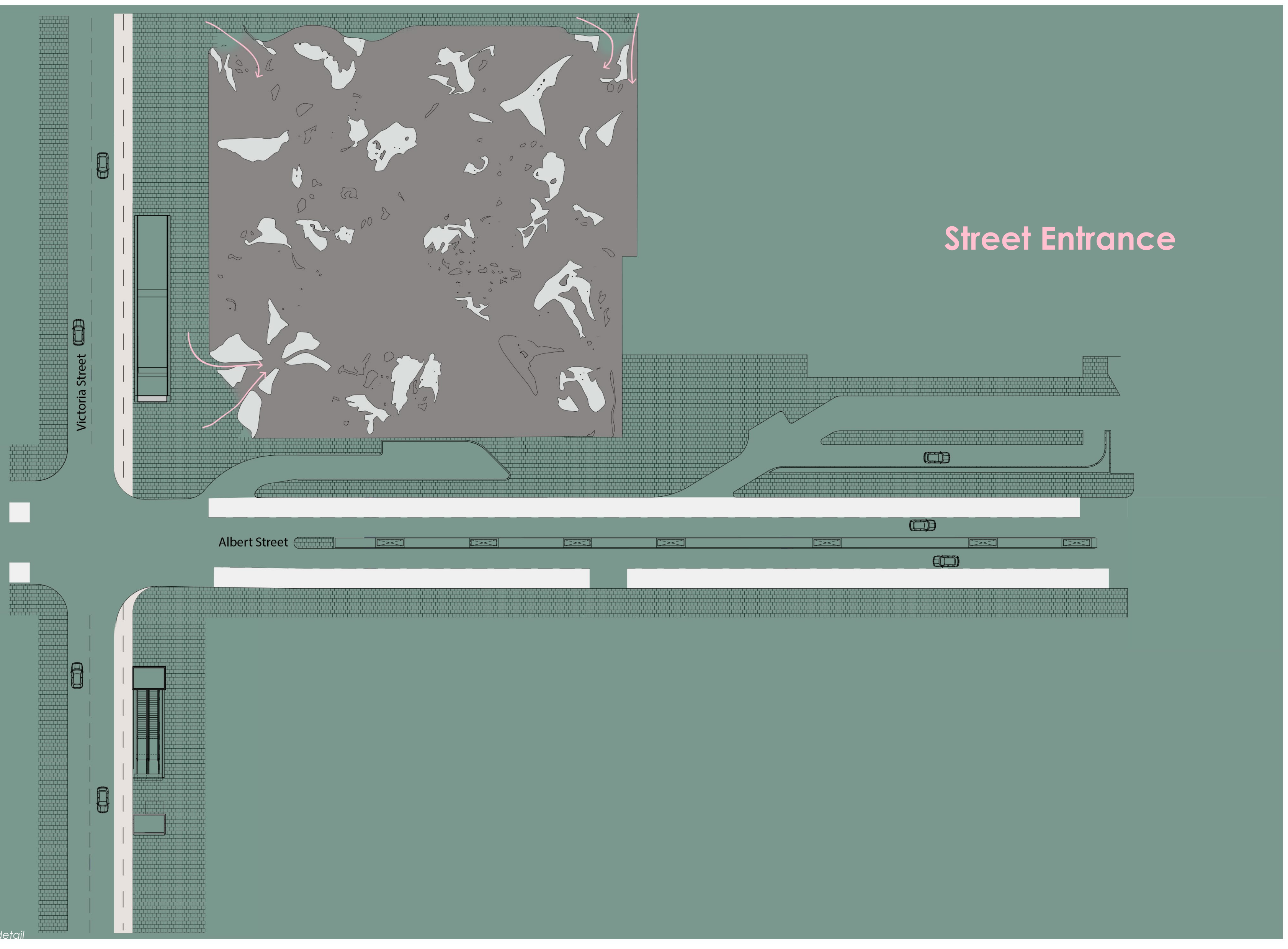




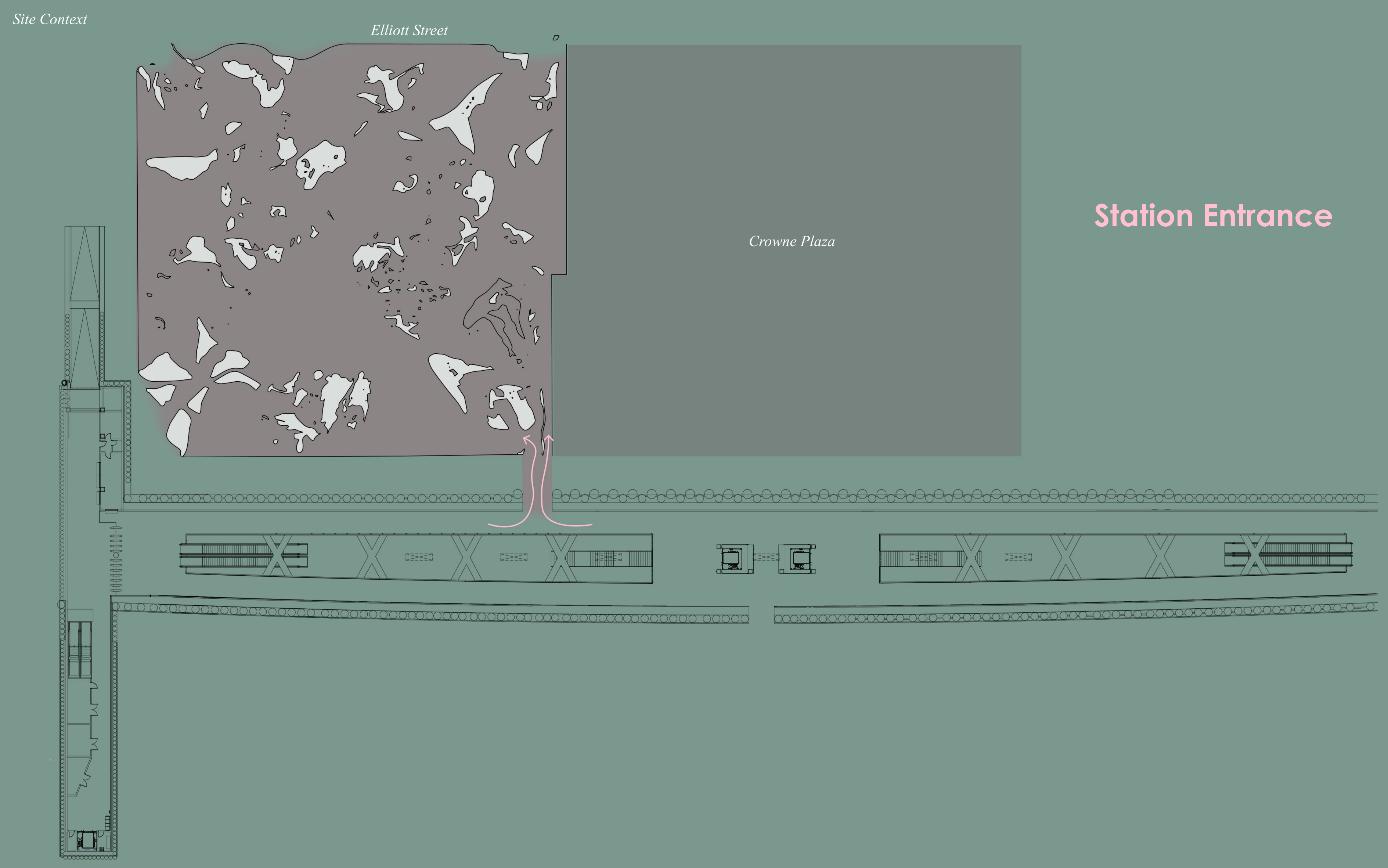


TEST FIVE

Extruding Drawing

Using Frederick Kiesler's belief in creating architecture as though you were occupying your own body, moving from one space to another as you move from thought to thought this case study influenced the next step: creating a progressive journey up towards large connected space. This starts when all the separated entrances gradually become one large space. These internal spaces are the inverse of the ground level space. This series test the same idea as placing the drawings on site introducing the reverse progression of anxiety, extruding these drawings to create a space above that releases anxiety. The underground area being a place where anxiety is heightened and the narrative sensory journey from the thoroughfare towards an journey from the is the experience of slowly releasing anxiety as the user travels upward. 

Journey 1

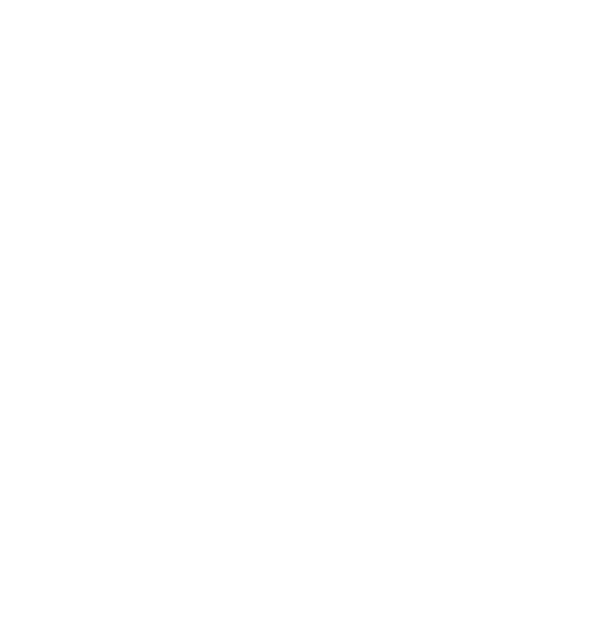
Ground

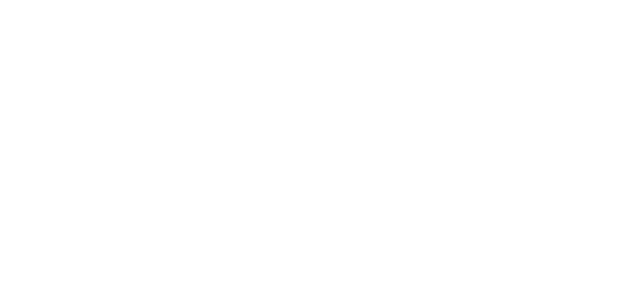
pit

Level One

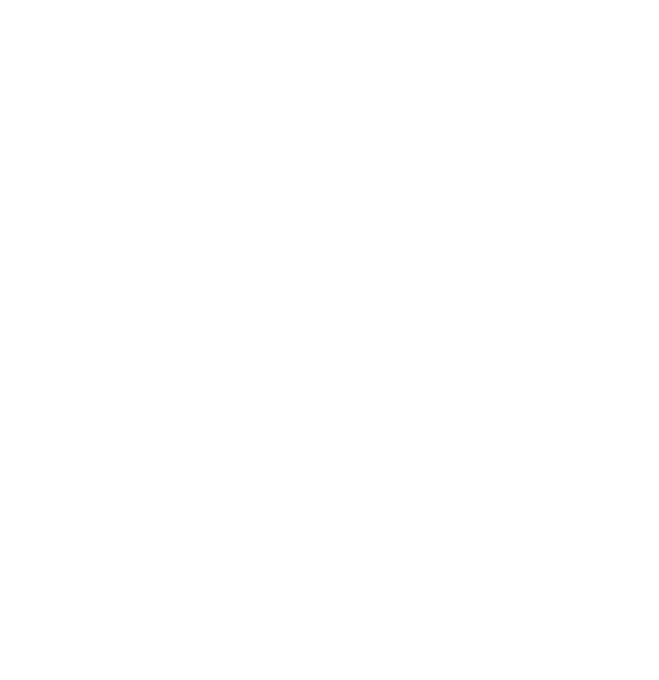

Level Two

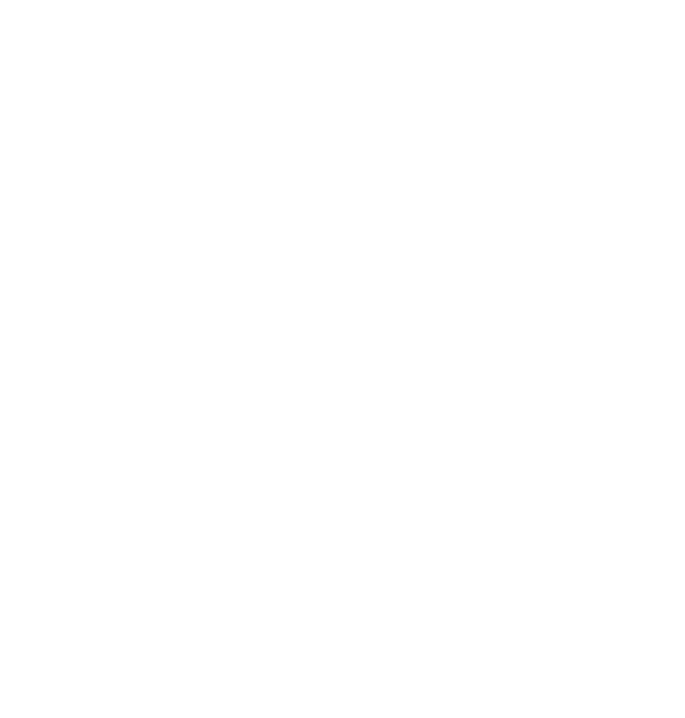

Level Three

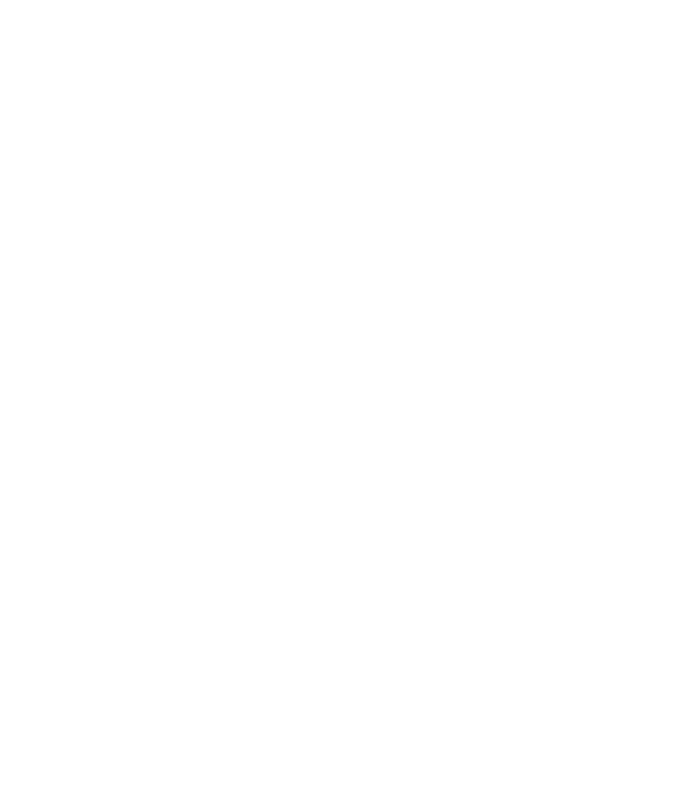

Level Four

\section{Journey 2}

(19.

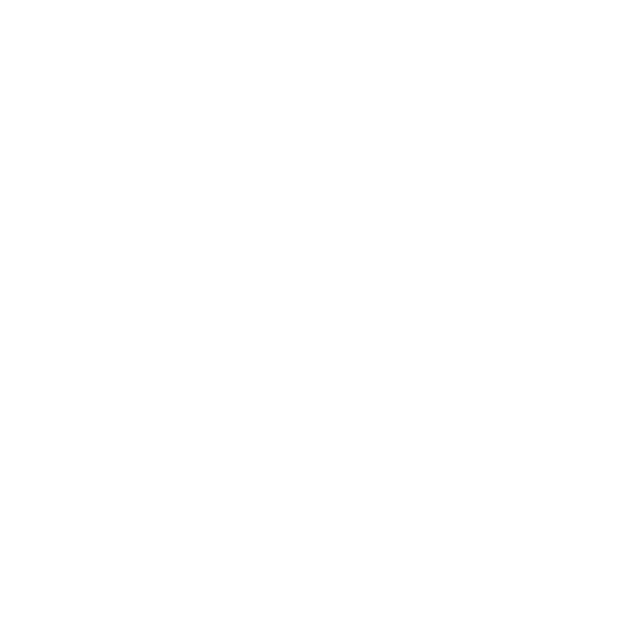

Level One

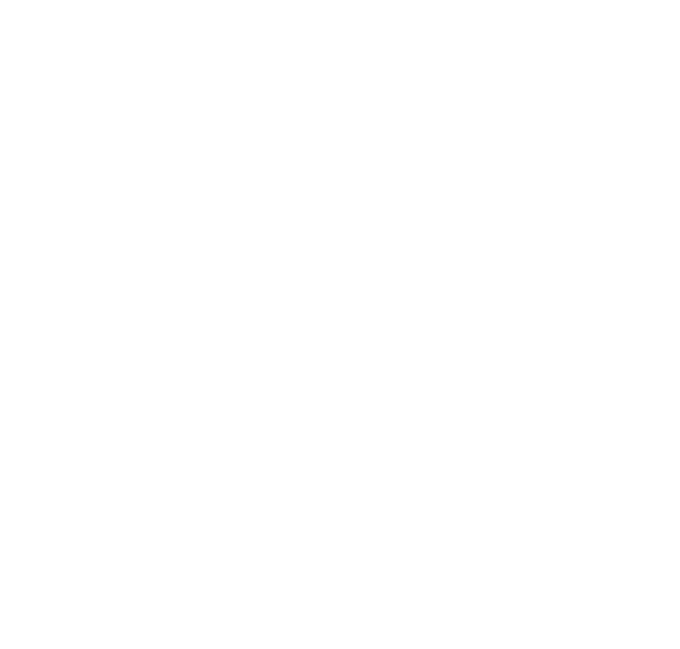

Level Two

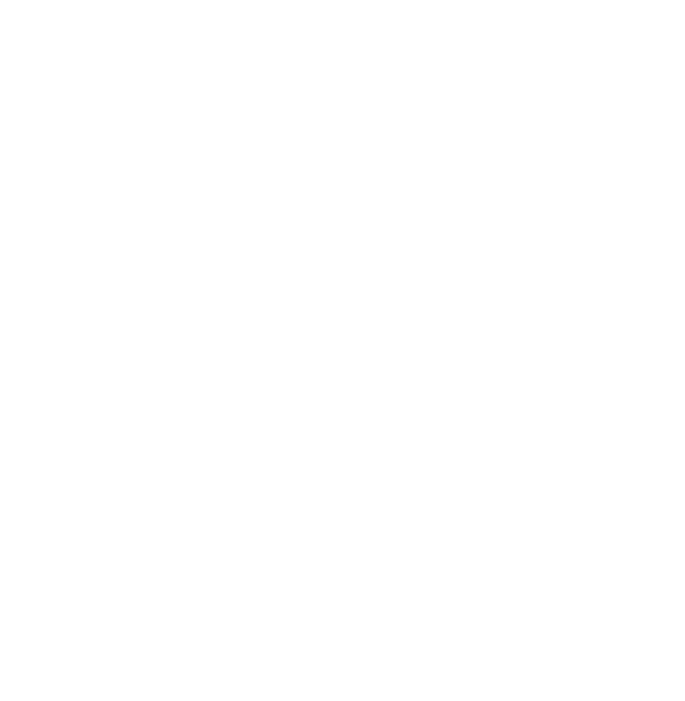

Level Three

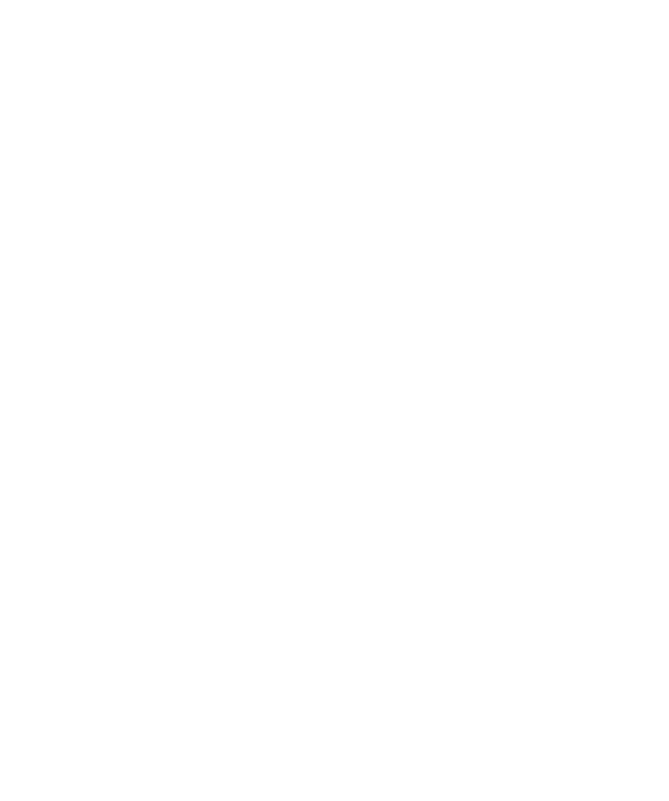




\section{Journey 3}

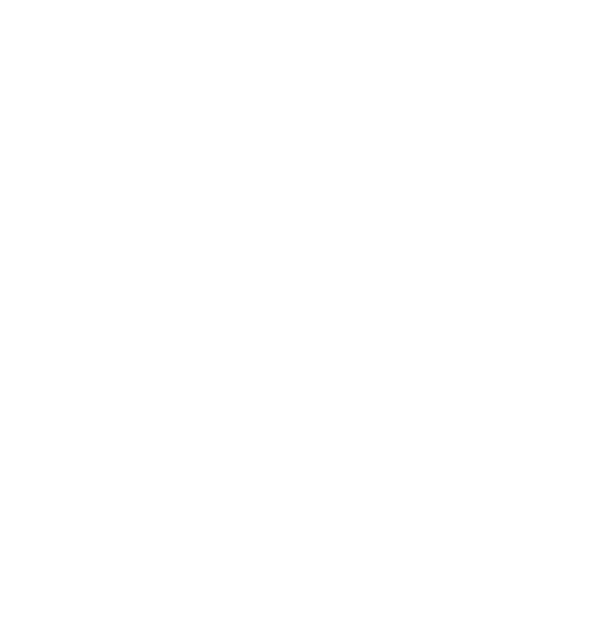

Ground

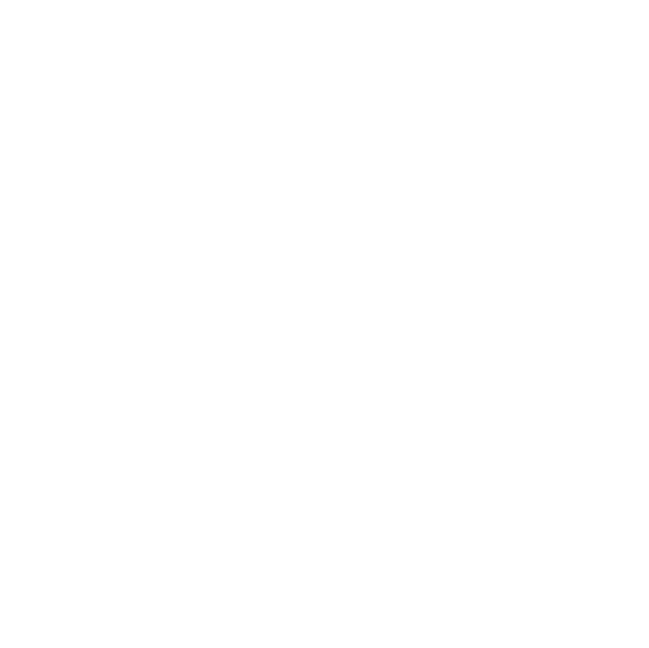

Level One

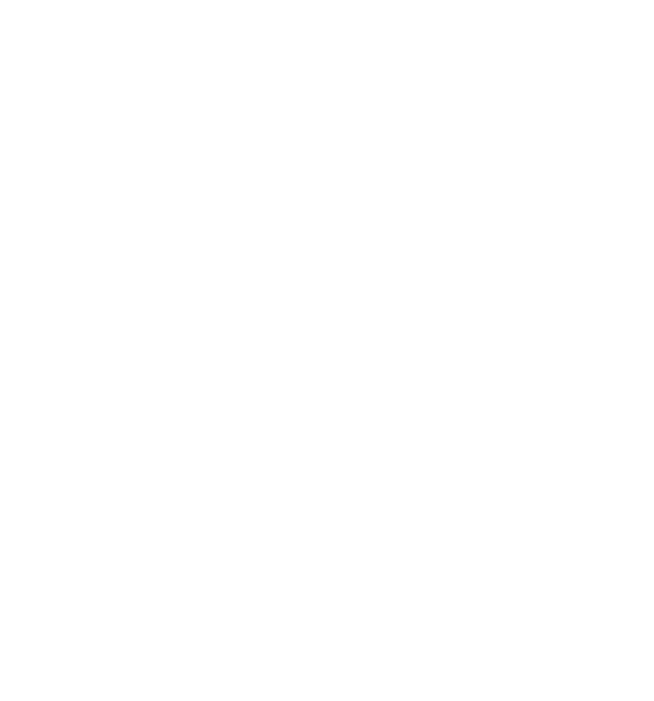

Level Two

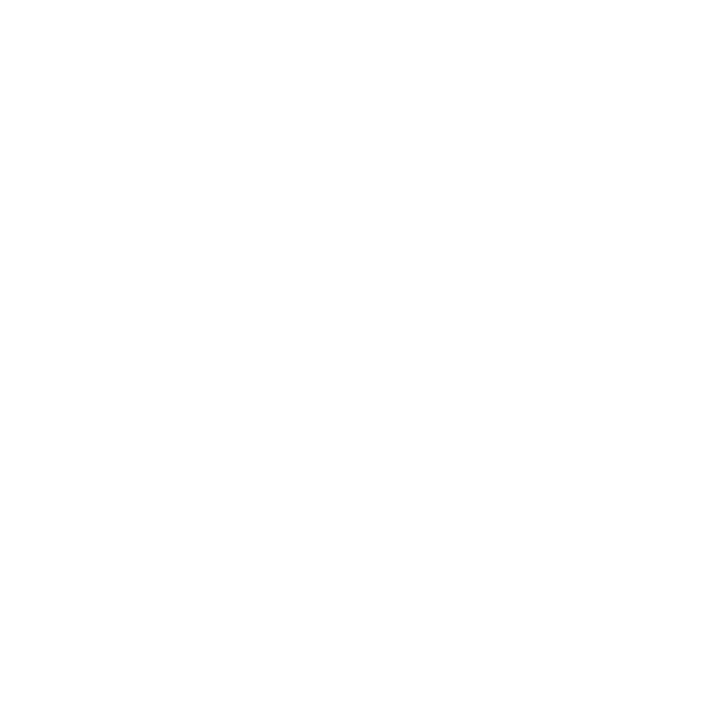

Level Three

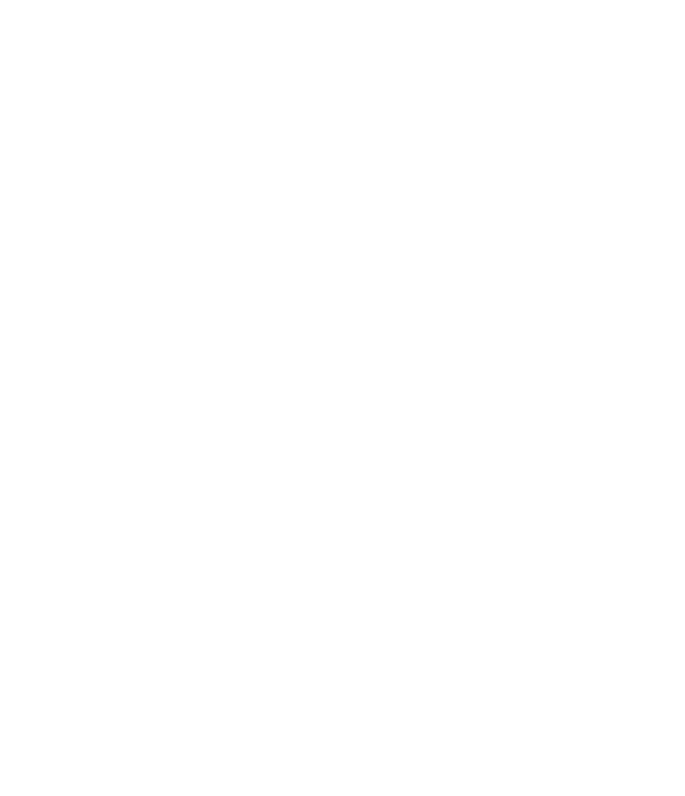

Journey 4

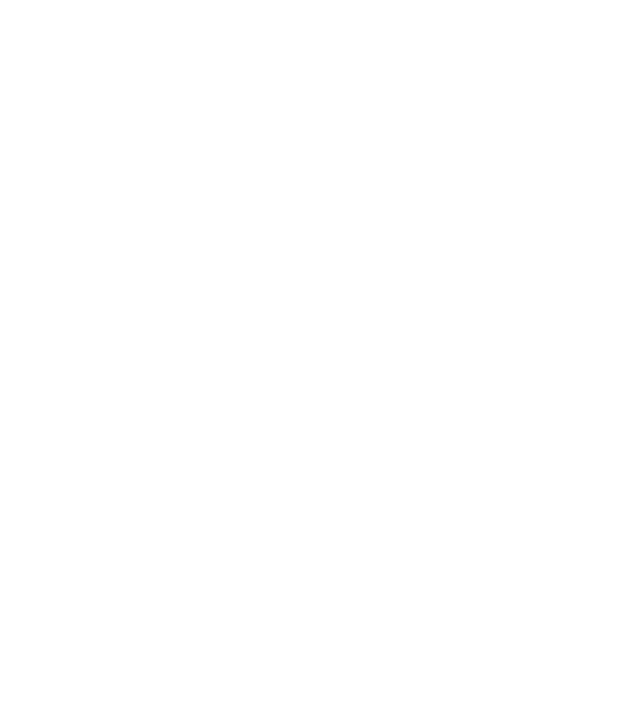

Ground

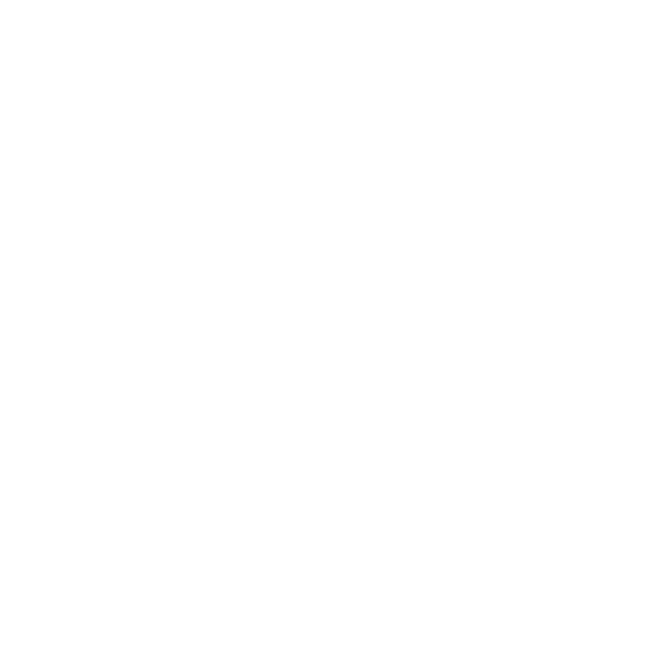

Level One

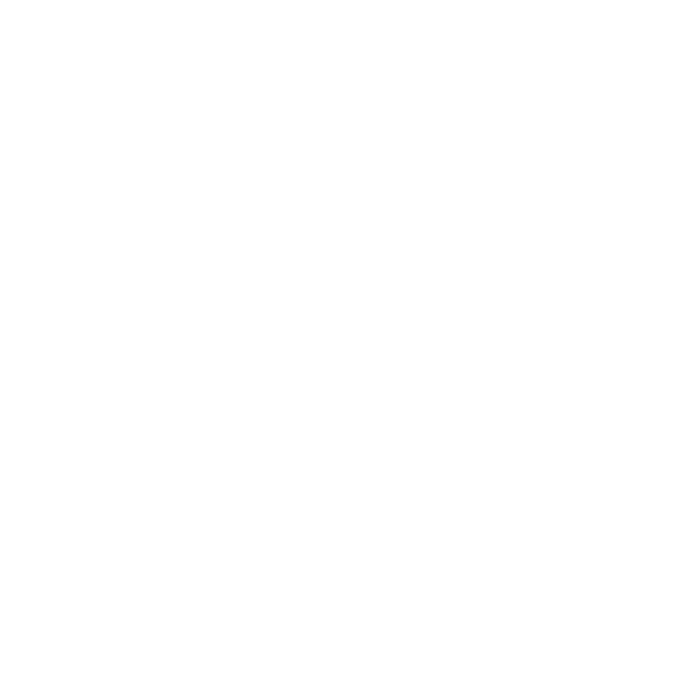

Level Two

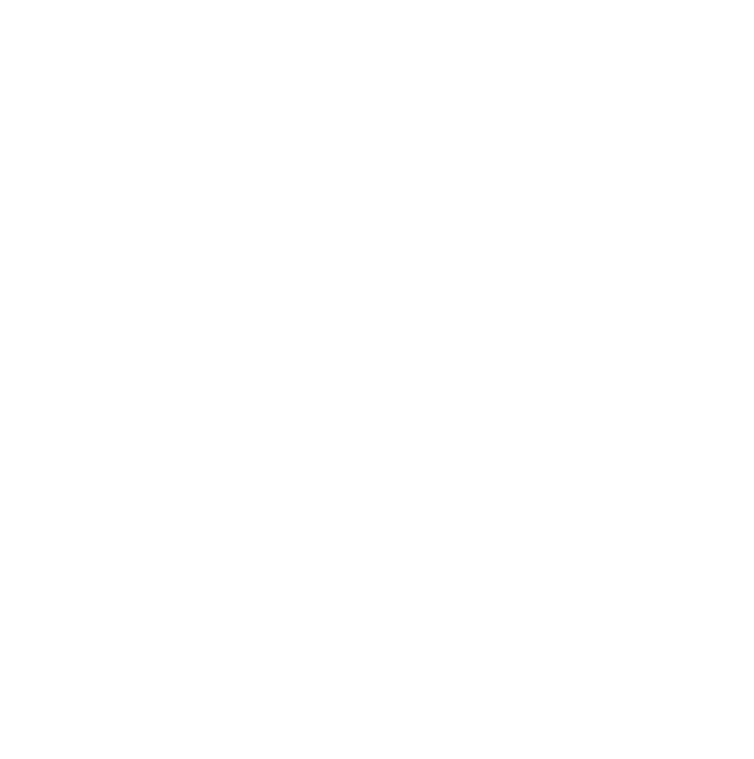

Level Three 


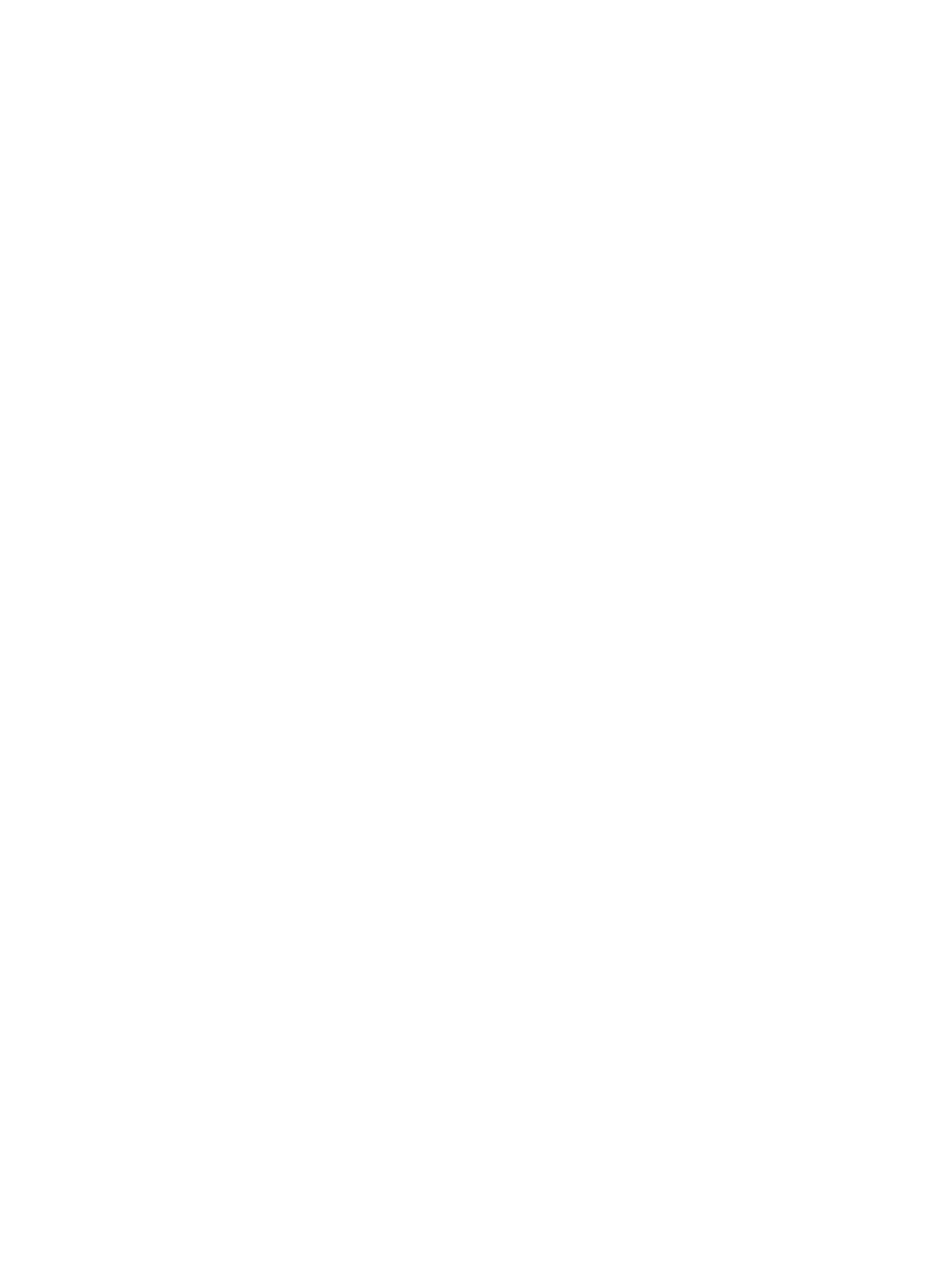

Journey 3

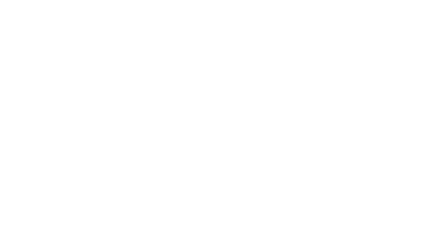

है
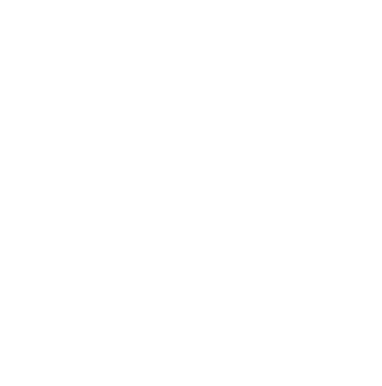

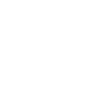

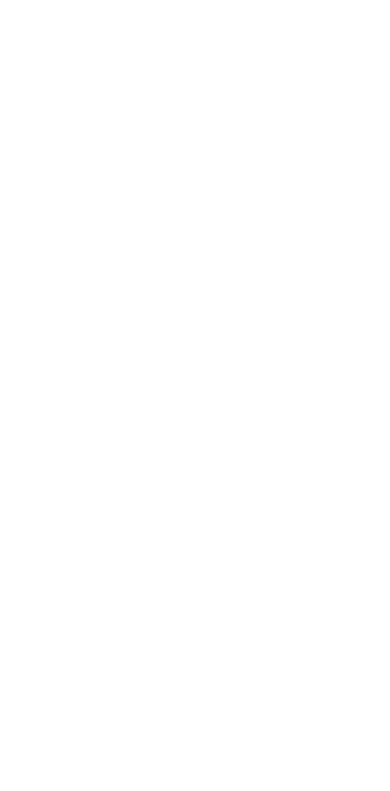

ting

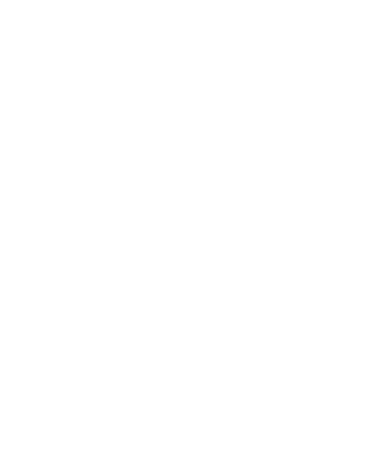

Journey 4
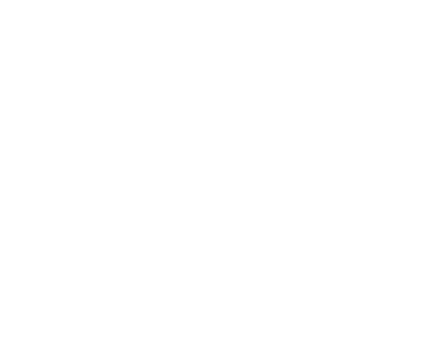
$\nabla$

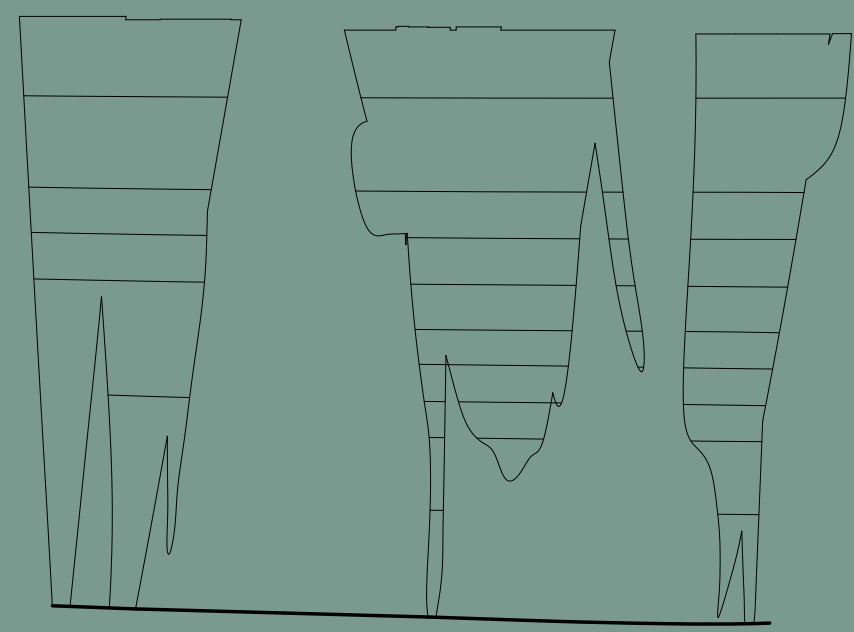

tes

$+\infty$

Hojesis

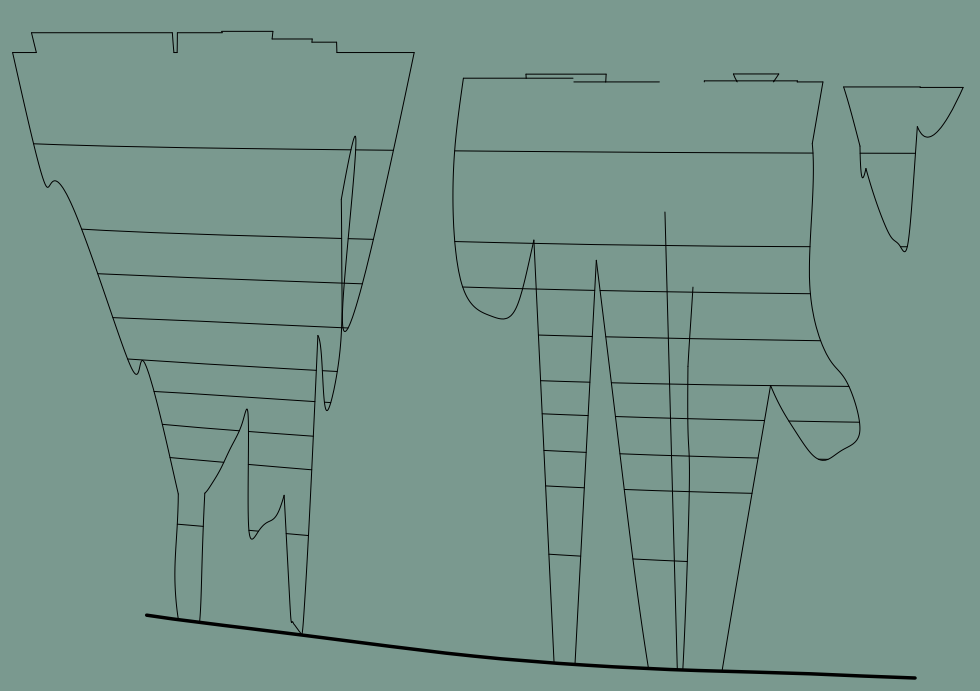

$\log x$ are

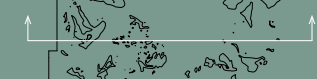

pis a d o

Pris

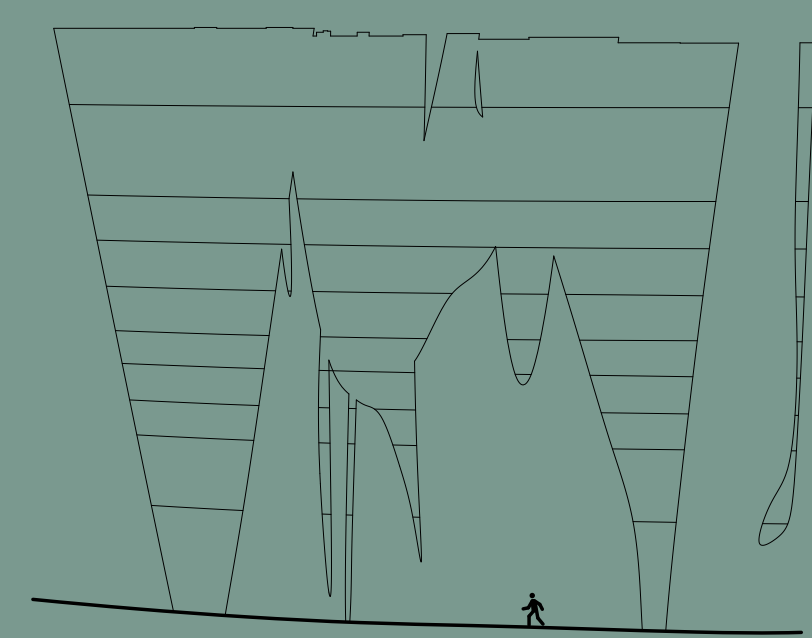

hes as

$18 x^{2}$

ton

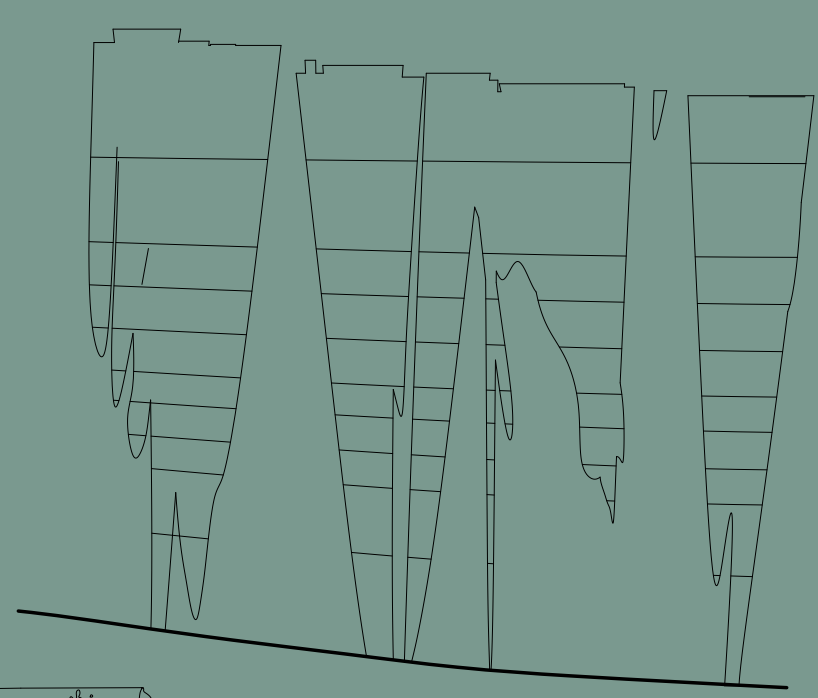

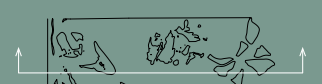

is

to

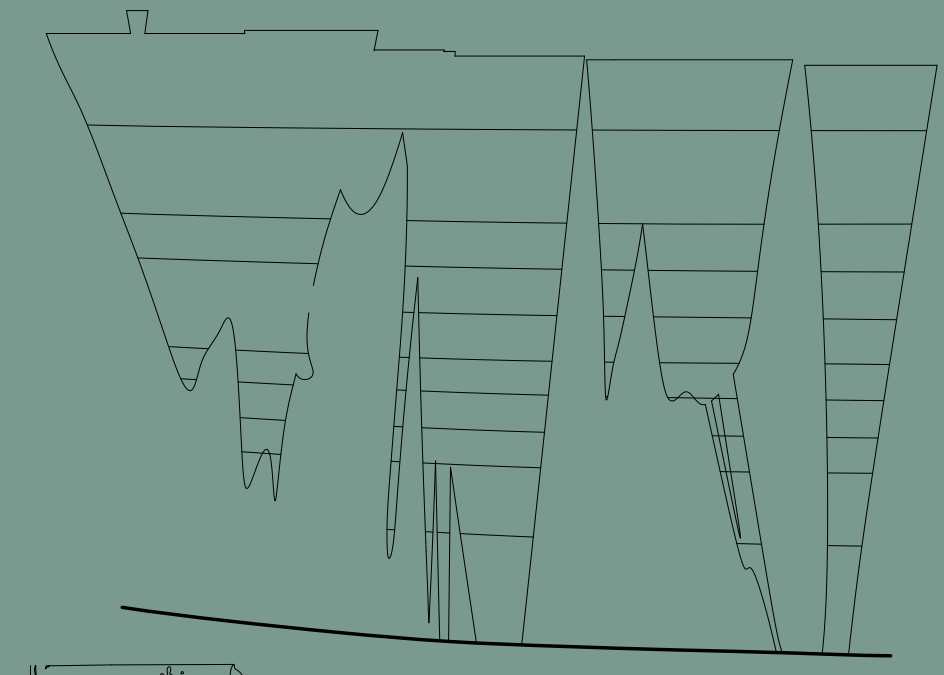

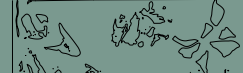

$4=0$

Pon

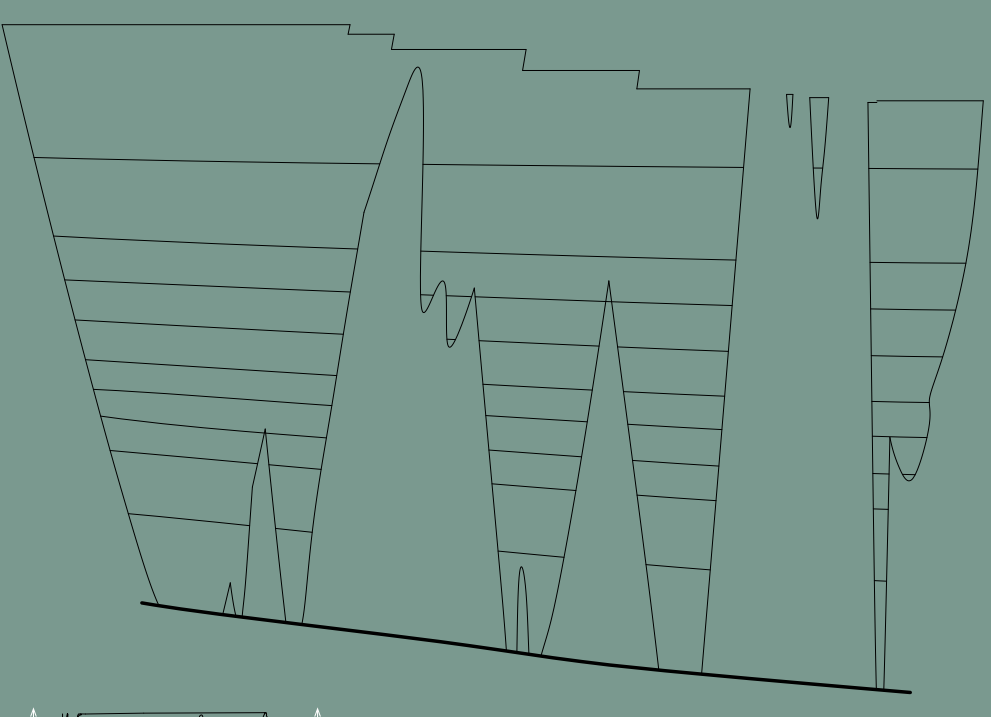

1 is torises

as a

$05=30$ 


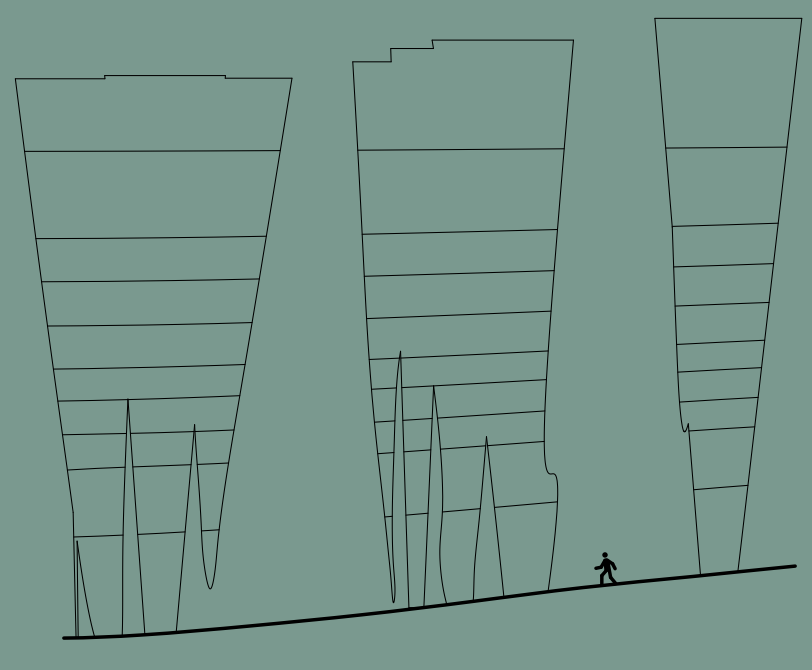

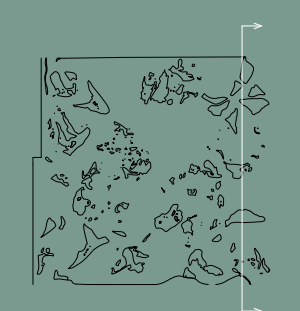

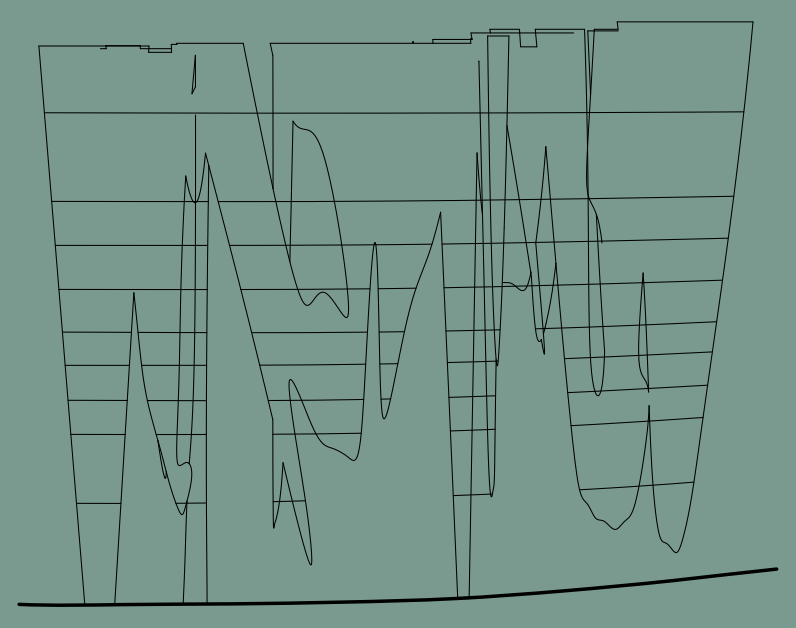

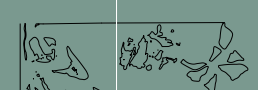

is a b

is $x^{2}$ is
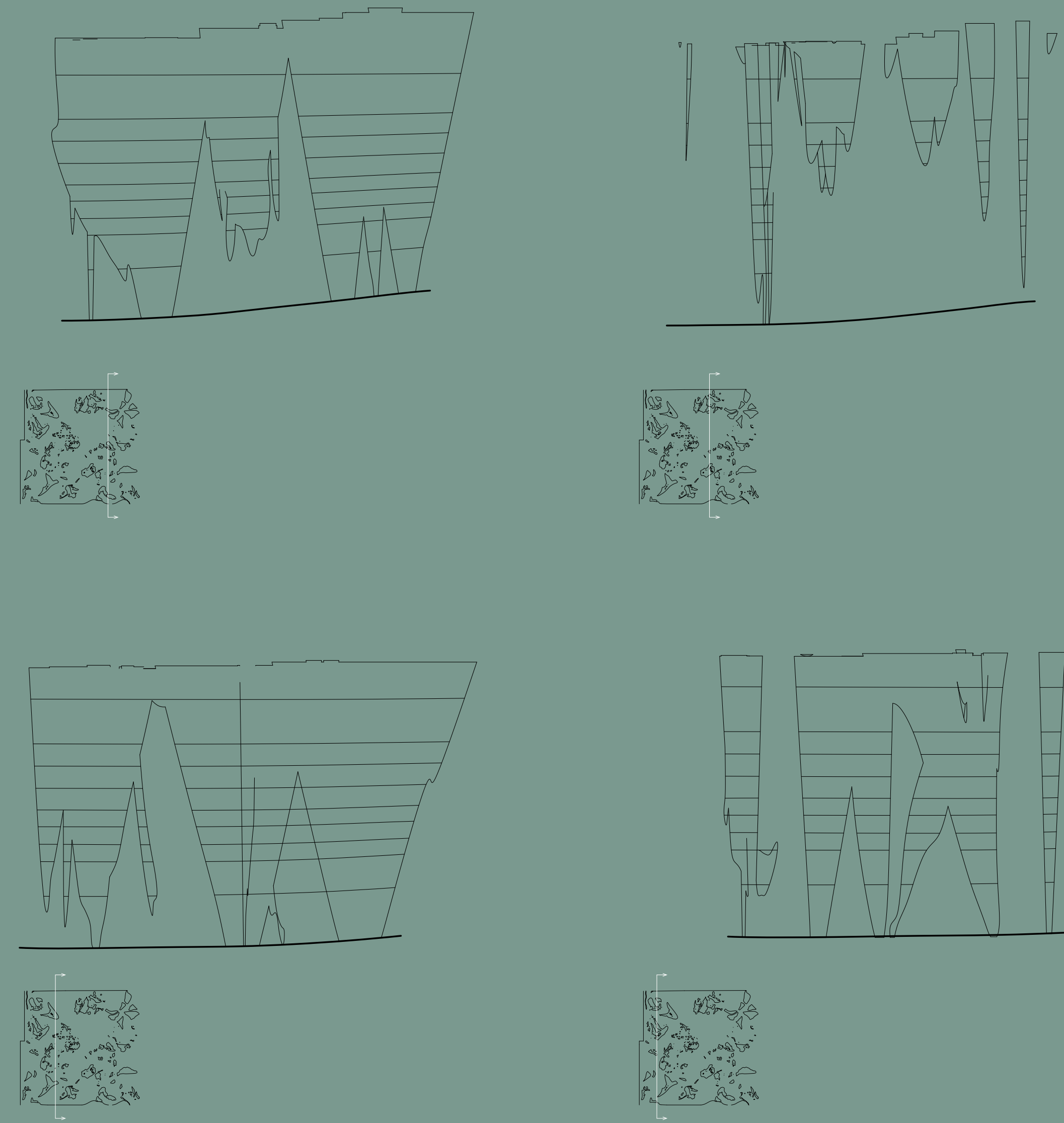

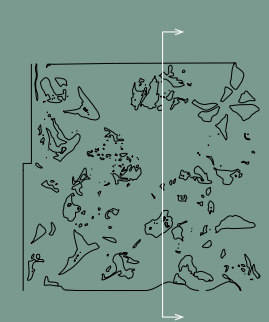

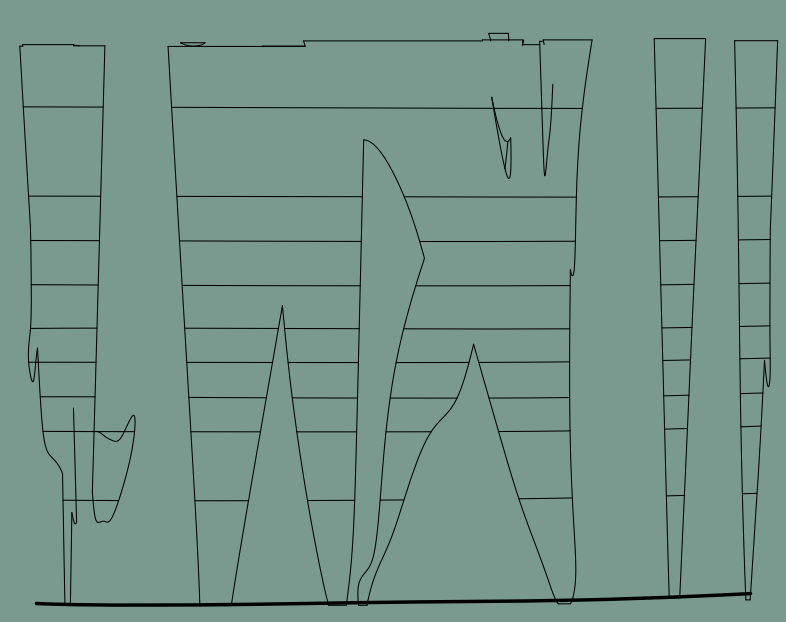

1. 

The form produced is the exterior design of the extruded drawing, shaped by the interior journey from the open thoroughfare, with multiple entrances, to a rooftop zone being one large open space. The internal form is wrapped in a simple box, which hides the organic form, representing the exterior of the body in relation to anxiety, where people tend to suppress their inner anxiety. The purpose of this design is for people to encounter a space which heightens their anxiety, to make them more self-aware of their physical and mental wellbeing. The journey up slowly red mental wellbeing. The journey un stimulation and creates a pathway to a place of calm, where extraneous sensory stimulation is removed.

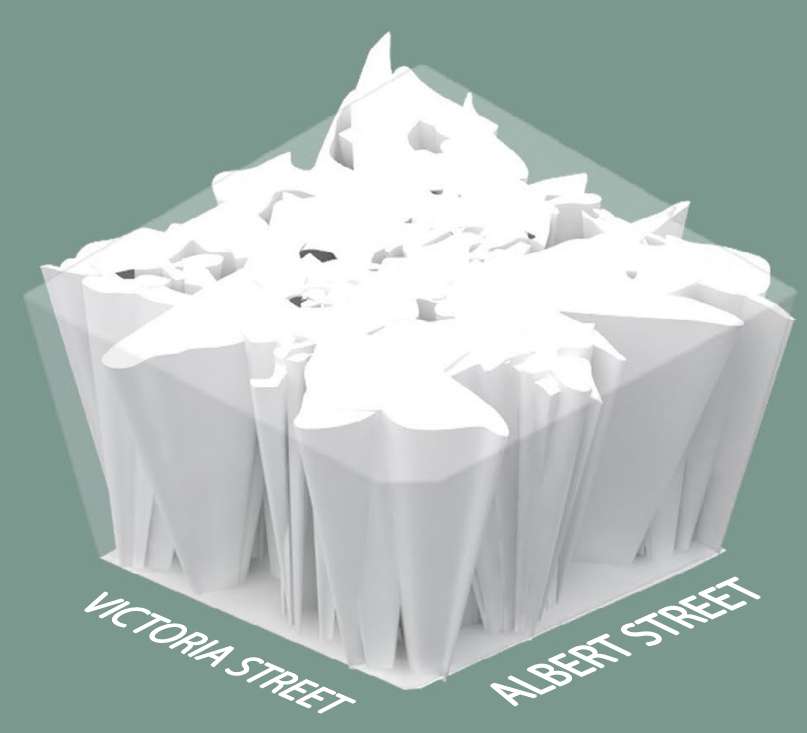

North Elevation

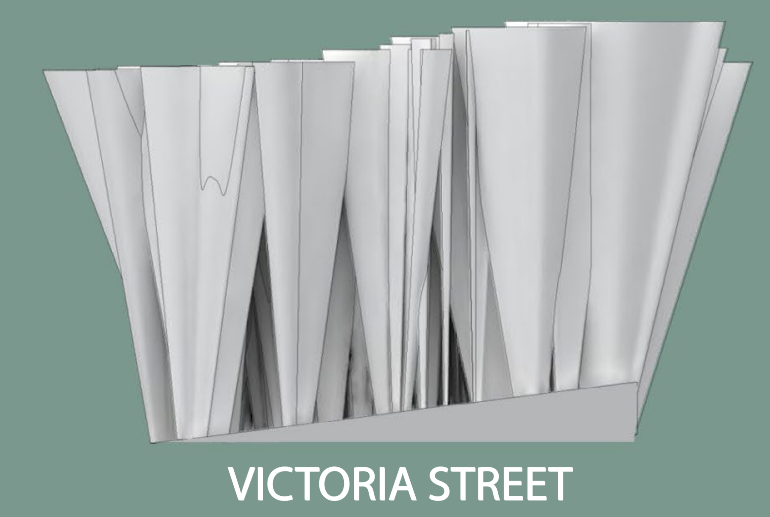

East Elevation

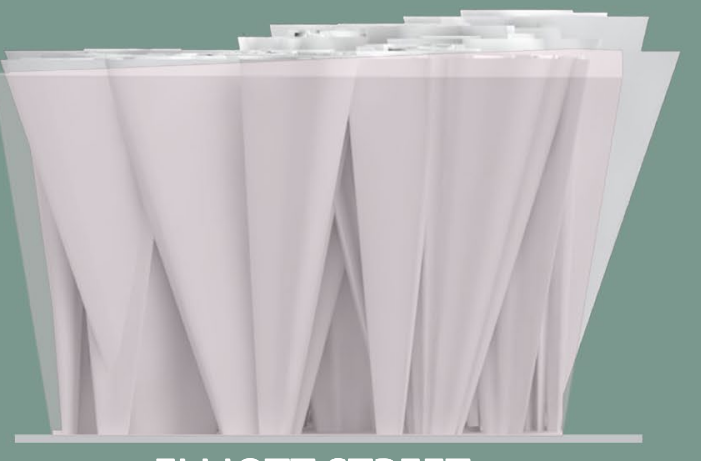

ELLIOTT STREET 


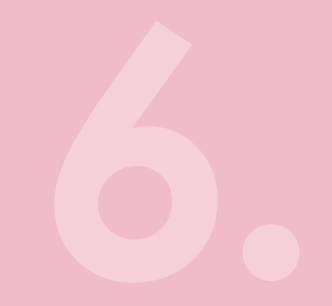

FINAL DESIGN 


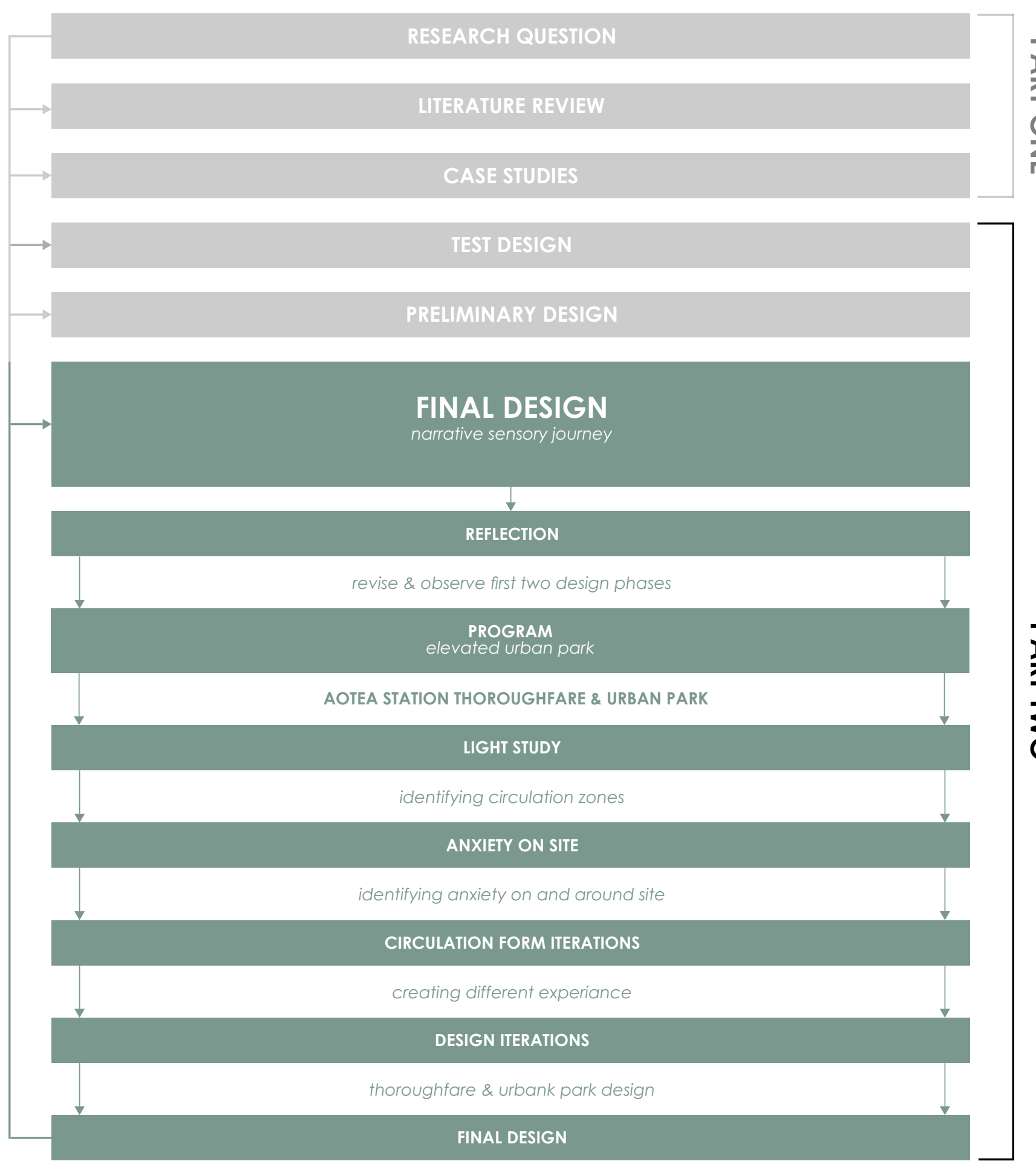

\section{INTRODUCTION}

phase three

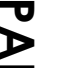

خ

The final phase is the continuation of the previous two design phases. It introduces a revised design and added program to create a stronger narrative sensory journey from an anxious space to one coxploing where oversim conditions, exploning where over-stimulation is located within and around the site, and how the design can encourage people to engage with the given narrative progression. The program plays a key role in how people experience the journey, where choice of different types of circulation give the user a slow, moderate, and fast journey upwards. 


\section{REFLECTION}

At this stage it was fitting to revise what had been explored and designed in the first two phases and reflect on what Observing the final result Observing the final results of the preliminary design, it had not been fully resolved in term of program, how sensory design is going to be used to create a narrative emotional journey, an how all the space is occupied. The final design phase has the potential to add program to site and create a stronger sensory experience where the thoroughfare is a place of heighted anxiety, the journey being the transitional space, and the addition of a program on top creating a place of calmness and release of anxiety. 


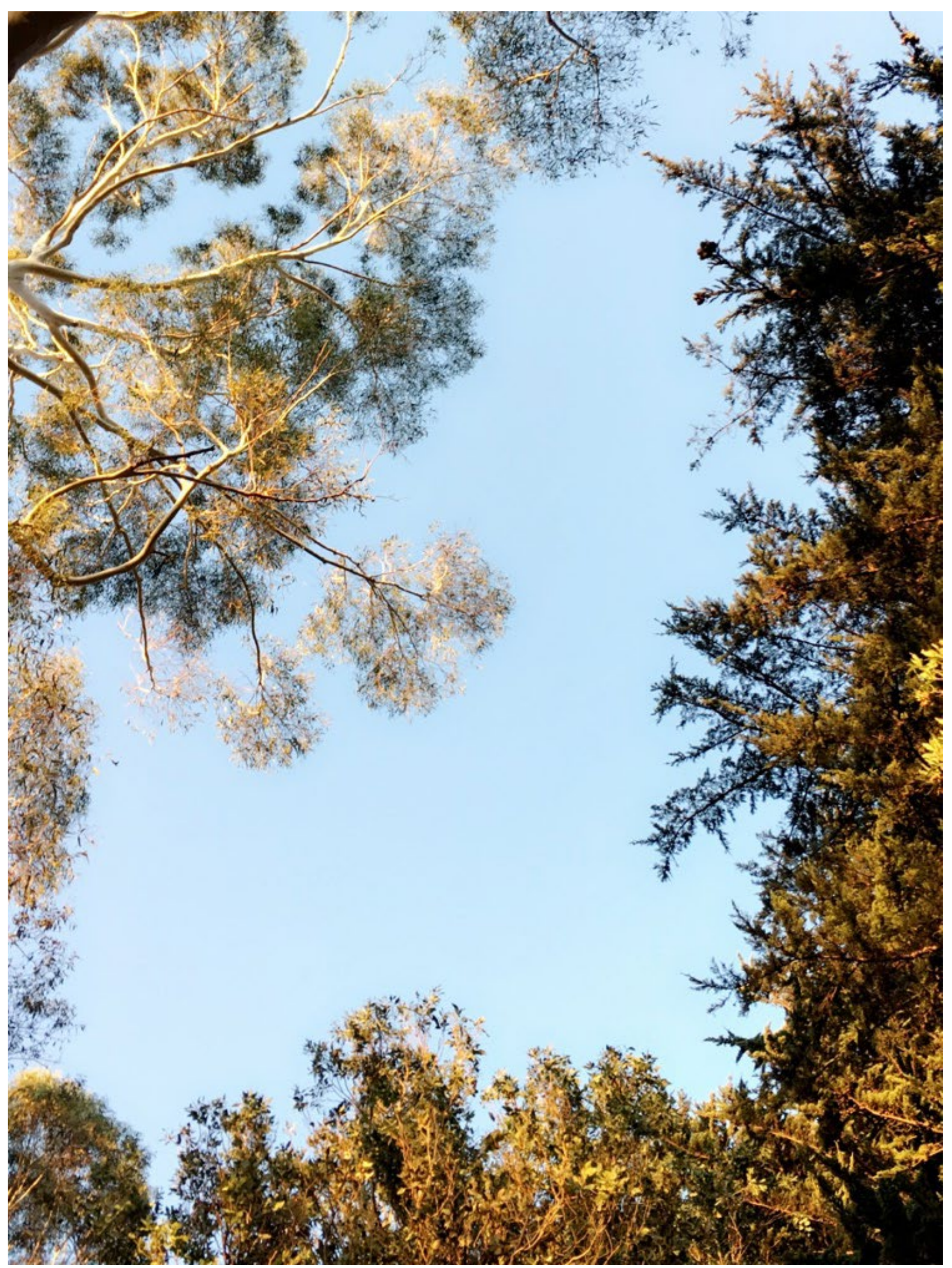

The chosen program for the final design phase is an elevated urban park that creates an architectural experience for users around the site and a place of respite. The program is chosen on the basis that it is able to reduce the overstimulation of the senses, returning the occupan of an urban dense environment to a place where sounds, smells, touch and sight are satisfying to both the body and mind. The program below the urban park is the thoroughfare from Aote Station to the wider urban environment whic is the zone where anxiety is heightened. There is an added potential for a large rest room are and commercial space in the future. 


\section{LIGHT STUDY}

site conditions

This investigation identifies where sunlight falls

on site throughout the year, which will influence

where circulat

the circulation is located in the design. Part

of this is to consider how these findings could

potentially add to the anxious/ uncomfortable

space in the thoroughfare, during summe

creating a hot interior and during winter cold

while the circulation, as a transitional zone,

becomes more comfortable as the user travels

towards the urban park. The following images

illustrate the sun's movement across the site at

different times of the day and year. 


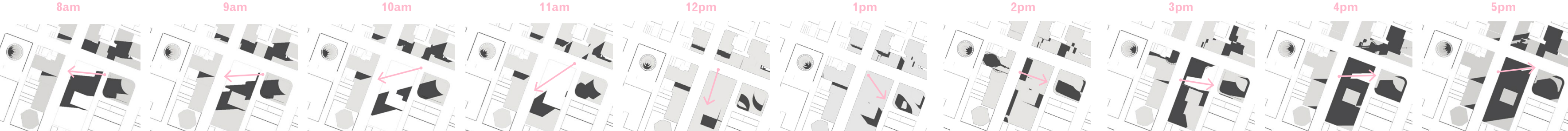<smiles>[AlH2]C1CC1</smiles><smiles>C1CCCC1</smiles>
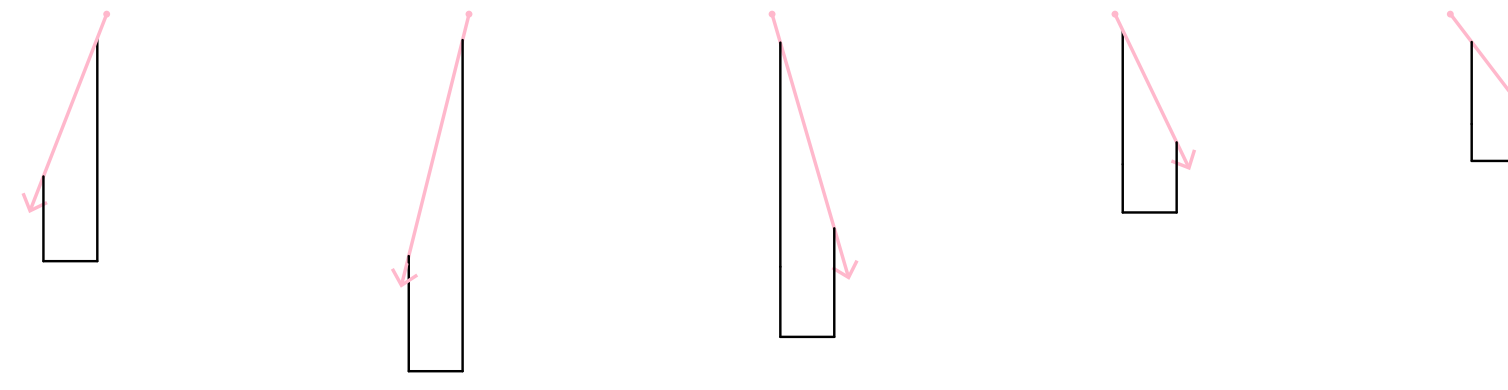

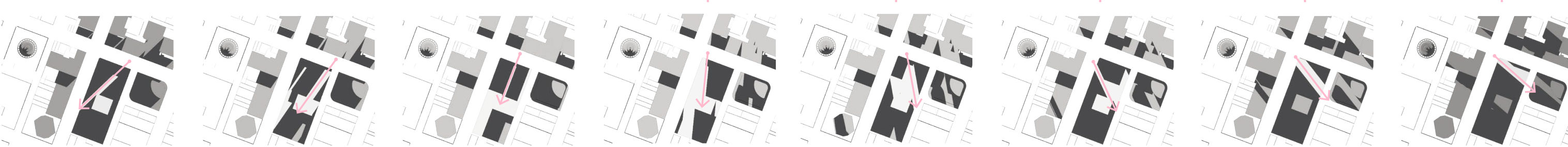
4
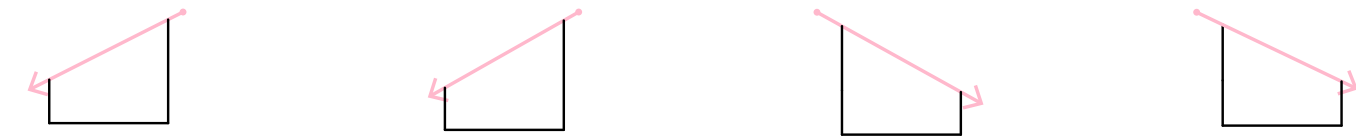

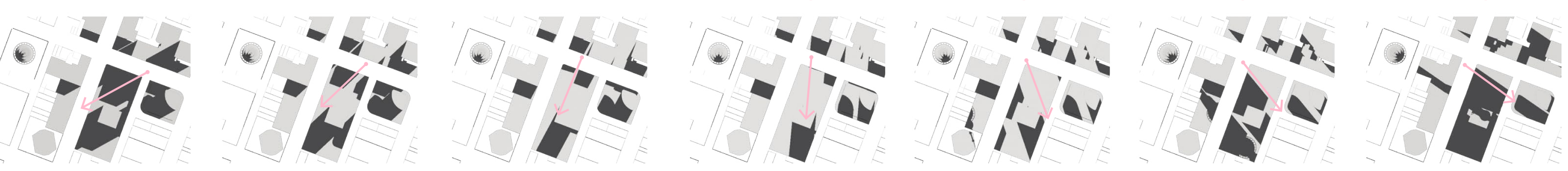
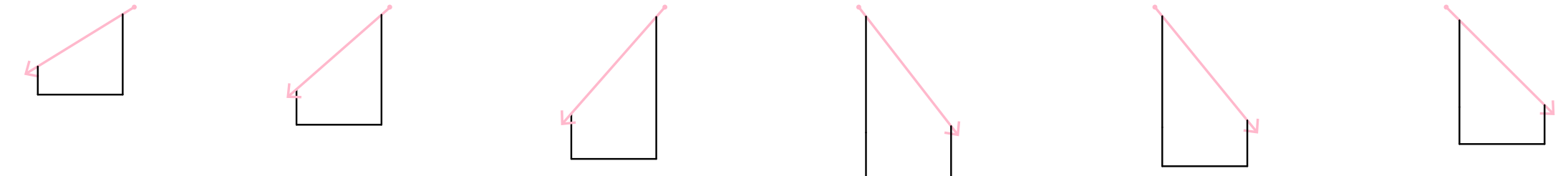


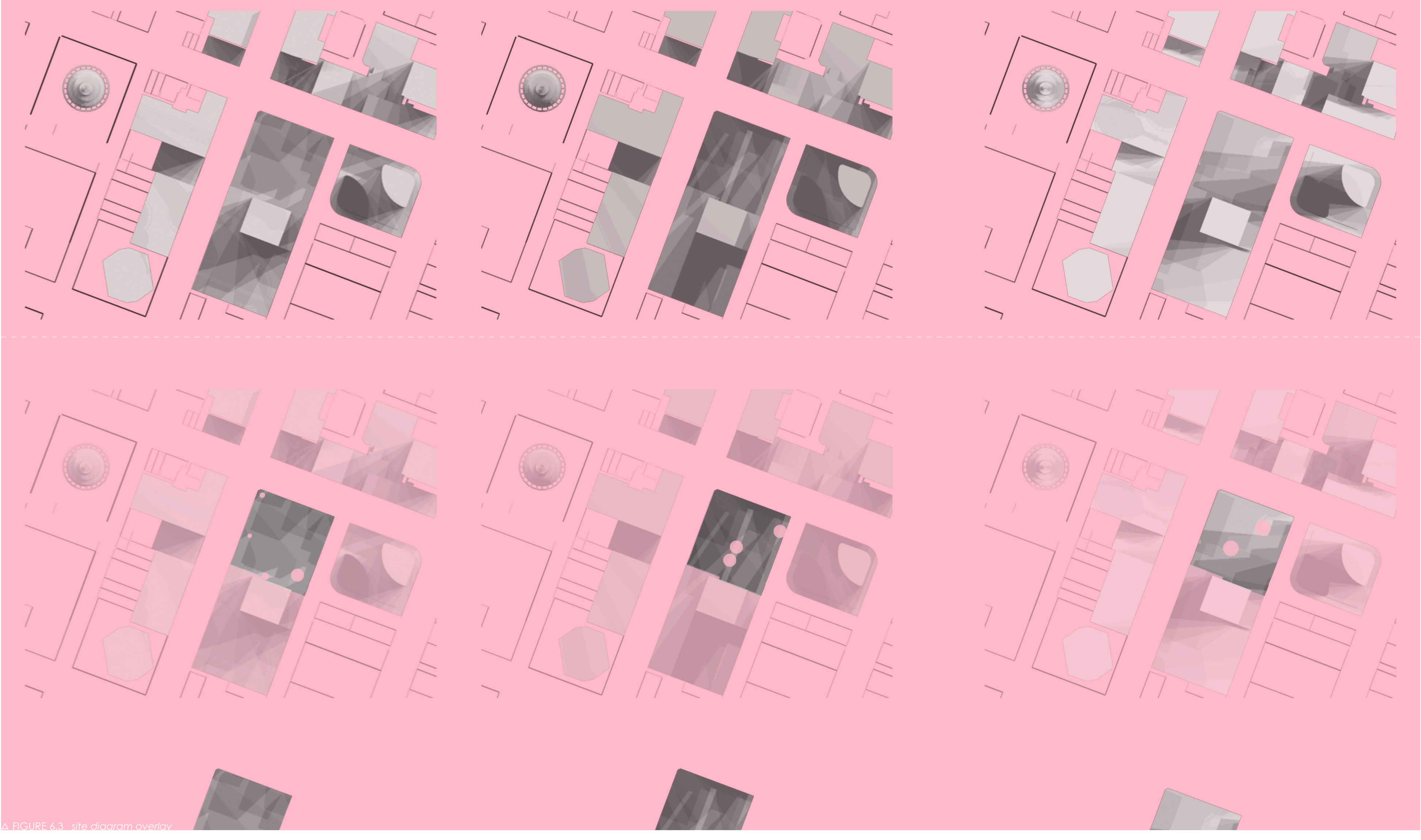





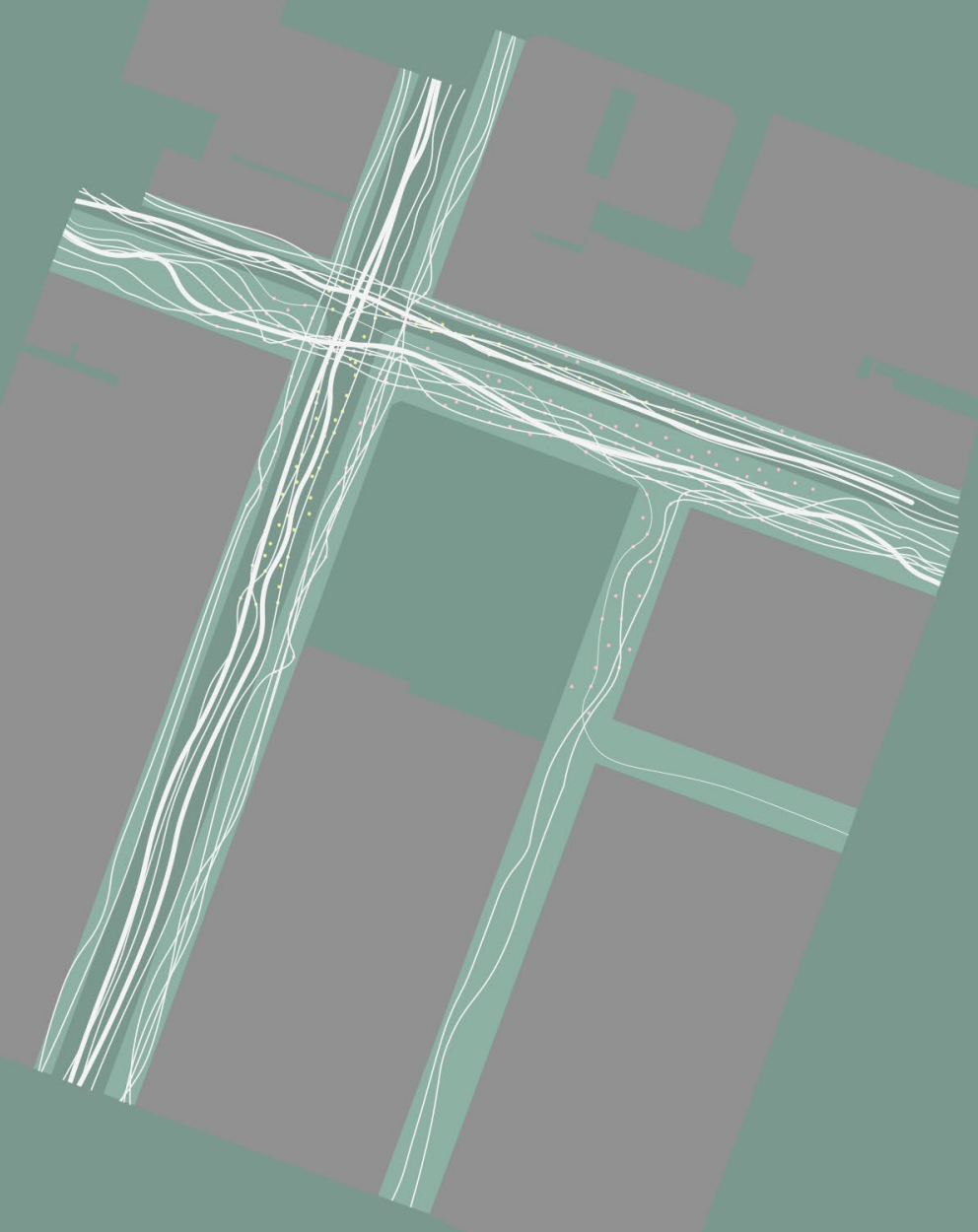

ANXIETY ON SITE

auckland central

Part of the design research is to identify where anxiety might occur on and around the proximity of the site. The narrative sensory journey will deliberately heighten anxiety in the thoroughfare zone in order to contrast with the architectural elements that can reduce anxiety and create a place of calm. The following and create a place of calm. The following
images showcase the areas where heighted anxiety is located. 


\section{FORM ITERATIONS}

The funnel locations identified in the light study suggested a way to create a series of the journeys from the to the urban park. This is the fist stage of the final design process, creating formal light "funnel" each with its' own circulation system. Each of the three circulation zones are to have different experiences for the user, the speed of the journey varying from, slow, moderate, to fast. 


\section{DESIGN ITERATIONS}

thoroughfare \& urban park

This stage continued with the development of the light funnels, or circulation forms, and now adds the full design to the site: struct program, and facade. The first image introduces pathways from Aoten Station which direct users un the three circulation zones through thee different pathways. Each is carved out from the original site where the structure is exposed. The form of the urban park landscape is inverte on the ceiling of the urban park. The secon iteration reduces the size of the organic form on the corner of Elliott and Victoria Streets and adds thickness between the thoroughfare and urban park. The third iteration showcases the

facade design, which juxtaposes the internal organic form that is wrapped with an external geometric form, expressing the exterior of the body in relation to anxiety, where the interior of the thoroughfare represents the suppressing f anxiety. The fourth iteration reduces the size of the facade and gives people a glimpse of the the facte and gives people a glinpse of the uran park from the extrior and in final design for the circulation, a ramp (slow journey), linear stairs (moderate journey), and spiral stairs (fast journey). The final design opens the thoroughfare area to create a larger more anxious space and finalises the form of the urban park, where trees are planted around the perimeter to reduce the surrounding noise and introduce natural sounds, smells, textures and visual effects. 

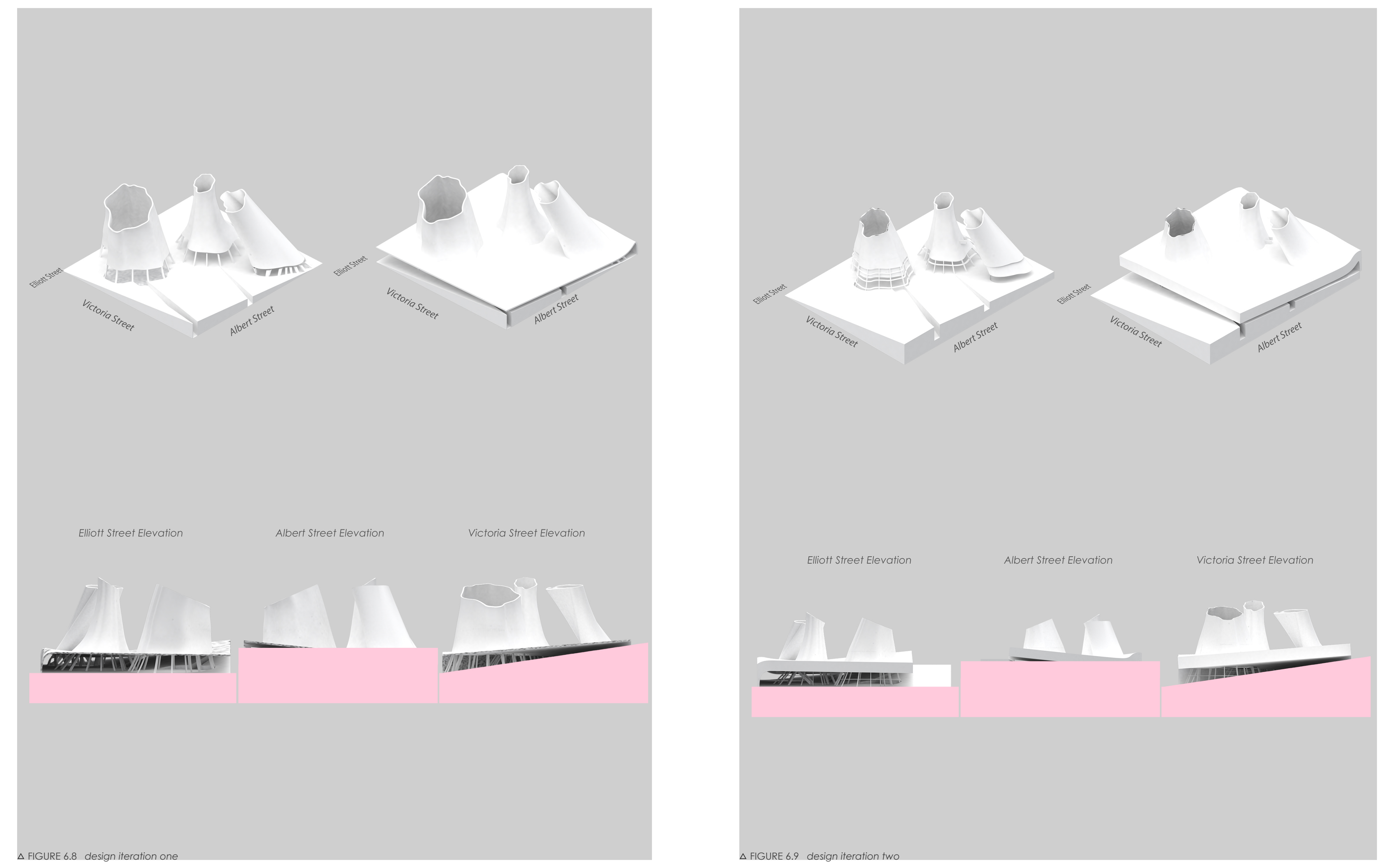

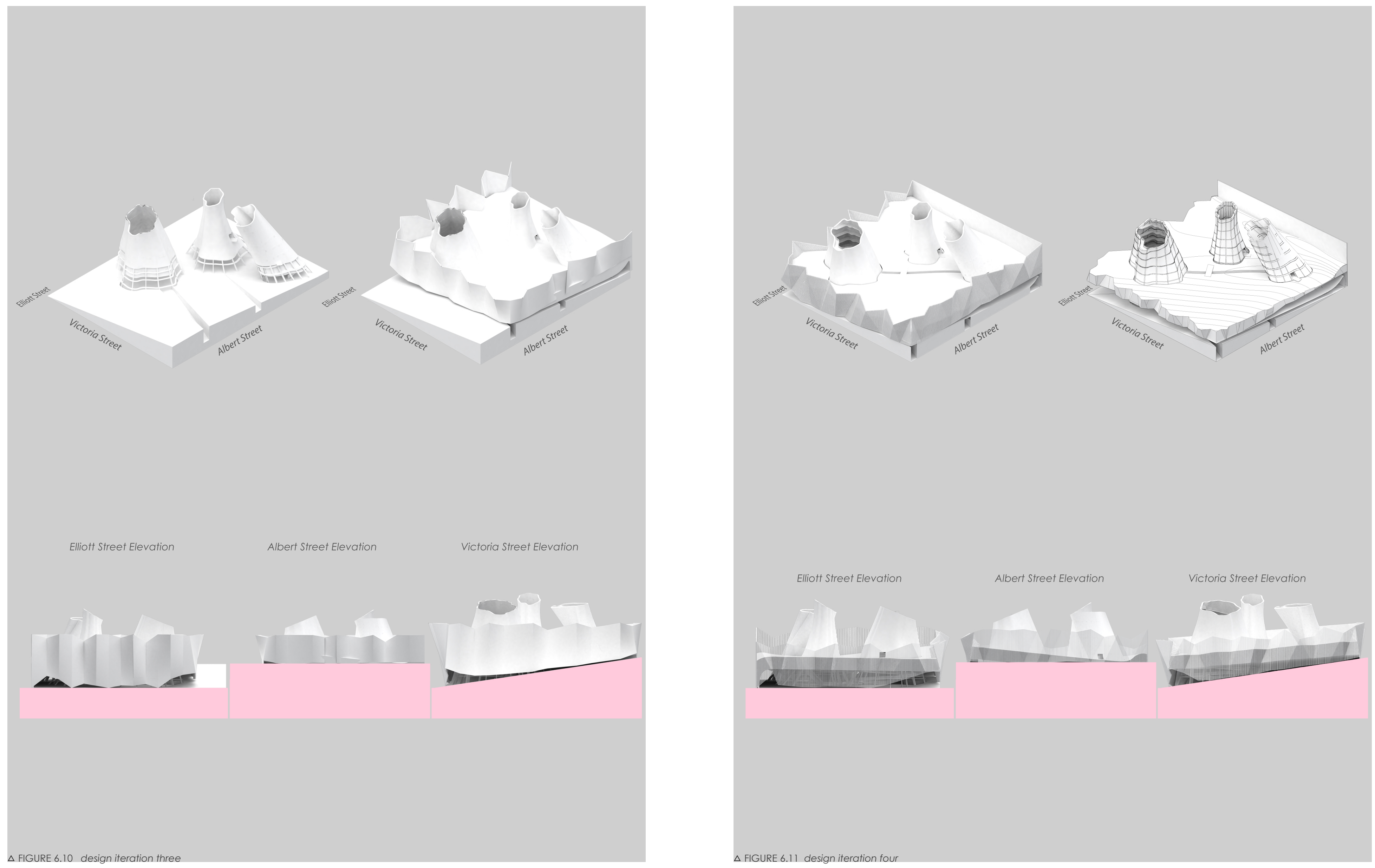

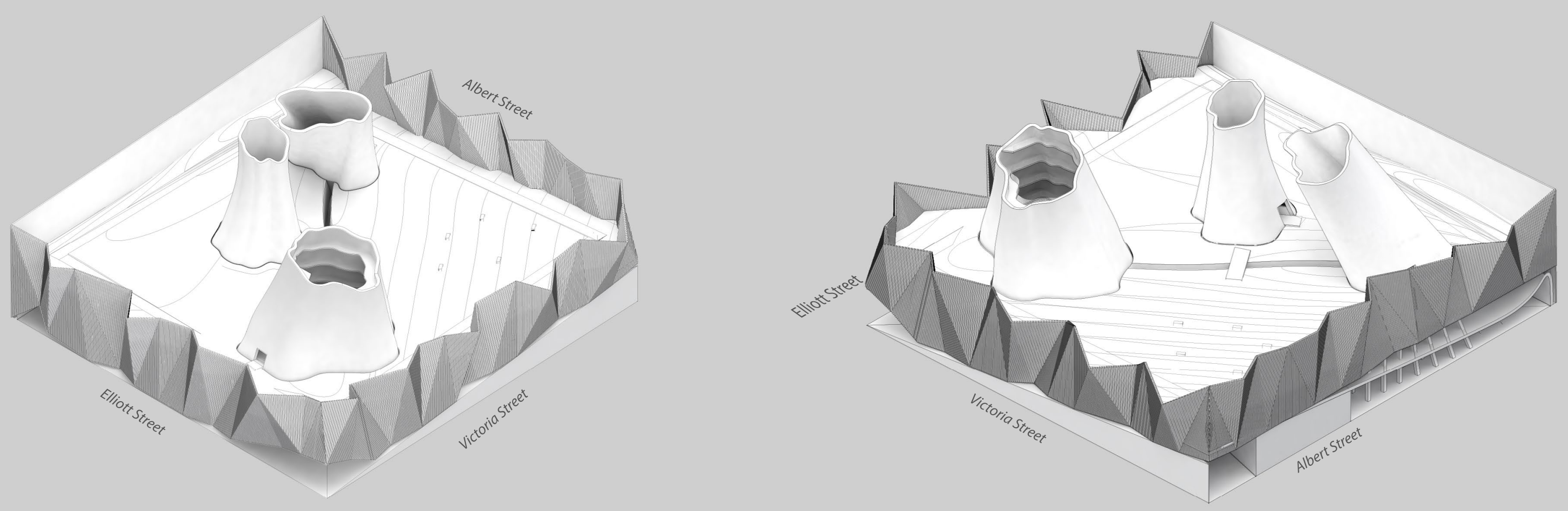

Elliott Street Elevation

Albert Street Elevation

Victoria Street Elevation

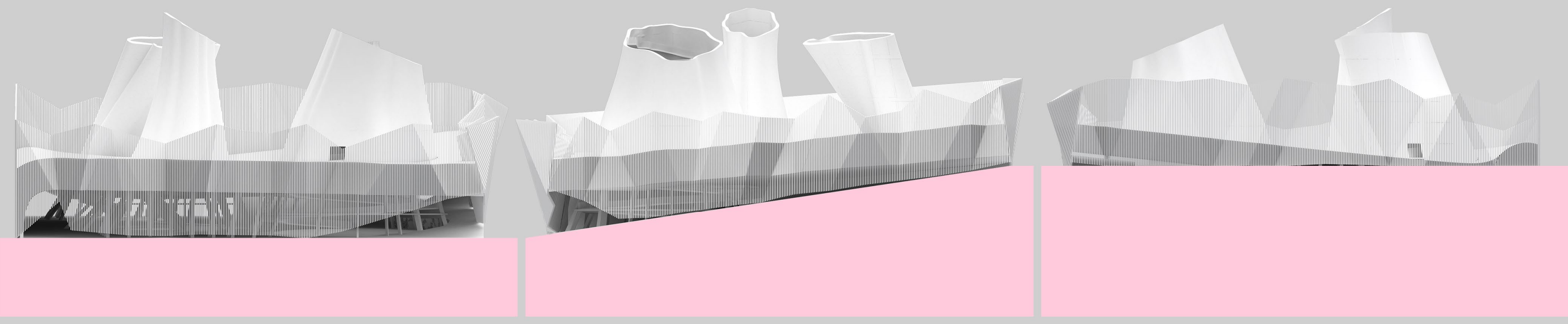



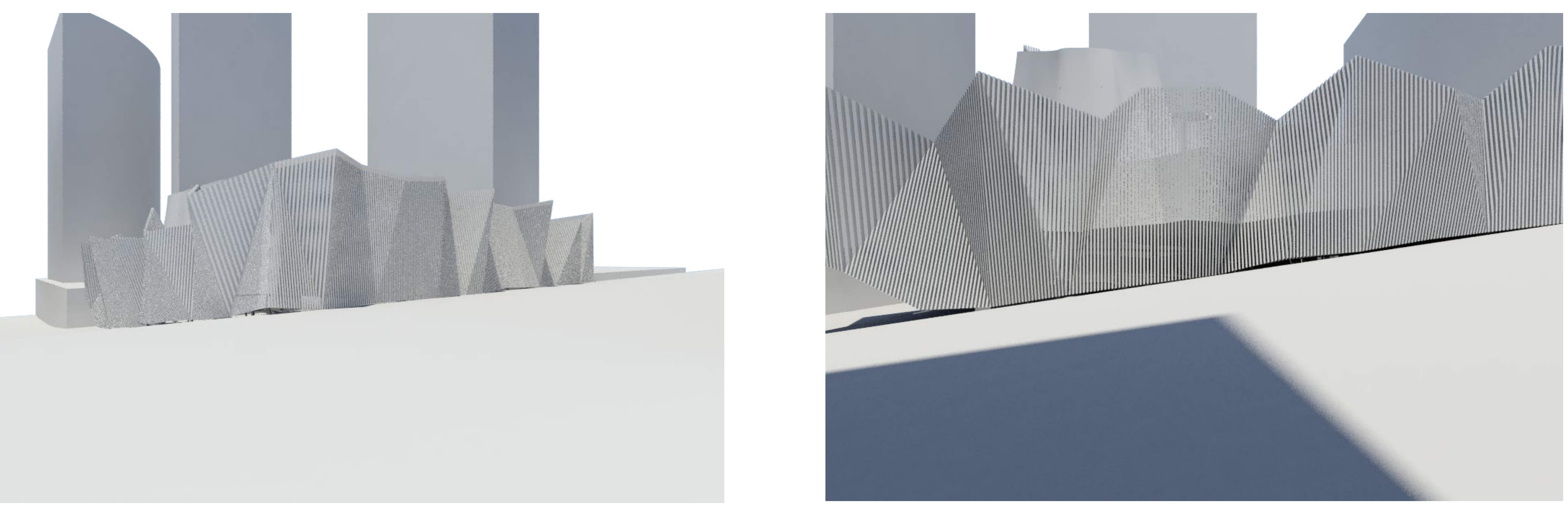


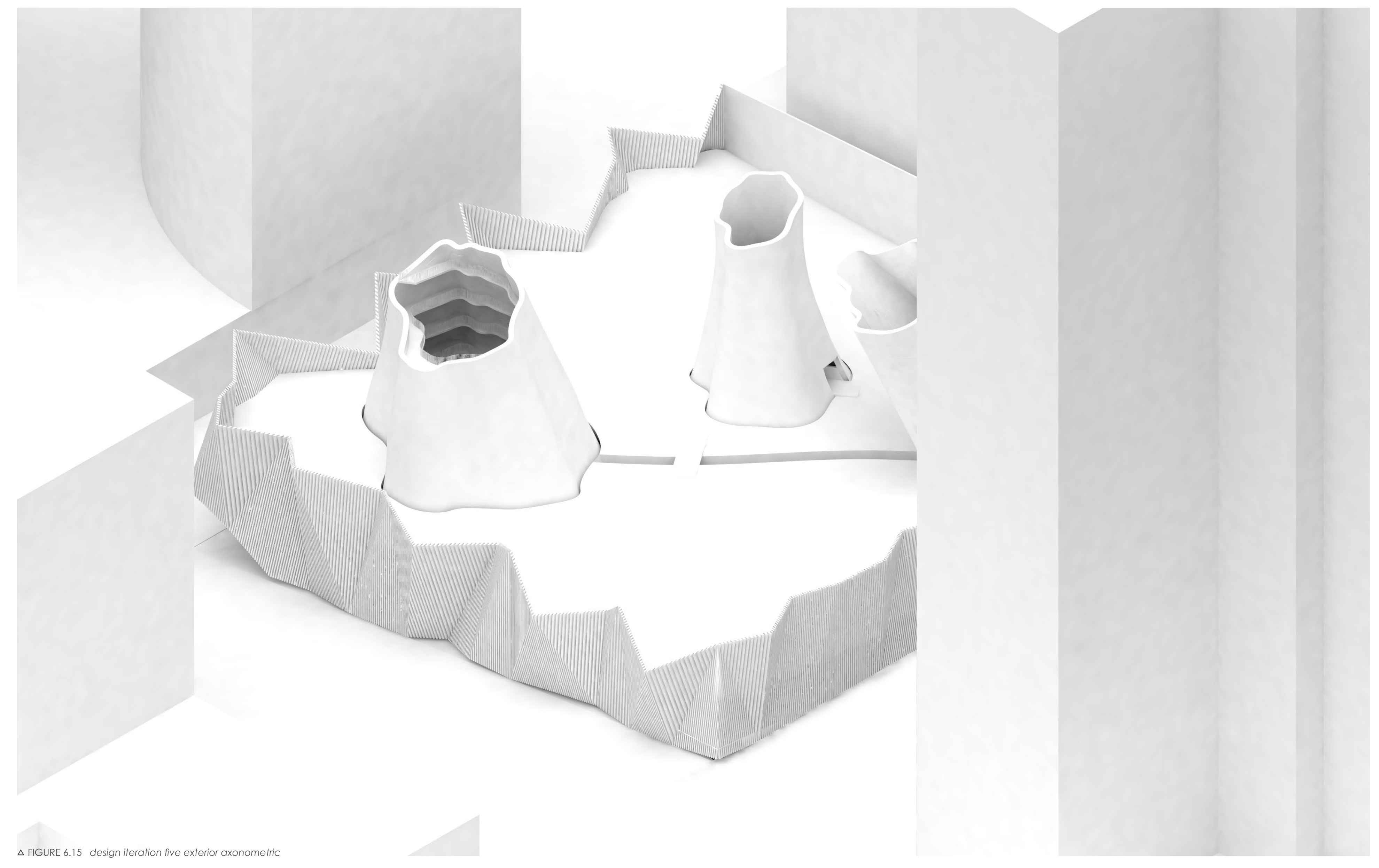




\section{FINAL DESIGN}

thoroughfare \& urban park This is the final part of the design phase where the narrative sensory journey from an anxious space to a place of calm is realised throug form, material, texture, light and shadow. The following images all illustrate the detaile design. The plans and sections showcase the detail of the narrative journey and overal architectural design, while the following renderings highlight the sensory and experience of the users through each of the three circulation paths from an anxious space to one of calm.
The urban park creates a place of peace, and introduces a dense green belt around the edge of the landscape, largely reducing the noises from the surrounding environment. This allows for the user to experience familiar senses, the smell of grass, wood and trees, the sound of water, the trees' movement in the breeze and birds sing. Together the touch, sound and visual aspects create a place of calm due to the instinctive response of the body and mind to a secluded natural environment. 


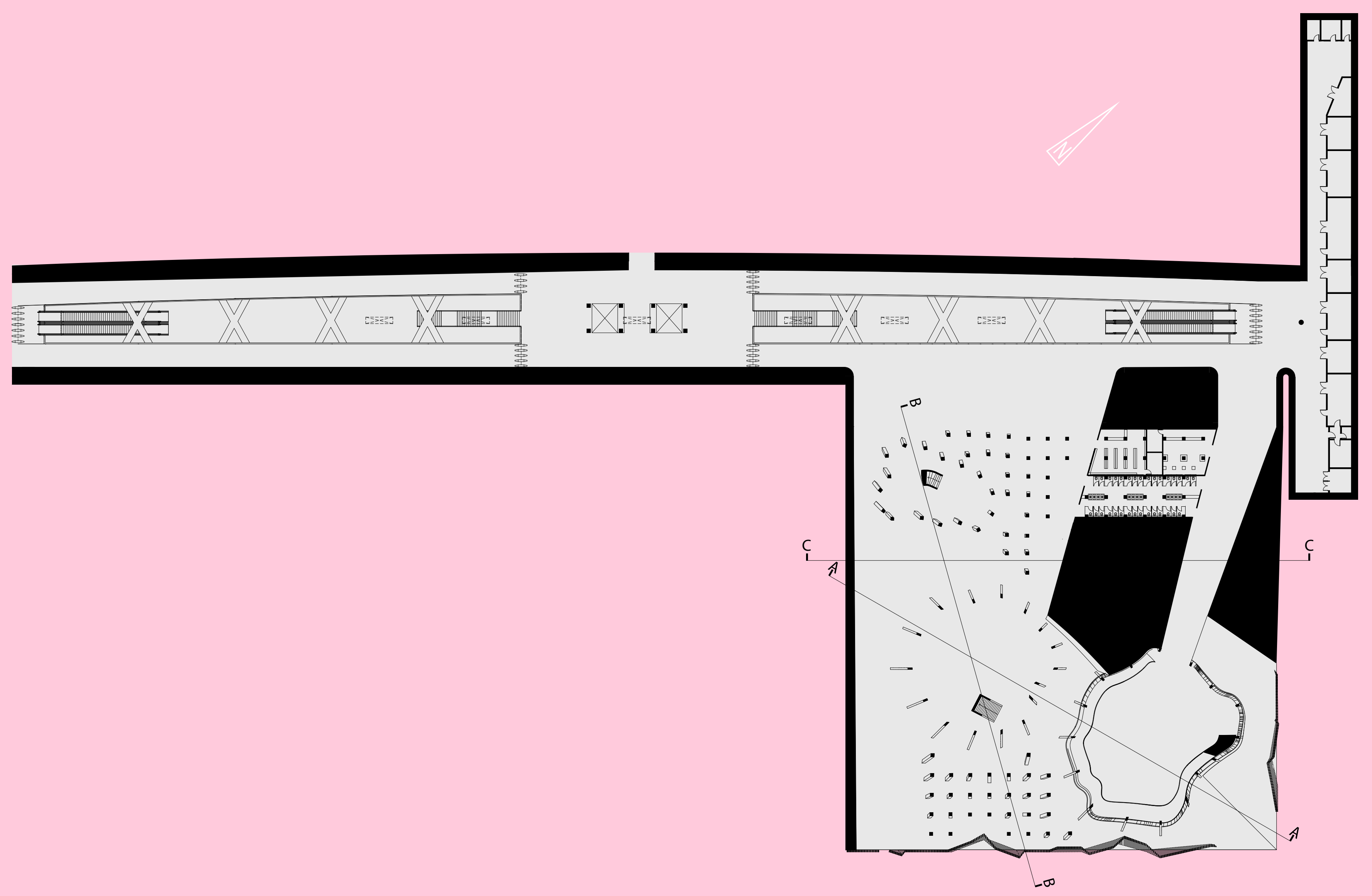




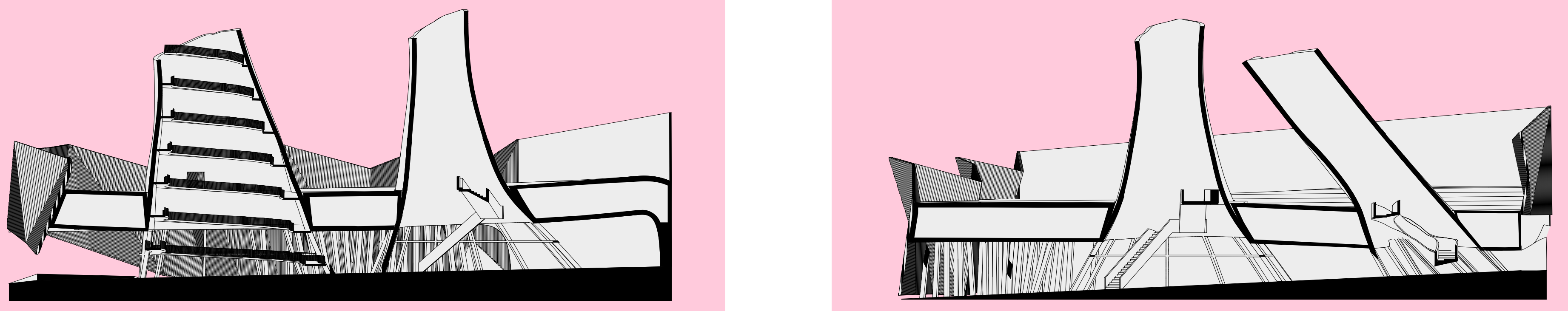


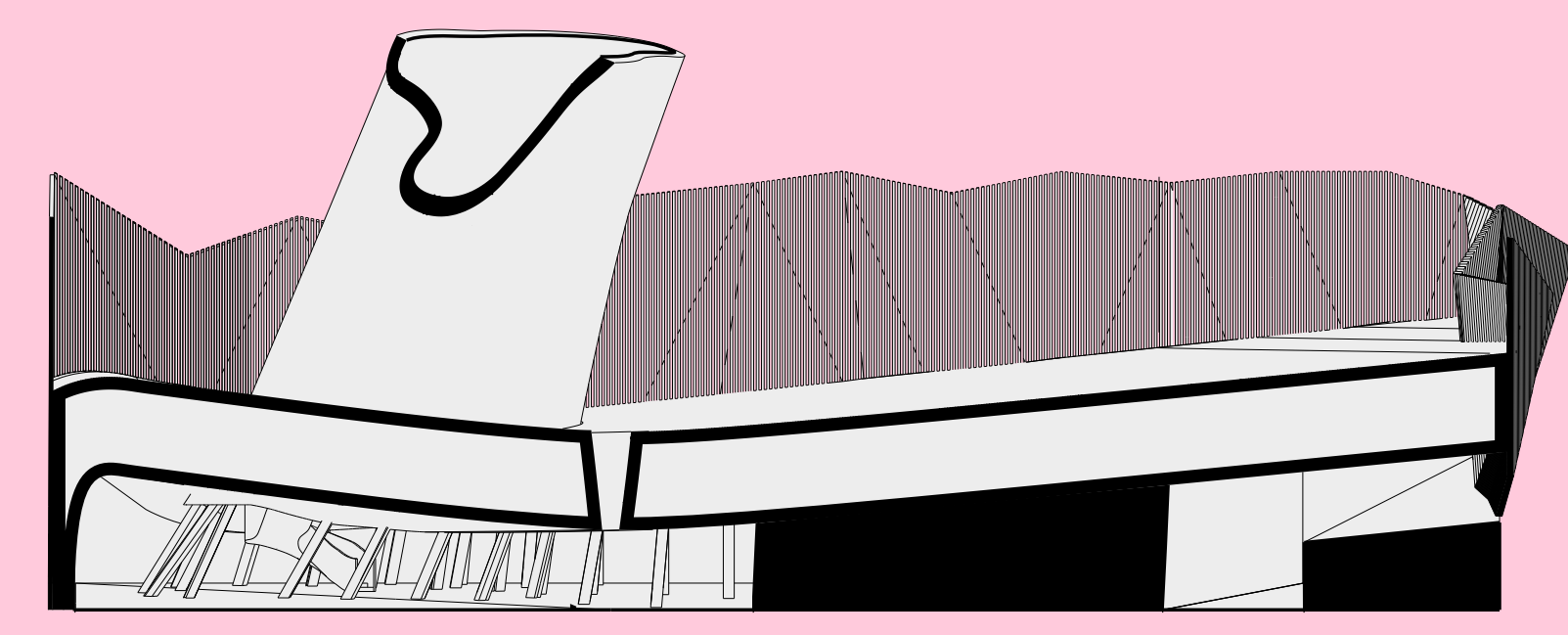




\section{JOURNEY ONE}

The following images illustrates the movement from Aotea Station and entering the thoroughfare zone. The pathway carved from the original site directs the user toward the large organic form, the ramp (slow journey) which not only has an entrance to the urban park, but travels to the top of the park for people to experience the full site and their surroundings from above. The surface is smooth and the user is able to touch the surfaces to enhance their journey upwards.

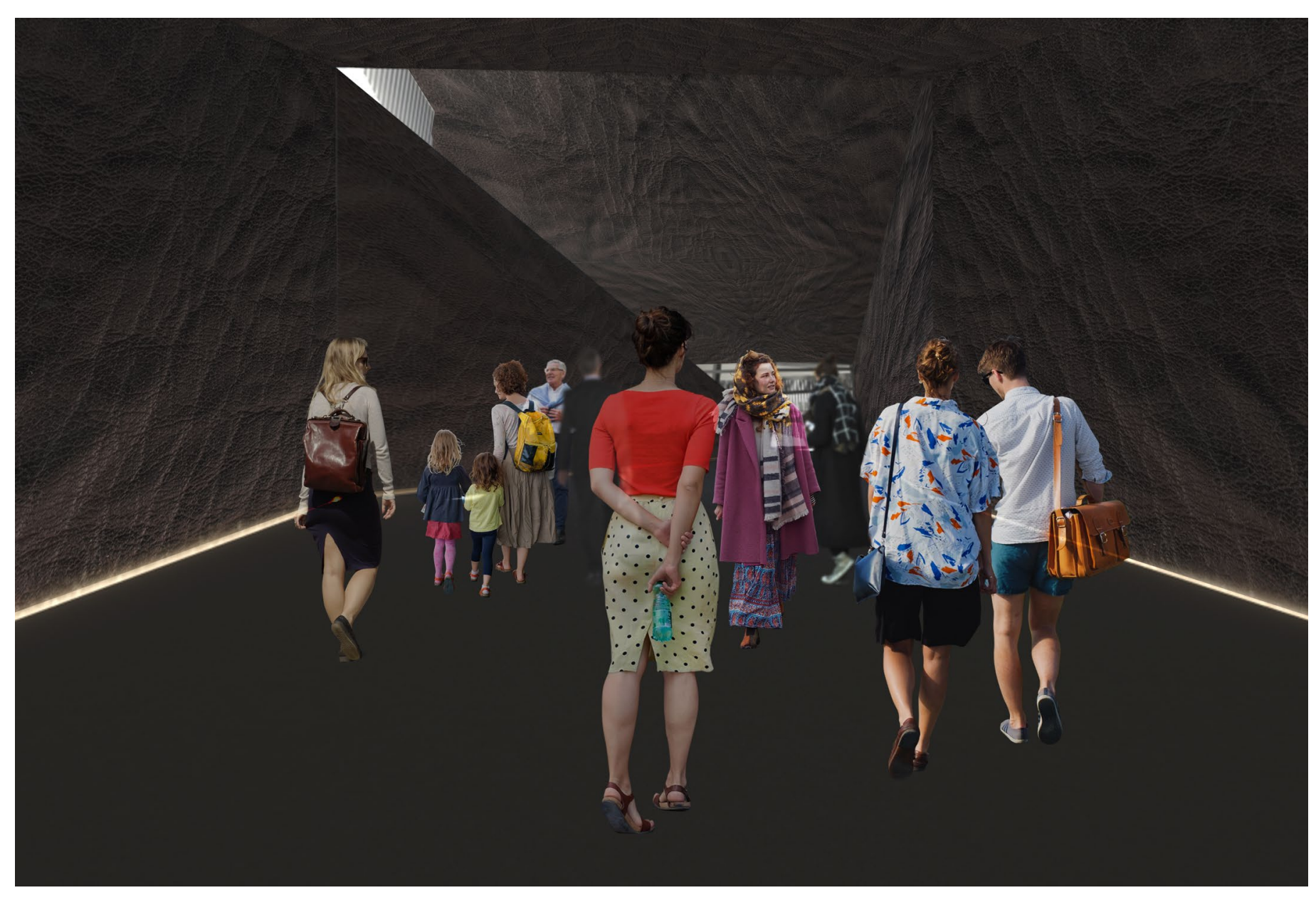



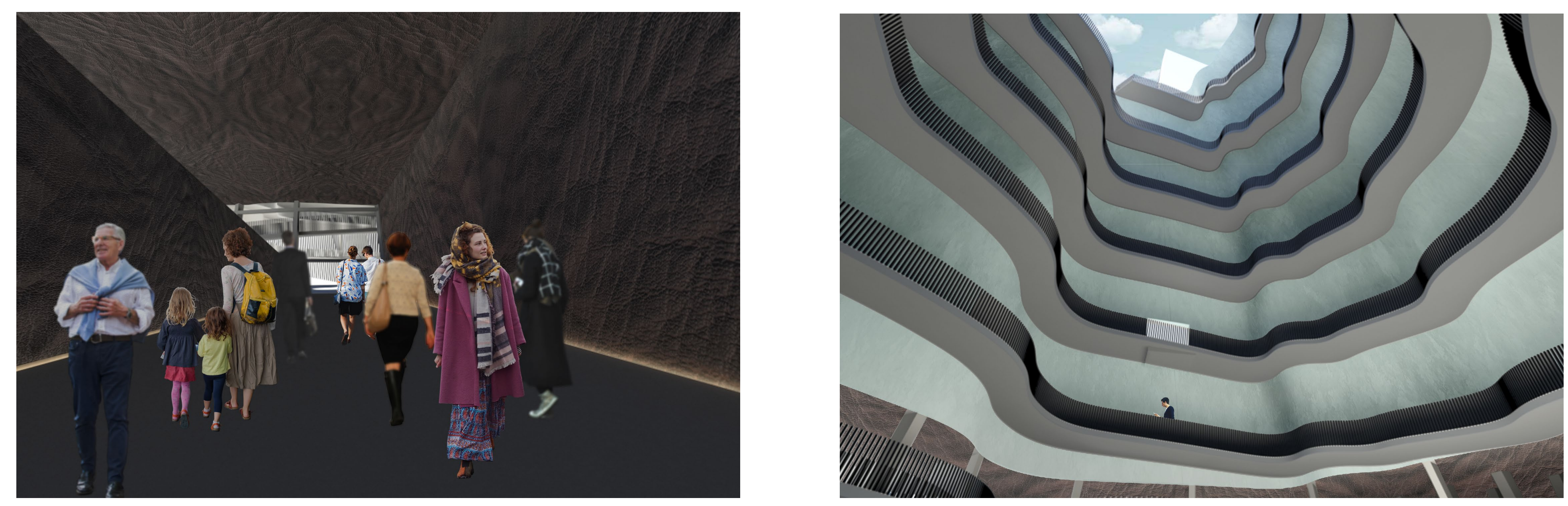


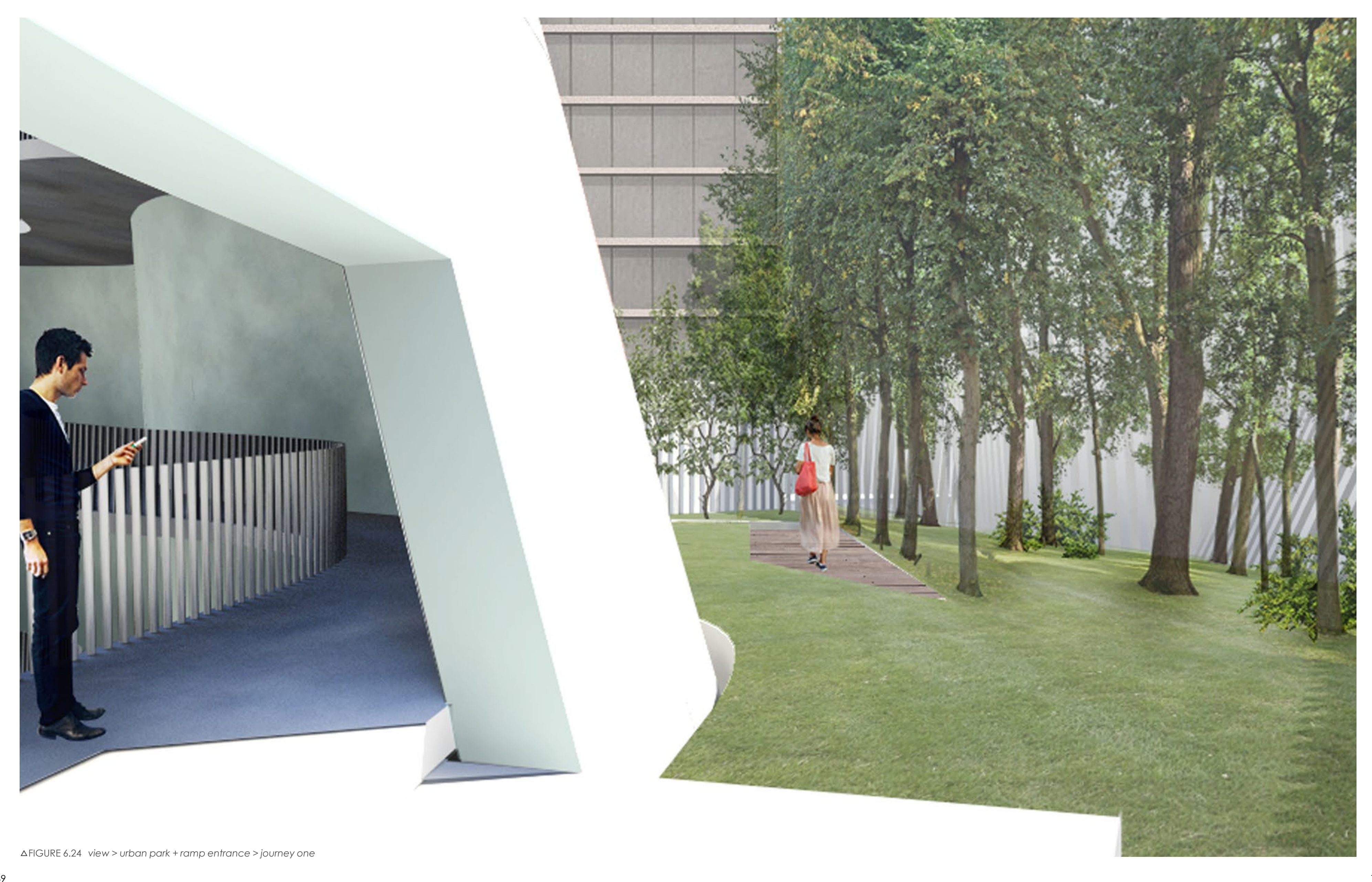




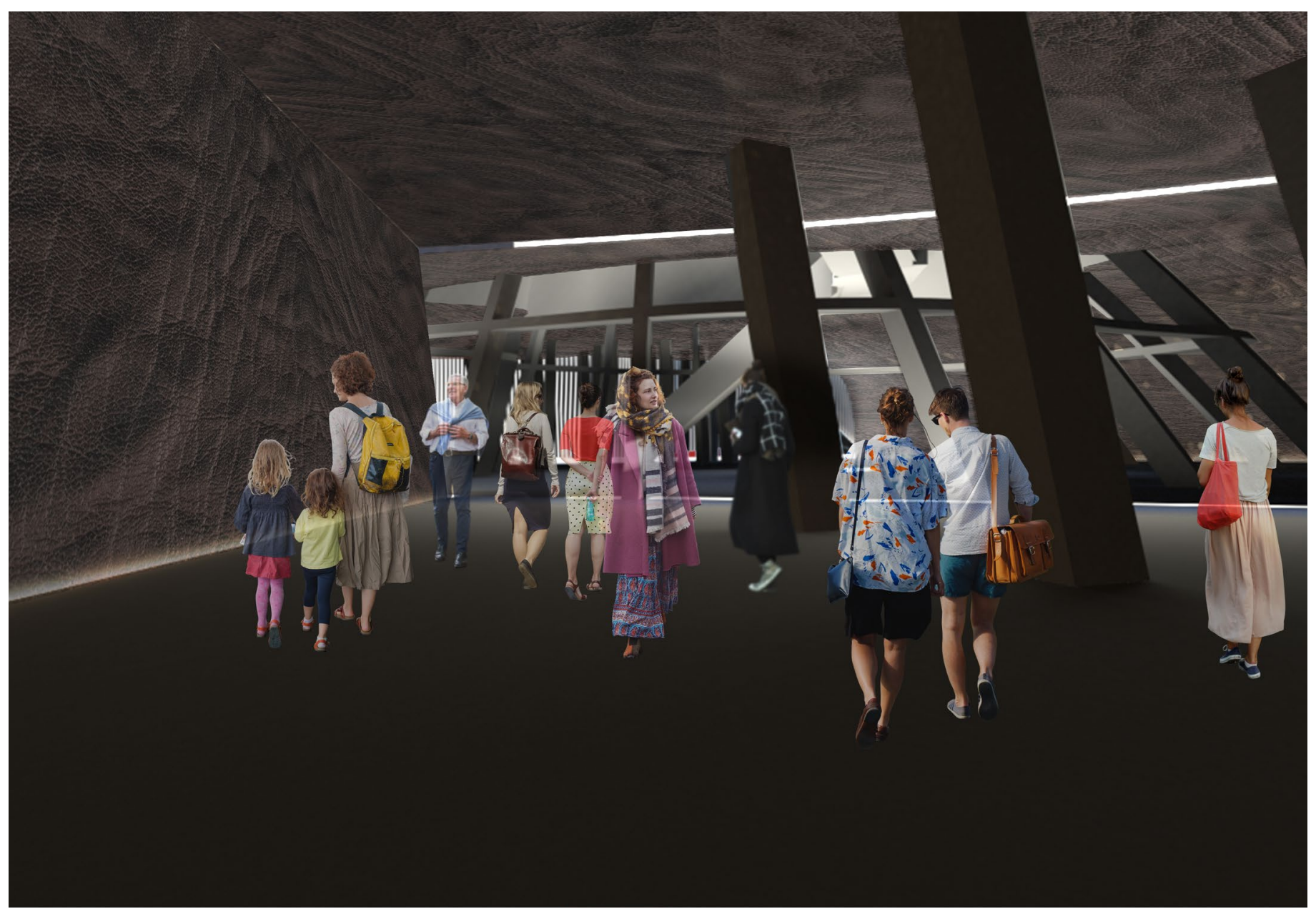

The following images illustrates the movement of occupants from Aotea Station and entering the thoroughfare zone. The entrance to the thoroughfare zone opens up and exposes arge structural elements which direct the use towards a linear staircase (moderate journey) The stairs give the opportunity for people to touch and interact with the surface of the form and give them a moment of pause and reflection, before entering the urban park. 

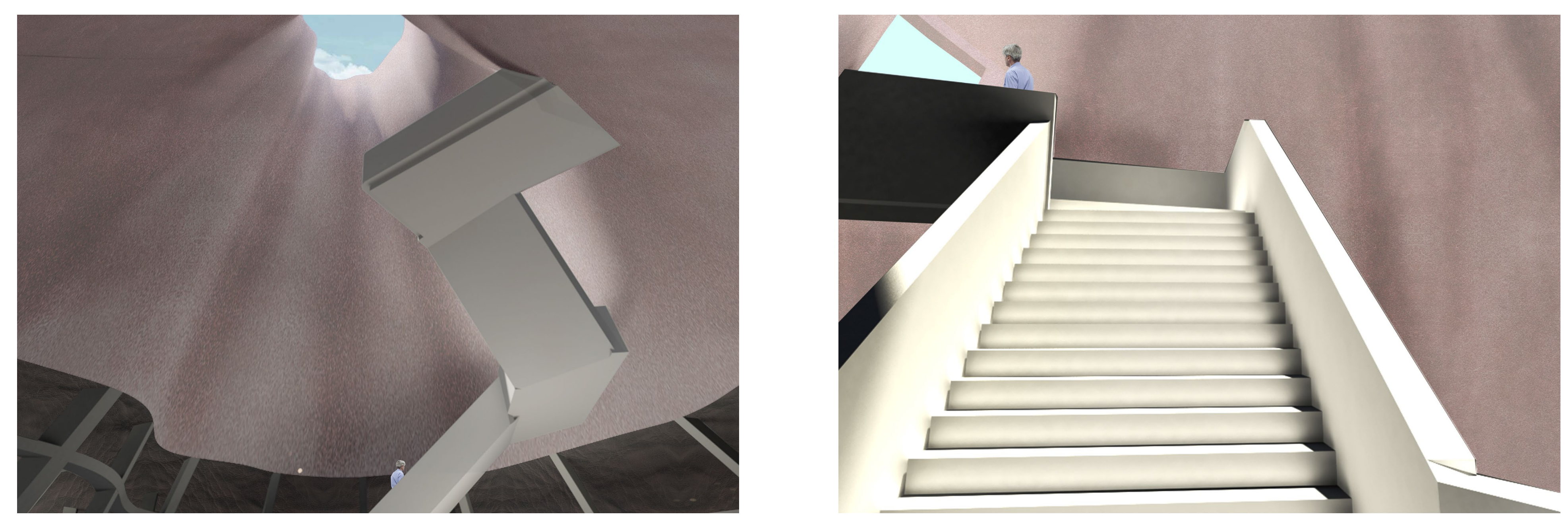


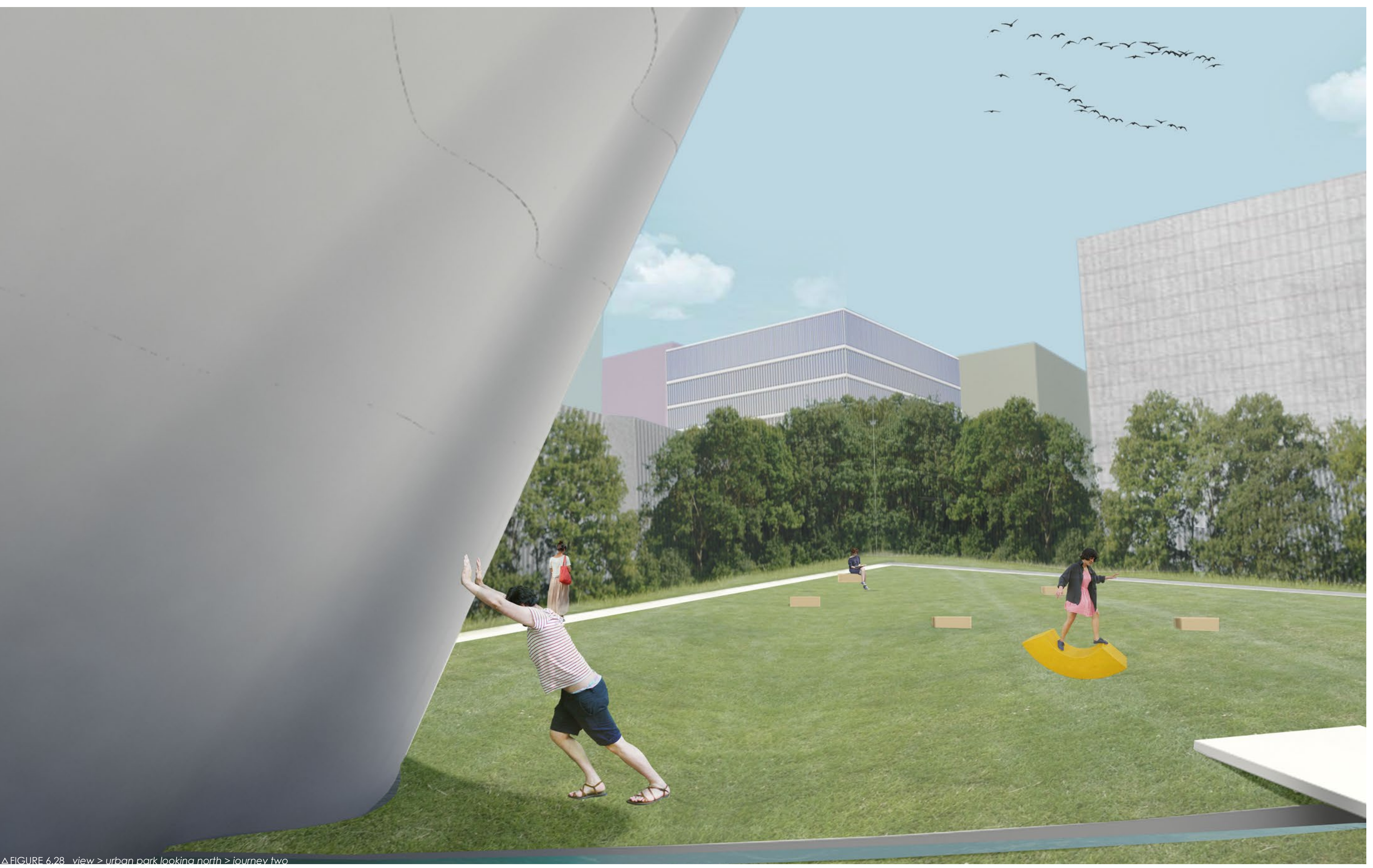




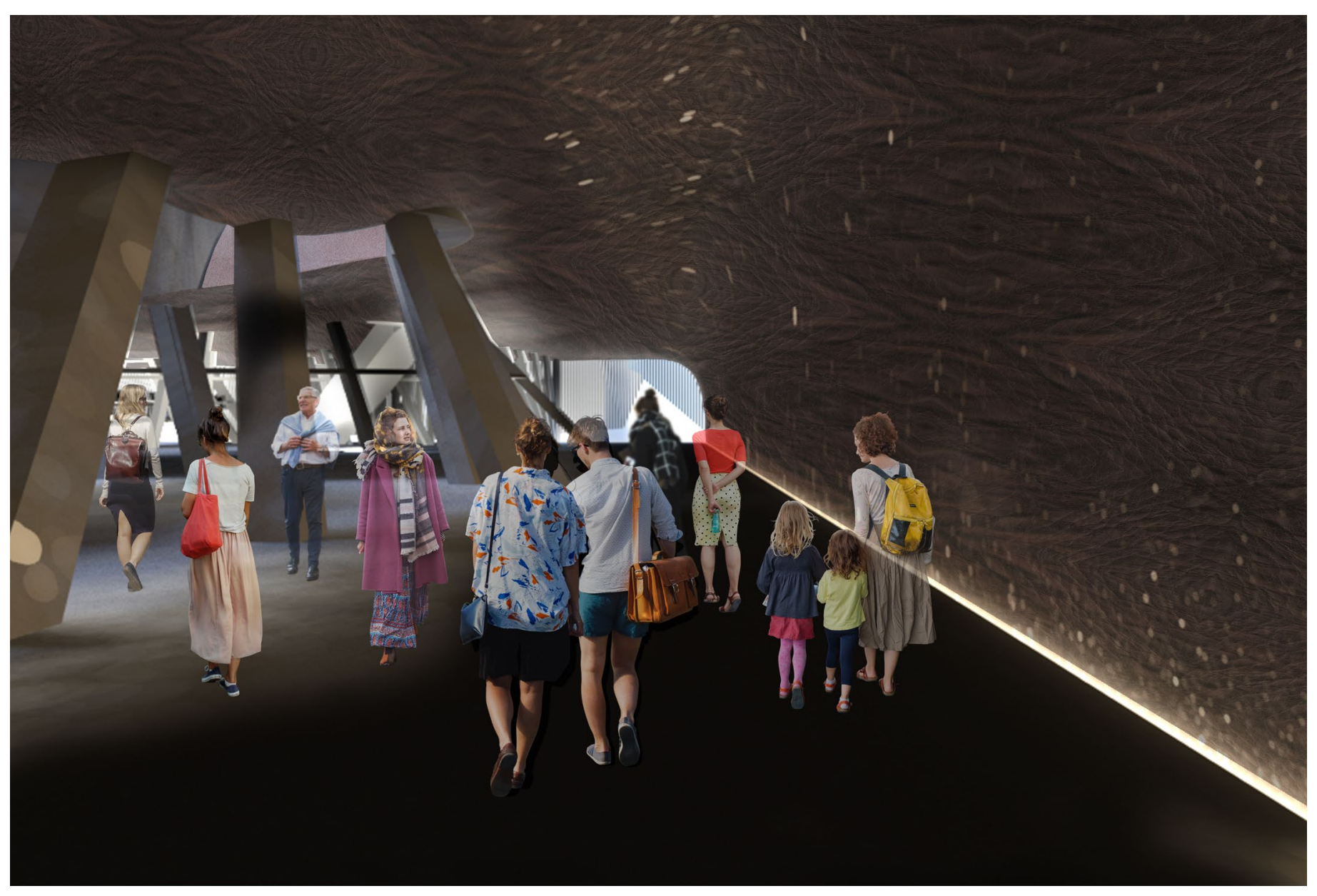

The following images illustrates the movement of occupants from Aotea Station and entering the thoroughfare zone. The entrance is the same as journey two but directs users under the spiral staircase (fast journey). This is for users who want to journey straight up to the urban park. The spiral staircase mimics the organic form of the light funnel but unlike the other two journeys it does not allow the user to interact with the surface, which is rougher. 

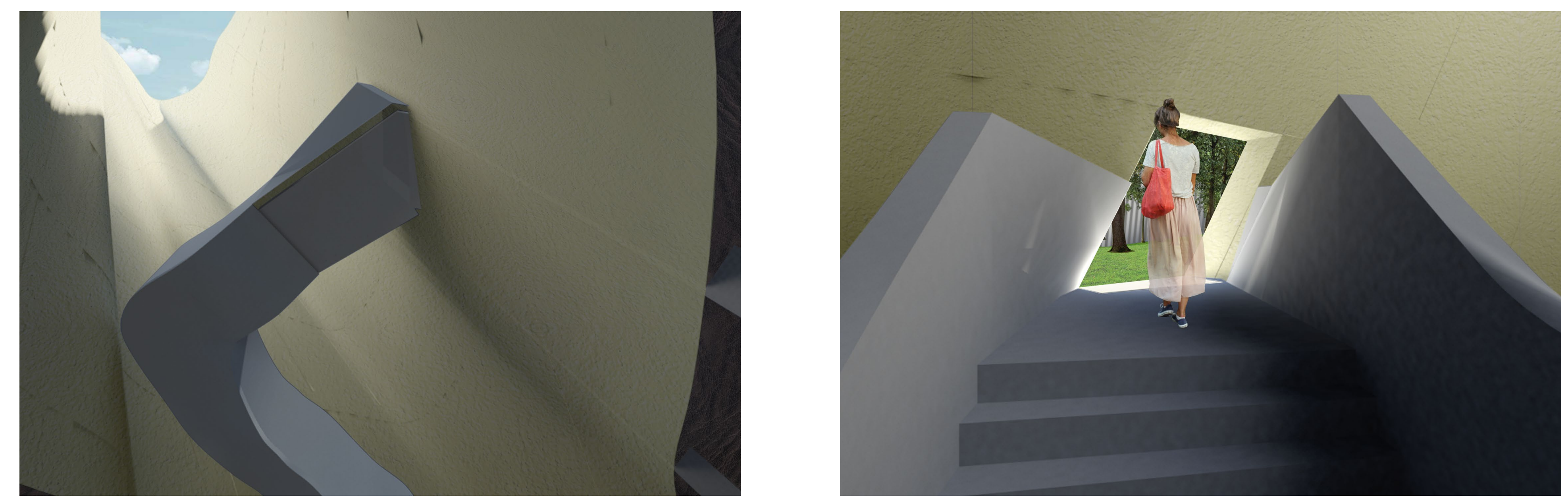


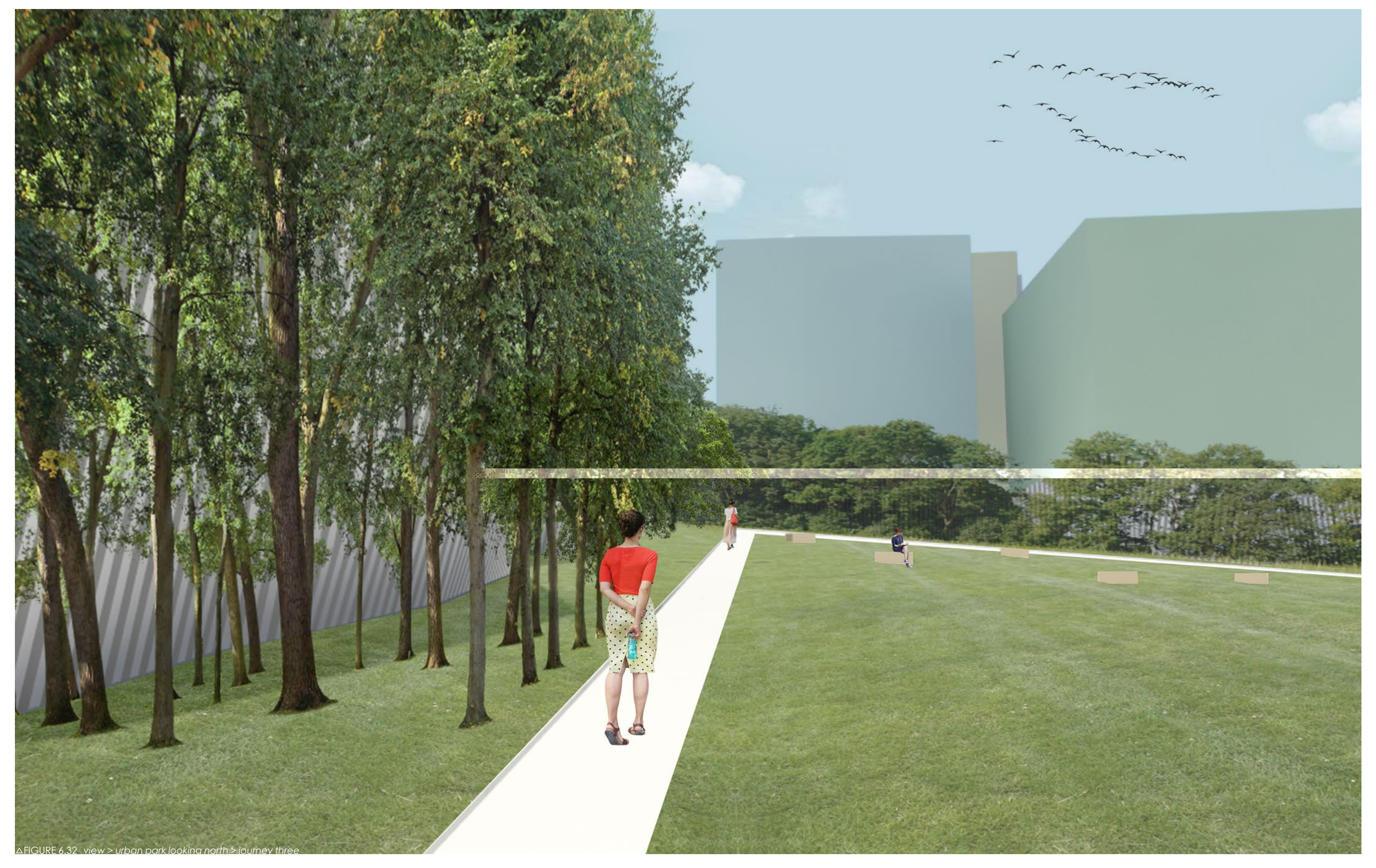




\section{CONCLUSION}




\section{CONCLUSION}

The intent of the design research project is to answer the questions, "how can architecture create relief from anxiety in the context of dense urban environment? How can sensory design create a narrative journey that transitions from anxious to calming?’

The first three chapters focused on the theortical background of narrative architecture and sensory design in relation to the body, both physically and mentally. The goal was to discover how narrative architecture and sensory design might be used in order to relieve anxiety in a dense, over-stimulated urban environment, through architecture. These methods were used to analyse five case studies that give a understanding of the topic, tho a greater muilt work, establishing a design frailt and for the three design phases.

The first design phase, 'Test Design', involve creating a series of physical models and drawings that explored and established narrative progression through the differen levels of anxiety. These techniques explored the experience of anxiety both physically and the experience of anxiety both physically and visually, two design phases used the findings from the previous tests to create a design in an urban dense environment in central Auckland, the proposed new Aotea Station. The preliminary design used some of the drawings from the first phase to create a narrative journey through the site, creating a reverse progression from anxious to calm. The final design reflected on the previous two design phases, developing the spatial and material qualities of the proposed design. Though the process, the progroposed design. Throun the process, the prom pran inas developed in order park was developed in order to create a narrative progression, releasing anxiety through sensory 


\section{CRITICAL REFLECTION}

The findings from this design research project demonstrate the importance of the iterative design process. The first design phase was successful, creating a narrative progressio through the levels of anxiety. However it could have explored further ways to heighten anxiety through different sensory methods, rather than testing only through sight and touch. The preliminary design shifted from testing throug abstract models to creating forms on a selected site. This led to the reverse progression, the journey towards a place of calm. The design journey towards a place of calm. The design was limited in its slccess as it had no program, and the scale was too large for an ind ividual to means. The only resolved result was the narrative journey. The final design illustrates the narrative sensory journey from the future Aotea Station, through to the wider urban area, and upwards to an elevated urban park. It introduces program and develops the design from the previous two phases, where the success of the design was making the thoroughfare zone the area of over stimulation and the urban park the area of calm. The intent of the interior was to create a space which heightens an individual's anxiety, allowing them to understand the conditions of their own body and mind the con a transitional zone. While this use of narrative sensory methods was successful way, the representation of this narrative journey needed further development.

A key point noted in the final design review was the value of creating a place where people experience heightened anxiety? This developed into the discussion of the levels of anxiety being the focus of the design, and the progression from one level to the next. A remaining question is if this framework might be usefully introduced into a home or workplace? In conclusion, this approcis a where the ing and go. However while place of relaxation and the workplace one of focus, both would benefit from the application of methods of sensory design.

To conclude, this thesis began with the proposition that architecture is ignoring the needs of the human body and mind by focusing on vision as the dominant sense, when al senses contribute to human wellbeing. The result of this research is a design that reconnects the human body and mind with a state of calm, by focusing on reducing anxiety in an urban by fock an architecture and sensory design. 


\section{8. \\ BIBLIOGRAPHY}




\section{BIBLIOGRAPHY}

Bloomer, Kent C and Moore Charles W. Body, Memory, and Architecture. London: Yale University Press, 1977.

Boettger, Till. Threshold spaces: transitions in architecture, analysis and design tools. Boston: Birkhäuser, 2014

Cantz, Hatje. Friedrich Kiesler: Endless House 1947-1961. Ostfildern-Ruit, Deutschland : Hatje Cantz, 2003.

Coates Nigel. Narrative Architecture. West Sussex: John Wiley \& Sons Ltd, 2012

Christel Nisbeth, Moa Liew. Monument of Anxiety: Creating and representing architecture through a filmic process. https://www. academia.edu/17338107/Monument_of_Anxiety_Creating_and_ representing_architecture_through_a_filmic_process (accessed March 10, 2017)
Franco, Jose Tomas. Tierra del Fuego: a dramatic memorial in honor of the vanished Selk'nam people. Archdaily.com. https://www. plataformaarquitectura.cl/cl/759094/tierra-del-fuego-un-dramatico-memorial-en-honor-al-desaparecido-pueblo-selknam. (accessed 12/06/2017).

Ganoe, Cathy J. Design as a Narrative: a Theory of Inhabiting Interior Space. New York: Interior Design Council, 1999.

Gibson, James J. The Senses Considered as Perceptual Systems. London: Allen \& Unwin, 1968

Heyler, Joanne. The Broad: an art museum designed by Diller Scofidio + Renfro. Los Angeles, CA, 2015

Holl Steven, Juhani Pallasmaa, and Alberto Pérez Gómez. Questions of perception: phenomenology of architecture. Tōkyō: $\bar{E}$ ando Yū, 1994

Joy Monice Malnar, Frank Vodarka. Sensory Design. Minneapolis: University of Minnesota, 2004.

Muraben, Billie. The Modernist Architect who helped to build Venice. AnOther. http://www. anothermag.com/design-living/9741/ the-modernist-architect-who-built-venice. (accessed May 22, 2017)

Pallasmaa, Juhani. An Architecture of the Seven Senses. Toward a New Interior: An Anthology of Interior Design Theory. Ed. Simon, Dan. New York: Princeton Architectural Press, 201 1. Pg 40-49. Book.

Schneider, Bernhard. Daniel Libeskind: Jewish Museum Berlin: Between the Lines. Munich: Prestel, 1999.

Schumacher, Thomas L. Terrangi's Danteum: architecture, poetics, and politics under Italian fascism. Ed2. Princeton Architectural Press, New York. 2004.

Sudjic, Deyan. John Pawson works. Ed2. New York: Phaidon Press Inc, 2005

Tanizaki, Ju'inchiro. In Praise of Shadows. New Haven, Conn: Leete's Island Books, 1977

Whyte, H Wiliam. The Social Life of Small Urban Spaces. Washington, D.C.: Conservation Foundation. 1980.

Zumthor, Peter. Atmospheres. Basel : Birkhäuser, 2006. Book. 


\section{CHAPTER 3}

3.1 David Libeskind (2014) - llan Besor

Source: <http://the-talks.com/interview/daniel-libeskind/>

3.3 Map - Urban Proximity (2010) - Google Maps

Source: <htpps://www.google.co.nz/maps/@52.5023147,13.3932529,670m/data=!3m1!1e3>

3.4 Jewish Museum Garden of Exile - David Libeskind (2010) Jens Ziehe Source: <http://blog sc

\section{IMAGE REFERENCE}

3.5 Frederick Kiesler (1955) - tbc

Source: <https://www.metalocus.es/sites/all/modules/copyprevention/transparent.gif>

3.6 Endless house concept drawing - Frederick Kiesler U 52 382294490551 FREDERICK_KIESLER_Croquis_iniciales_Endless_House_19581960_Img._Kiesler_archive.jpg>

3.7 Endless House concept model - Frederick Kiesler - Frederick Kiesler

\section{CHAPTER 2}

2.1 Temple House - Uno Tomoaki (2012) - William Weaver

source: <https://www.futuristarchitecture.com/21339-light-architecture.htm।

3.8 Endless House concept model - Frederick Kiesler - Frederick Kiesler

Source: <http://www.altertuemliches.at/files/imagecache/b558xh304/1457489610064_0. jpg>

2.2 West Village Townhouse - Hirsch | Corti Architecture - Hirsch |

Source: <http://hirschcorti.com/projects/west-village-townhouse/>

Light Lab 5.1 - VaV Architects (2012) - Jonathan Russell
Source: <https://www.archdaily.com/288596/light-lab-5-1-vav-archects/50905ccc28ba0d49e6000022-light-lab-5-1-vav-architects-photo>

2.4 Monastery of Novy Dvur - John Pawson (2004) - John Pawson

2.5 The Danteum - Giuseppe Terragni - (1938) - Giuseppe Terrag

Si

3.11 Tierra del Fuego - Martin Masse - Martin Masse source: <https://images.adsttc.com/media/images/548f/50cb/e58e/cefo/e000/0034/slideshow/martin-masse-remember 10.jpg? 1418678465 >

3.12 Tierra del Fuego - Martin Masse - Martin Masse source. <hifps.//images.adstic.com/media/images/548//50b4/es8e/ced8/d000/0034/side show/martin-masse-remember7.jpg? 1418678443> 
3.13 Tierra del Fuego - Martin Masse - Martin Masse source: <https://images.adsttc.com/media/images/548f/509a/e58e/ced8/d000/0032/slideshow/martin-masse-remember5.jpg? 1418678422>

A 1 Levels of anxiety (2007) 199

3.14 Charles Renfro, Ricardo Scofidio and Elizabeth Diller - Diller Scofidio + Renfro Source: <https://archich
press\%2Cformat>

3.16 Map - Urban Proximity (2010) - Google Maps Source: <https://www.google.co.nz/maps/@34.0544738,-1 18.2527522,914m/data=!3ml!!e3>

3.17 Broad museum concept diagram - Diller Scofidio + Renfro Source: <https://cdn.sanity.io/images/q2talbkqz/production/NYJpVXJqMl uisCNRgoAlewuE-3304x2527.jpg? $\mathrm{W}=30008 \mathrm{fft}=\mathrm{max} \& \mathrm{q}=90>$

3.18 Broad museum section - Diller Scofidio + Renfro Source: <https://images.adsttc.com/media/images/571d/a9e4/e58e/cel 14/2800/002b/
slideshow/The_Broad_east_west_section.jpg? 1 1661561819>

3.19 Broad Museum foyer interior (2015) - Diller Scofidio + Renfro Henrick Kam

Source: < Ktpp//4 bp blogspot.com/-GVBfGnMp4DU/VgGaAOgenf//AAAAAAAABDA/ RVeZihrBUKg/s640/Broad\%2BMuseum\%2Bopening_\%252306_Sep\%2B20th_\%25C2\%25A9Hen -

3.20 Carlo Scarpa (1977)

Source: <htps://indiburffles,wordpress.com/2018/02/carlo-scarpal.jpg?w=7008h=>

3.22 Brion Cemetery - Carlo Scarpa - unknown

Source: <http://i.imgur.com/RsEQEC3.jpg>

3.23 Brion Cemetery - Carlo Scarpa - Frederico Covre

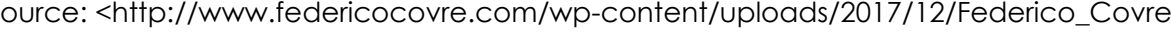
Tomba_Brion_arch_Carlo_Scarpa_2017_06.jpg>

\section{CHAPTER 5}

5.1 Auckland CBD (2014)

Source: <htfps://diliemmaxdotnet.files.wordpress.com/2014/02/auckland-tower-site.jp- 


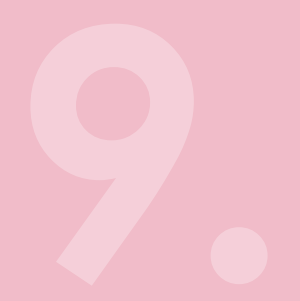

APPENDIX 
Table 13.1 LEVELS OF ANXIETY

\section{Anxiety Level Psychological Responses}

\section{Wide perceptual field}

Sharpened senses

Effective problem solving

Increased learning ability

Irritability

Moderate $\quad$ Perceptual field narrowed to immediate task

Selectively attentive

Cannot connect thoughts or events independently

Increased use of automatisms

Perceptual field reduced to one detail or scattered details Cannot complete tasks

(effectively

Behavior geared toward anxiety relief and is usually ineffective

Doesn't respond to redirection

Feels

Ritualistic behavior

Perceptual field reduced to focus on self

Cannot process any environmental stimul

Distorted perceptions

Loss of rational thought

Doesn't recognize potential danger

Can't communicate verbally

Possible delusions and hallucinatio
May be suicidal
Physiologic Response

\section{Restlessness}

I "butterflies"

Difficulty sleeping

Muscle tension

Diaphoresis

Pounding pulse

Headache

Dry mouth

High voice pitch

Faster rate of speech
Gl upset

Frequet

requent urination

Severe headache

, and diarrhea

Rigid stance

Nigid stance

Pale

Tachycardia

Chest pain

May bolt and run

OR

Totally immobile and mute

Dilated pupils

increased blood pressure and pulse

Flight, fight, or freeze

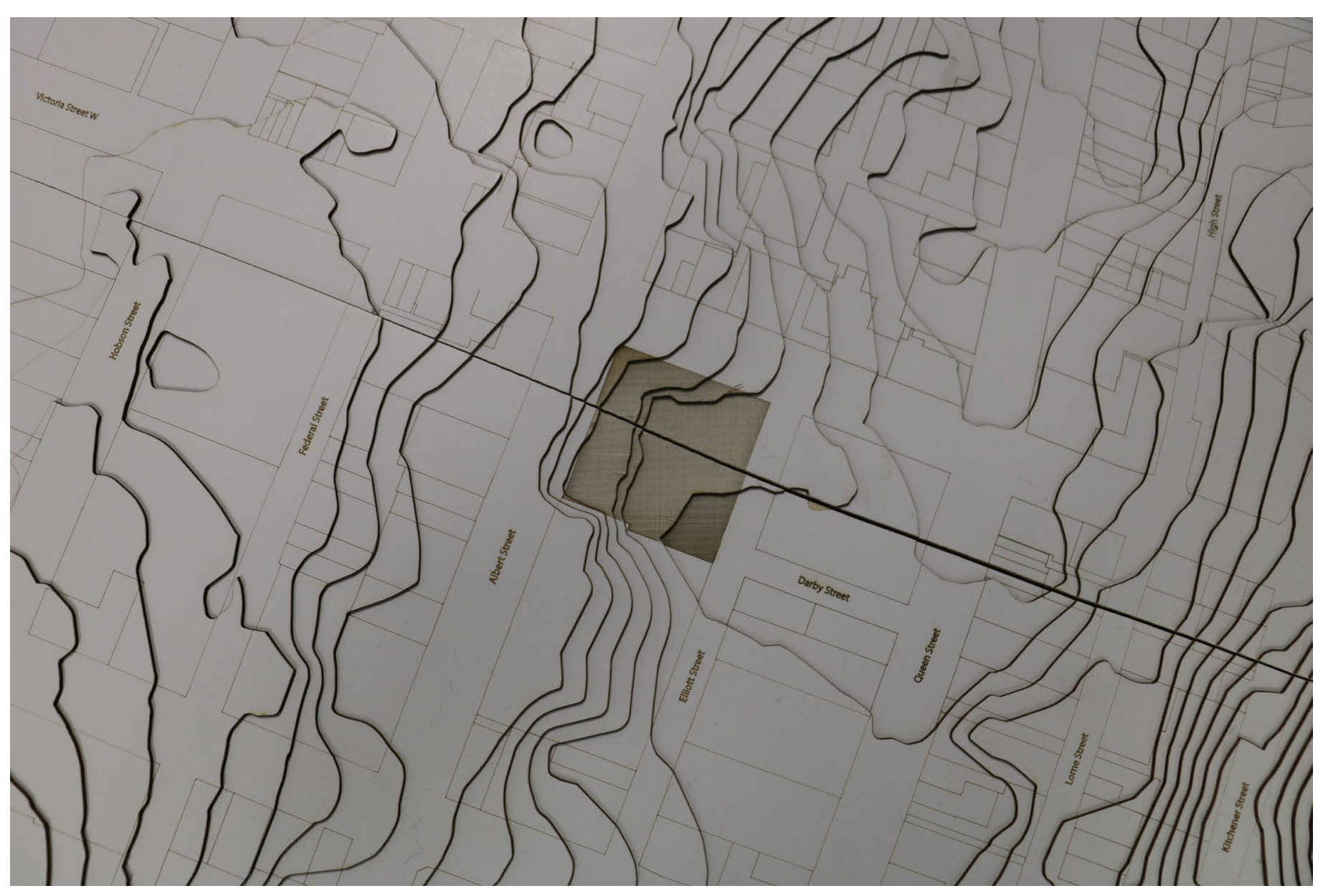



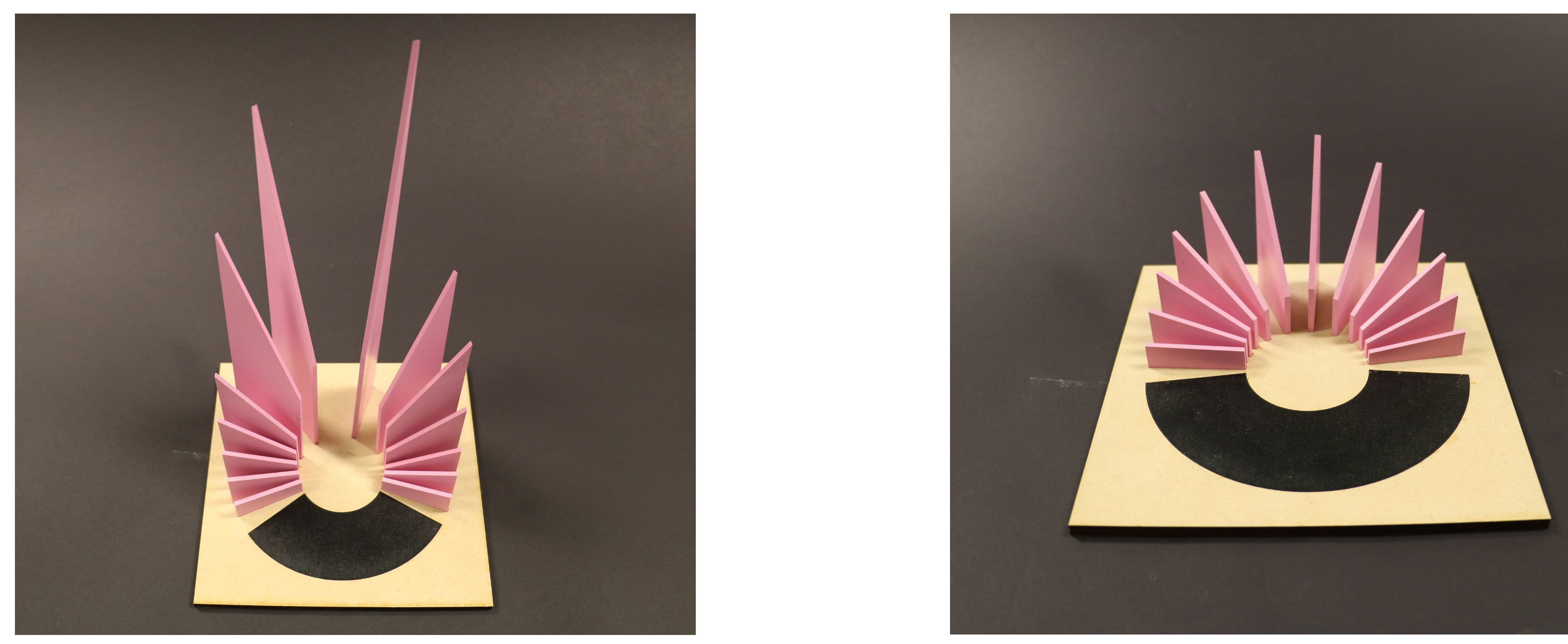


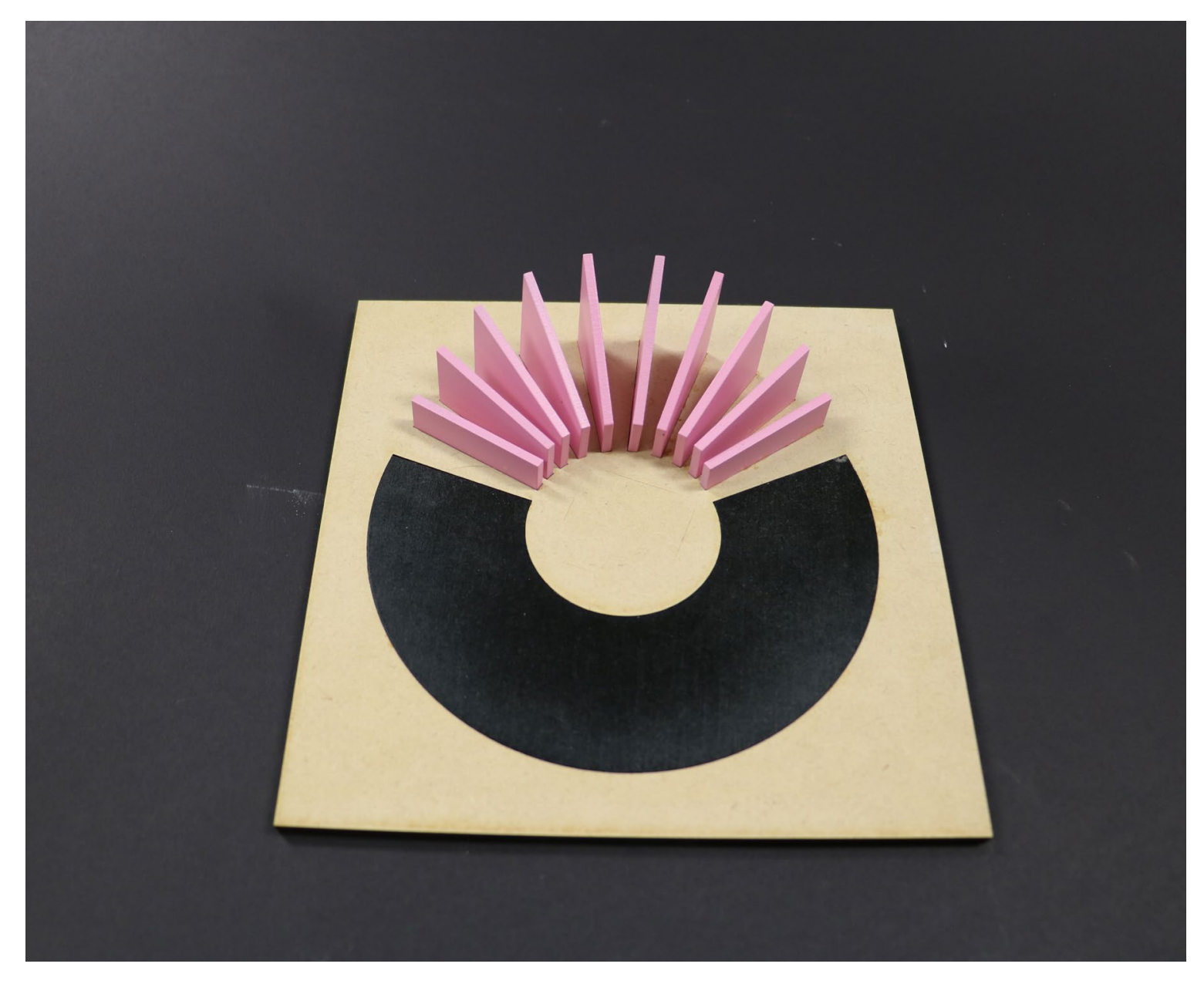


Releasing Anxiety

Victoria University of Wellington,

School of Architecture

2018 Ben Snooks

First Edition

Printed - Wellington, New Zealand

2018 